\title{
REGIONAL ANALYSIS OF ANNUAL PRECIPITATION MAXIMA IN MONTANA
}

By Charles Parrett

\section{U.S. GEOLOGICAL SURVEY}

Water-Resources Investigations Report 97-4004

Prepared in cooperation with

MONTANA DEPARTMENT OF NATURAL

RESOURCES AND CONSERVATION

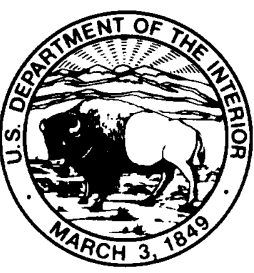

Helena, Montana

March 1997 


\title{
U.S. DEPARTMENT OF THE INTERIOR BRUCE BABBITT, Secretary
}

\author{
U.S. GEOLOGICAL SURVEY \\ Gordon P. Eaton, Director
}

For additional information write to:

District Chief

U.S. Geological Survey

Federal Building, Drawer 10076

Helena, MT 59626-0076
Copies of this report may be purchased from:

U.S. Geological Survey Branch of Information Services

Box 25286

Denver, CO 80225-0286 


\section{CONTENTS}

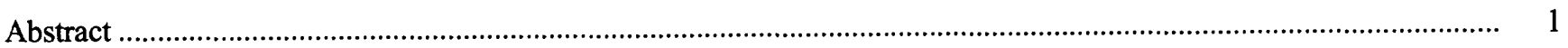

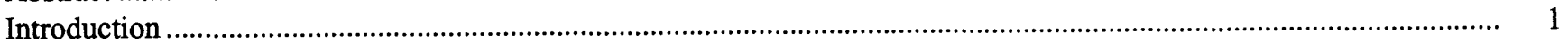

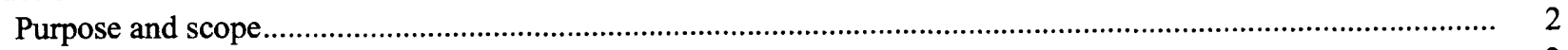

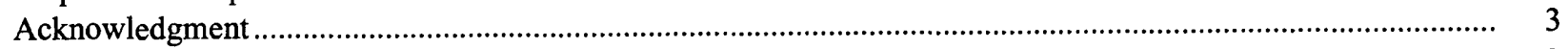

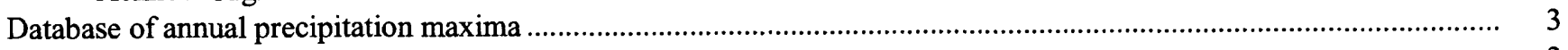

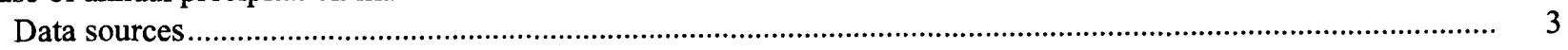

Effects of missing periods of record .........................................................................................................

Test for equivalency of annual daily and 24-hour maxima ...............................................................................

Test for equivalency of annual maxima based on different annual periods........................................................ 4

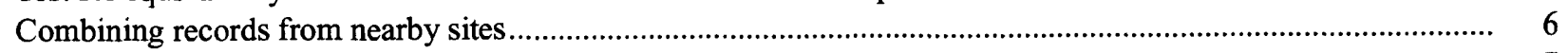

Tests for serial correlation and stationarity of annual precipitation maxima ...................................................... 7

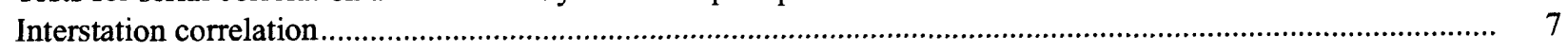

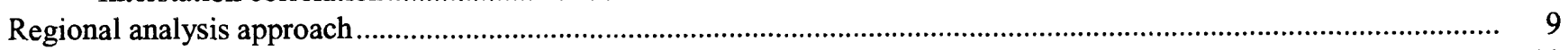

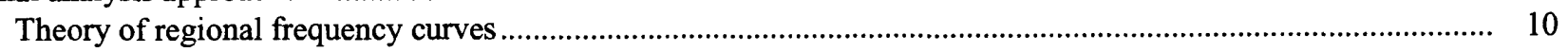

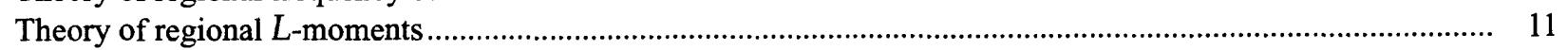

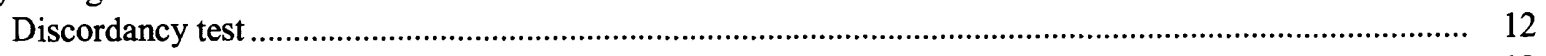

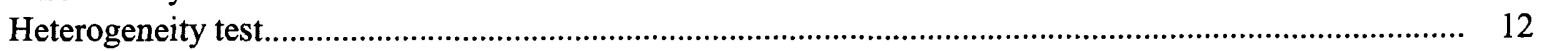

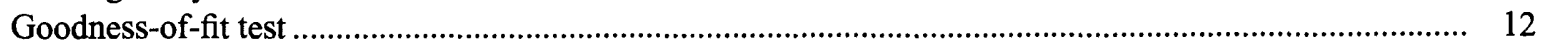

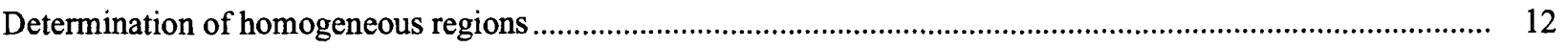

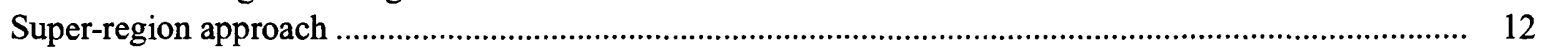

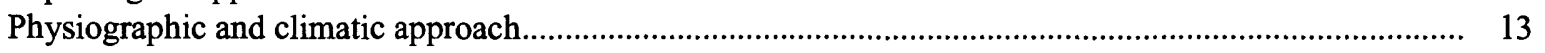

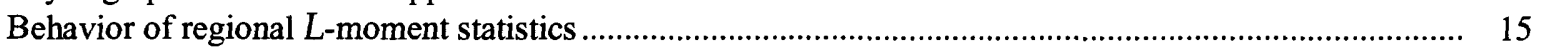

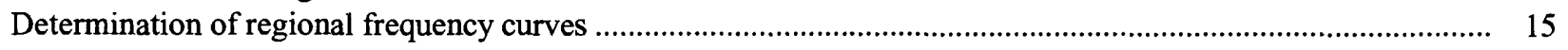

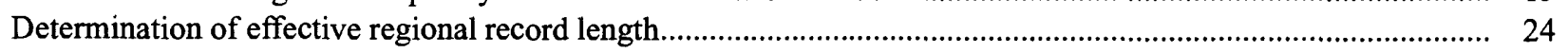

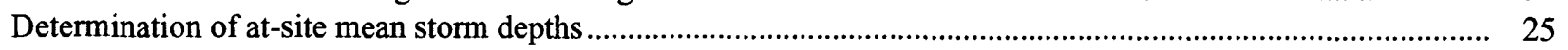

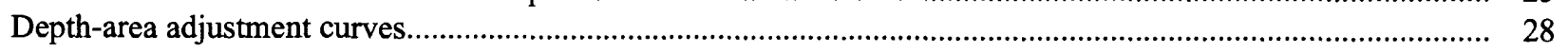

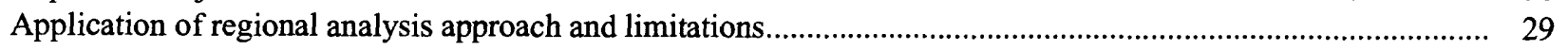

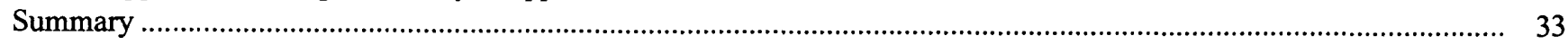

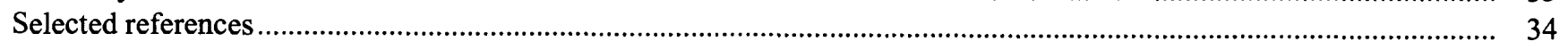

\section{ILLUSTRATIONS}

Plate 1. Map showing locations and types of annual-maxima precipitation stations, Montana and northern Wyoming, and homogeneous regions, Montana.

2. Map showing mean annual precipitation in Montana, base period 1961-90

Figure 1. Graph showing types of annual-maxima precipitation stations and lengths of record, Montana and northern Wyoming.

2. Graph showing types of annual-maxima precipitation stations and site elevations, Montana and northern Wyoming.

3. Boxplots showing distribution of interstation correlation coefficients by duration for annual precipitation maxima, Montana and northern Wyoming

4-17. Graph (s) showing:

4. Relation between interstation correlation coefficient and distance between sites for 24-hour duration annual precipitation maxima, Montana and northern Wyoming.

5. LOWESS trend lines for interstation correlation coefficient versus distance between sites for annual precipitation maxima, Montana and northern Wyoming.

6. Relation between $L-C V$ and duration of precipitation in each region and adjustment to regional average value of $L-C V$ for 6-hour duration annual precipitation maxima in Region 2, Montana.. 


\section{ILLUSTRATIONS--continued}

Figure 4-17. Graph (s) showing:

7. Relation between $L$-Skew and duration of precipitation in each region and adjustment to regional average value of $L$-Skew for 6-hour duration annual precipitation maxima in Region 2, Montana.

8. Relation between $L$-Kurtosis and duration of precipitation in each region and adjustment to regional average value of $L$-Kurtosis for 6-hour duration annual precipitation maxima in Region 2, Montana.

9. $L$-moment ratios for annual precipitation maxima in Region 1, Montana..................................... 18

10. $L$-moment ratios for annual precipitation maxima in Region 2, Montana.................................... 19

11. $L$-moment ratios for annual precipitation maxima in Region 3, Montana...................................... 20

12. Regional frequency curves for dimensionless annual storm depths in Region 1, Montana ............... 21

13. Regional frequency curves for dimensionless annual storm depths in Region 2, Montana ............... 21

14. Regional frequency curves for dimensionless annual storm depths for Region 3, Montana.............. 22

15. Regional frequency curves for dimensionless 2-hour duration annual precipitation depth, Montana 22

16. Regional frequency curves for dimensionless 6-hour duration annual precipitation depth, Montana 23

17. Regional frequency curves for dimensionless 24-hour duration annual precipitation depth, Montana 23

18. Comparison of scatterplots of rank versus recurrence interval for the 40 largest annual precipitation events with curves for large, independent samples of various sizes, Regions 1,2 , and $3 \ldots \ldots \ldots \ldots \ldots \ldots \ldots . . . . . . . .26$

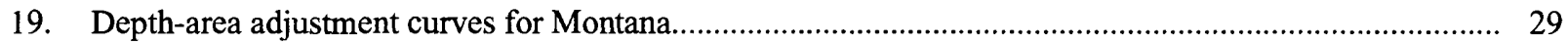

20. Storm-depth frequency curves for hypothetical site in Region 1, Montana ............................................... 33

\section{TABLES}

Table 1. Precipitation stations, Montana and northern Wyoming, and pertinent station information ....................... 36

2. Precipitation stations for which records were extended by addition of data from nearby stations, Montana.. 6

3. Mean value of serial correlation coefficient and attained significance level for annual precipitation maxima in Montana

4. Results of regression analyses for trend in annual precipitation maxima over time for selected stations in Montana

5. Results of heterogeneity tests and regional average $L$-moment ratios for 24-hour duration annual precipitation maxima in Montana.

6. Results of heterogeneity tests and regional average $L$-moment ratios for 2-hour duration annual precipitation maxima in Montana.

7. Results of heterogeneity tests and regional average $L$-moment ratios for 6-hour duration annual precipitation maxima in Montana.....

8. Regional average $L$-moment ratios for 6-hour data in Region 2, Montana

9. Parameters for Generalized Extreme Values (GEV) distribution applied to 2-6-, and 24-hour duration storm depths in Montana.

10. Total station-years of storm-depth record and effective record length by duration and region, Montana ........

11. Regression equations for estimation of mean storm depth for indicated duration in Montana ..................... 27

12. Results of comparison test between regression equations and methods in NOAA Atlas 2, volume 1, Montana ....

13. Standard deviation of residuals and mean values of interstation distance and elevation difference for use of a nearby station to estimate mean storm depth, Montana

14. Dimensionless storm depths for indicated durations and recurrence intervals for hypothetical site in Region 1, Montana......

15. Storm depths for indicated durations and recurrence intervals for hypothetical site in Region 1, Montana ... 32 


\section{CONVERSION FACTORS AND VERTICAL DATUM}

\begin{tabular}{rcl}
\hline Multiply & By & To obtain \\
\hline foot & 0.3048 & meter \\
inch & 25.4 & millimeter \\
mile & 1.609 & kilometer \\
square mile & 2.59 & square kilometer \\
hour & 3,600 & second \\
minute & 60 & second \\
\hline
\end{tabular}

Sea level: In this report, "sea level" refers to the National Geodetic Vertical Datum of 1929--a geodetic datum derived from a general adjustment of the first-order level nets of both the United States and Canada, formerly called Sea Level Datum of 1929. 


\title{
Regional Analysis of Annual Precipitation Maxima in Montana
}

\author{
By Charles Parrett
}

\section{Abstract}

Dimensionless precipitation-frequency curves for estimating precipitation depths having large recurrence intervals were developed for 2-, 6-, and 24-hour storm durations for three homogeneous regions in Montana. Within each homogeneous region, at-site annual precipitation maxima were made dimensionless by dividing by the at-site mean and pooled for analysis to yield a single dimensionless frequency curve applicable for each duration. $L$-moment statistics were used to help define the homogeneous regions and to develop the dimensionless precipitation-frequency curves.

Data from 405 daily and hourly precipitation stations operated by the National Weather Service and 54 daily precipitation stations operated by the Natural Resources Conservation Service were used to develop the database of annual precipitation maxima. Statistical tests were applied to the annual precipitation maxima to ensure that the data were not serially correlated and were stationary over the general period of data collection (1900-92). The data also were tested for spatial independence using the interstation correlation coefficient and found to have a small degree of interstation correlation.

Several attempts were made to delineate homogeneous regions. Three regions previously delineated on the basis of physiography and climate were tested and found to be acceptably homogeneous for purposes of this study. The same regional boundaries were used for all storm durations. Region 1 consisted of generally mountainous western Montana where large storms generally receive their moisture from the Pacific Ocean. Region 2 included the mountains forming the eastern edge of the Rocky Mountain range where large storms are often the result of the orographic uplifting of moisture systems originating in the Gulf of Mexico. Region 3 consisted of the plains areas of eastern Montana where large storms may originate from moisture sources in the Pacific Ocean or the Gulf of Mexico.

Within each homogeneous region, regional values of $L$-moments and $L$-moment ratios were used to calculate parameters of several candidate probability distributions. A goodness-of-fit test was used to help select an acceptable distribution for each duration within each region. The distribution that most often satisfied the goodness-of-fit test and was thus selected as the best distribution for all durations and regions was the 3parameter Generalized Extreme Value (GEV) distribution. The GEV distribution was used to construct dimensionless frequency curves of annual precipitation maxima for each duration within each region. Because each region exhibited some heterogeneity and because of uncertainty about the appropriate probability distribution, each dimensionless frequency curve was considered to be reliable for recurrence intervals up to the effective record length rather than the station-years of record. Because of significant, though small, interstation correlation in all regions for all durations, the effective record length was considered to be less than the total number of station-years of data. The effective record length for each duration in each region was estimated using a graphical method and found to range from 500 years for 6-hour duration data in Region 2 to 5,100 years for 24-hour duration data in Region 3.

Use of the dimensionless frequency curves to estimate precipitation depths for specified durations and exceedance probabilities at ungaged sites requires the estimation of mean at-site values of annual storm depth for the specified durations. Ordinary least-squares regression equations for the estimation of mean storm depths for durations of 2,6 , and 24 hours were developed. Explanatory variables for the regression equations included site location (latitude and longitude) and mean annual precipitation. The regression equations were tested against methods for estimating mean values previously developed by the National Weather Service and were determined to be generally more reliable within Montana than the previously developed methods. Use of a nearby precipitation station to estimate mean storm depth at an ungaged site was also tested and found to be at least as reliable as use of a regression equation.

\section{INTRODUCTION}

Because the consequences of dam failure can be catastrophic, spillway design typically is based on the magnitude of an extremely rare, large flood. For those 
dams, where the risk to human life would be large in the event of failure, spillways are commonly designed to safely pass the Probable Maximum Flood (PMF). The PMF is an extreme flood that is considered to be the largest that could occur at a given site considering the most adverse combination of prevailing meteorologic and hydrologic conditions. The determination of the PMF for a given site is a fairly complex procedure that requires use of a rainfall-runoff model to simulate the runoff from a storm having the Probable Maximum Precipitation (PMP) depth under "worst-case" antecedent-moisture and infiltration conditions. Determination of the PMP storm, in turn, is also complex and is based on the extrapolation of data from the largest storms known to have occurred in broadly defined regions of the country that are presumed to be meteorologically similar. Although procedures for estimating PMP are well-documented and in wide use, estimates of PMP and the resultant estimates of PMF commonly are controversial, particularly for sites where evidence of large storms and large historical floods may be lacking. The controversy is difficult to address because the probability of exceedance of the PMP storm is unknown and may be variable from site to site. Without knowing the probability of exceedance of the PMP or the PMF storm, accurate assessment of risk is not possible.

To better evaluate risk of dam failure and establish a more consistent basis for spillway design, a synthetic design storm having depths and temporal characteristics that are based on probability of exceedance is highly desirable. Unfortunately, most individual precipitation stations have record lengths less than 100 years, and the low probabilities of annual exceedance $(0.01$ to 0.00001$)$ of the storms required for conservative design cannot be reliably determined at any single station. A regional analysis of annual precipitation maxima in the State of Washington (Schaefer, 1990), however, determined that data from individual precipitation stations could effectively be pooled within homogeneous regions. Based on the successful pooling of data, the effective record length within regions was extended to several thousand stationyears. Thus, within homogeneous regions, extreme annual precipitation maxima (storm depths) having the necessary low probabilities of annual exceedance can be reasonably estimated from the pooled data. A second study in Washington (Schaefer, 1989) analyzed the temporal characteristics of extreme storms in Washington and developed dimensionless depth-duration frequency curves. Procedures also were developed for using the calculated storm depths for selected low probabilities of exceedance together with the dimensionless depth-duration curves for various exceedance probabilities to construct synthetic storms for design purposes. The results of the work in Washington have enabled dam-safety engineers to more reliably ascertain the risks associated with various spillway design alternatives and to reduce costs in many cases by using risk-based designs that were more cost-effective than those required by use of the deterministic PMP-based design standard.

\section{Purpose and Scope}

Based on the success of the studies in Washington, the U.S. Geological Survey, in cooperation with the Montana Dam Safety Section of the Montana Department of Natural Resources and Conservation (DNRC), undertook a study to: (1) conduct a regional analysis of annual precipitation maxima in Montana and (2) develop dimensionless depth-duration curves and procedures for constructing large synthetic storms for design purposes. This report describes the methods and results of the regional analysis.

The regional analysis was based on annual precipitation-maxima data for storm durations of 2,6, and 24 hours. An annual precipitation maximum at a precipitation station for a specified duration, such as 2 hours, is the maximum precipitation amount, in inches, recorded during any 2 -hour reporting period during the year. For purposes of this report, the term "annual precipitation maximum" is equivalent to "storm depth" or "precipitation depth for some specified duration" and the terms may be used interchangeably. For the 2-hour duration, annual maxima from 115 hourly recording stations in Montana and 4 hourly recording stations in Wyoming were used in the analysis. Data from Idaho were initially considered for inclusion in the database, but a preliminary analysis by the Montana Department of Natural Resources and Conservation (Gary R. Fischer, oral commun., 1995) indicated that storm characteristics were significantly different in Idaho than in Montana. The difference presumably is due to the greater influence of Pacific Ocean based winter storms in Idaho than in Montana. Data from North Dakota and Canada also were considered for inclusion, but considerably more data compilation and reduction would have been required to make those data usable. For the 6-hour and 24-hour durations, annual maxima from 118 hourly recording stations in Montana and 4 hourly recording stations in Wyoming were used. In addition, data from 337 daily recording stations, 22 of which were in Wyoming, were used for the analysis of 24-hour duration storms. All hourly recording stations and 283 of the daily recording stations were operated by the National Weather Service (NWS), while 54 of 
the daily recording stations were operated by the Natural Resources Conservation Service (formerly the Soil Conservation Service). Sites operated by the Natural Resources Conservation Service, commonly referred to as SNOTEL sites, were included in this study to obtain more precipitation data for the mountainous areas of the State. All sites had at least 10 years of annual-maximum precipitation data. The location and type of precipitation station are shown on plate 1 at the back of the report, and the stations and supplementary information are listed in table 1 at the back of the report.

$L$-moment statistics (Hosking, 1990) were computed for the at-station annual precipitation maxima and used to help determine homogeneous regions using procedures developed by Hosking and Wallis (1993). Within each homogeneous region, a probability distribution was selected based on $L$-moment statistics for dimensionless values of pooled at-site annual precipitation maxima for each duration. The at-site annual maxima for each duration were made dimensionless by dividing by the at-site mean values of annual maxima. The selected probability distributions were used to prepare dimensionless regional frequency curves. The dimensionless regional frequency curves are presented in terms of recurrence intervals rather than exceedance probabilities. The reciprocal of exceedance probability is equal to recurrence interval. For example, an annual precipitation maxima with an exceedance probability of 0.01 has a recurrence interval of 100 years. The equivalent record lengths for the combined at-site data were estimated for each duration within each region and were used as an indication of the relative reliability of the regional frequency curves.

To enable the dimensionless regional frequency curves to be used to estimate precipitation depths at ungaged sites for 2-, 6- , or 24-hour storms, a method for estimating mean values of 2-, 6- , or 24-hour duration precipitation depths was required. Accordingly, regression equations relating mean values of storm depths to various precipitation station characteristics (latitude, longitude, and mean annual precipitation) were developed.

\section{Acknowledgment}

Throughout the course of this study, Dr. Melvin G. Schaefer, Washington Department of Ecology, provided insight and encouragement to the author. Dr. Schaefer also reviewed portions of the data analysis and interpretation and offered technical advice that was appropriate and hèlpful. His timely and cheerful assistance is gratefully acknowledged.

\section{DATABASE OF ANNUAL PRECIPITATION MAXIMA}

Annual precipitation-maxima data were obtained from several sources. The data required careful scrutiny to ensure that periods of missing record did not bias the reported annual maxima. In addition, various statistical tests were made to ensure that (1) annual daily maxima were equivalent to annual 24-hour maxima after application of a constant adjustment factor, (2) annual maxima based on different annual periods were equivalent, (3) records from stations located relatively close together could be combined, and (4) annual maxima were not serially correlated and were stationary over the general period of data collection (1900-92). Finally, the cross-correlation between annual maxima for each station-pair for each duration was calculated and compared with distance between stations in each pair.

\section{Data Sources}

Annual precipitation-maxima data for NWS stations previously had been compiled by the National Climatic Data Center and were obtained from the Montana Department of Natural Resources and Conservation (Gary Fischer, written commun., 1994). Hourly precipitation data from the National Climatic Data Center generally were available only for the period 1948 to the present. Annual precipitation-maxima data for NWS hourly stations operated before 1948 were previously compiled by the National Weather Service and were obtained from the Washington Department of Ecology (M.G. Schaefer, written commun., 1994). Daily precipitation data for SNOTEL stations were obtained from the Montana Natural Resources Information System (J.R. Stimson, written commun., 1994), and annual maxima were extracted and formatted to be compatible with data for National Weather Service stations. Data were available through 1992 for most currently operated SNOTEL stations and some NWS daily and hourly stations. Data were available through 1991 for most currently operated NWS stations.

\section{Effects of Missing Periods of Record}

Virtually all precipitation stations used in the study had some periods of missing record. Reported annual maxima for stations having missing record were 
likely to be incorrect and biased on the low side if the periods of missing record occurred during times of heavy precipitation. Accordingly, annual data having periods of missing record were carefully checked to ensure that the reported maxima for those years were true maxima. If a reported maximum for any duration could not be verified as the true maximum, the maximum for that duration for that year was excluded from subsequent analyses. Considerable judgment was required to decide whether a reported annual maximum was to be used or excluded. If a period of missing record was long but generally dry and in a season of low storm activity at nearby precipitation stations, the reported annual maxima for all durations were likely to be used. However, if even a short period of missing record coincided with heavy rains at nearby stations, the annual maxima were likely to be excluded.

During some periods of missing record at some stations, precipitation gages continued to collect precipitation that was not recorded. In those instances, the first recorded amount after a period of missing record commonly was the accumulated total for the period of missing record and not the amount for the observational period for the station (one hour for hourly stations; one day for daily stations). Reported maxima based on data accumulated during missing periods of record were likely to be incorrect and biased on the high side. Again, careful scrutiny and judgment were required to determine whether reported annual maxima having possible accumulation errors were to be used or excluded.

\section{Test for Equivalency of Annual Daily and 24-hour Maxima}

The use of annual precipitation-maxima data from the 337 daily stations for analysis of 24-hour duration data greatly expanded the number of stations and overall length of record (fig. 1) and resulted in a denser areal distribution of data. Moreover, the use of data from daily stations in the SNOTEL network enabled the only generally available high-elevation precipitation data in the State to be considered in the regional analysis (fig. 2). However, daily maximum precipitation generally tends to be less than 24-hour maximum precipitation, because daily maxima are determined for a fixed time period, typically midnight to midnight, that may not include the true maximum 24-hour period of rainfall. Previous studies (Miller and others, 1973; Weiss, 1964) found that at-site annual daily maxima generally were equivalent to at-site annual 24-hour maxima after the daily maxima were multiplied by a constant correction factor of 1.13 .
To determine whether corrected daily maxima were equivalent to 24-hour maxima in Montana, data for 65 stations having at least 10 concurrent years of daily and 24-hour maxima were tested. A non-parametric, two-sided rank-sum test was used to compare paired values of annual 24-hour maxima and annual daily maxima multiplied by the 1.13 correction factor at each of the 65 stations. The results of the rank-sum tests are reported as p-values. A p-value is the probability of obtaining a sample test statistic as extreme as that observed under the hypothesis that the medians of the corrected daily maximum and 24-hour maximum are identical. For example, a sample test statistic with a p-value of 0.05 would be expected to occur about 5 times in 100 repeated trials if the sample pairs were randomly drawn from two populations with identical medians. The p-value was less than 0.05 ( 5 percent significance level) at 2 of the 65 stations (about 3 percent), indicating that annual daily maxima were different from annual 24-hour maxima. At a significance level of 5 percent, about 3 stations out of 65 could be expected to show a difference just by chance alone. Accordingly, it was concluded that annual 24-hour maxima and annual daily maxima, after multiplication by 1.13 , were equivalent and could be combined.

\section{Test for Equivalency of Annual Maxima Based on Different Annual Periods}

The hourly and daily precipitation data were obtained from different sources and, in some instances, the sources used different months to separate annual periods in the different data sets. Specifically, annual maxima for hourly data obtained from the National Climate Data Center were based on a climatic year beginning in September, whereas annual daily maxima obtained from the National Climate Data Center were based on the calendar year beginning in January. Annual daily maxima from SNOTEL stations were based on the water year beginning in October. To ensure that the annual maxima based on years with different beginning months were equivalent, annual maxima for 2-, 6-, and 24-hour duration data for 20 randomly selected sites were recompiled based on the calendar year. The recompiled data were compared to the annual maxima based on the climatic year using a two-sided rank-sum test. At each site, the annual maxima for each duration for the annual periods with different beginning months were found to be not significantly different. The smallest $p$-value for any duration was 0.09 , while the largest p-value was 1.00 . The $p$-values generally were greater than 0.7 , clearly indicating that the differences between annual maxima 


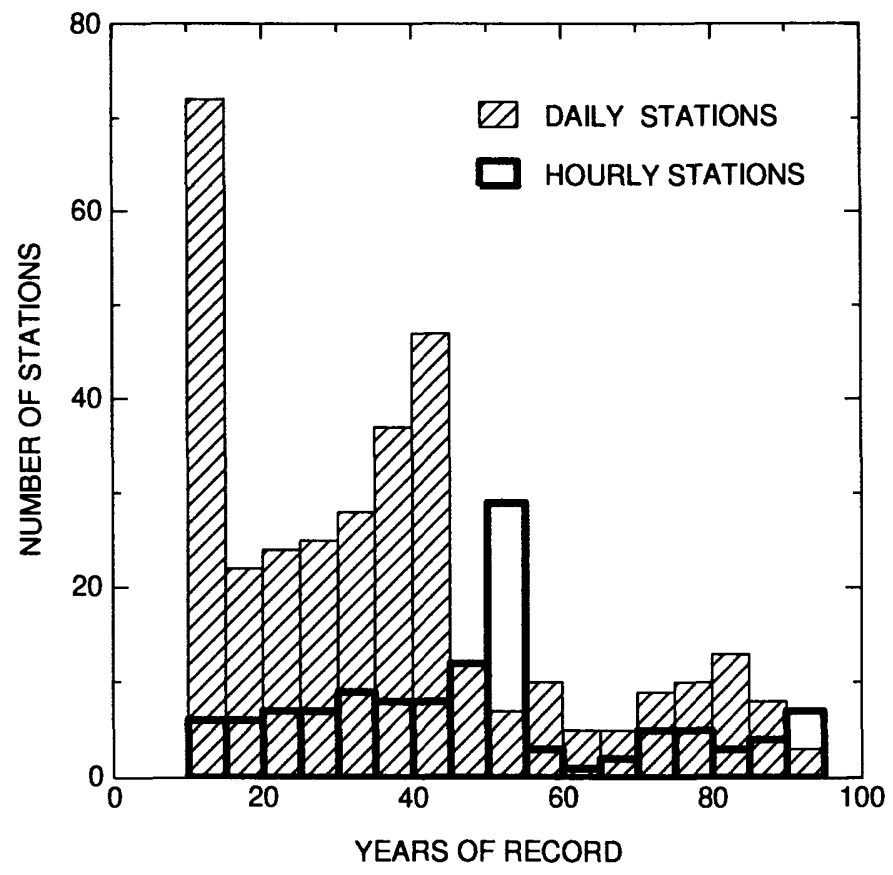

Figure 1. Types of annual-maxima precipitation stations and lengths of record, Montana and northern Wyoming.

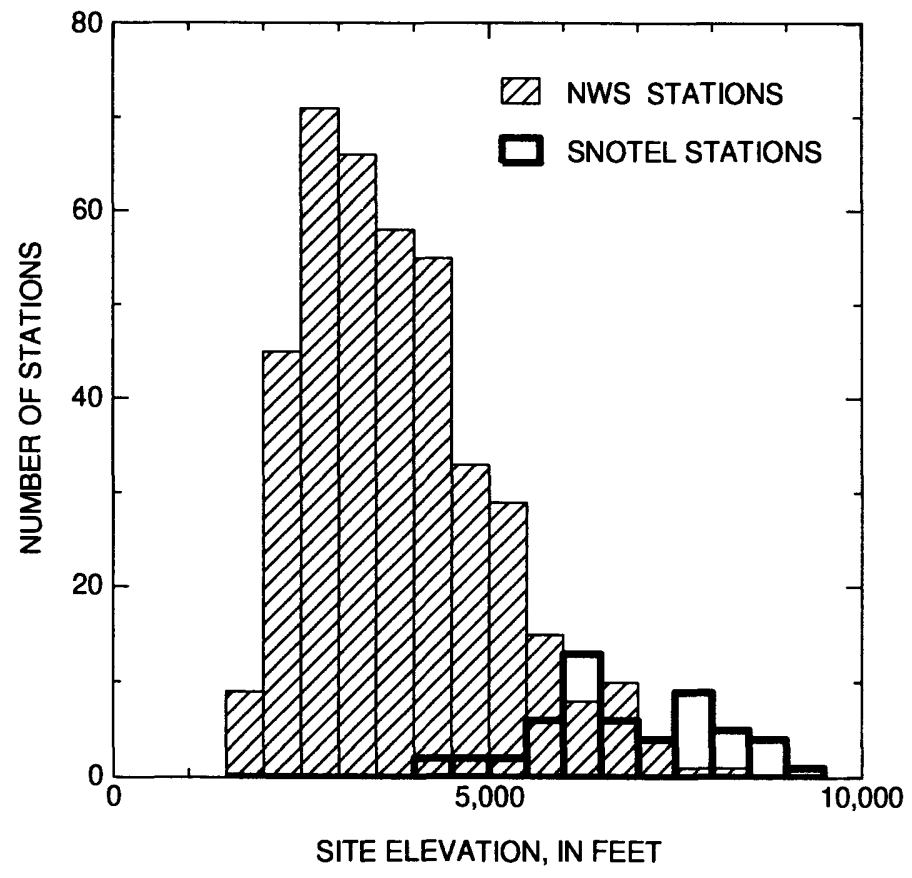

Figure 2. Types of annual-maxima precipitation stations and site elevations, Montana and northern Wyoming.

based on years with different months were not significant at the 20 test sites. This is consistent with findings by Schaefer (M.G. Shaefer, Washington Department of Ecology, oral commun., 1995) regarding analysis of annual maxima. Based on the clear indication of no difference between maxima determined from a climatic year and a calendar year, it was assumed that the same clear indication of no difference would result from a 
comparison between water year and calendar year or between water year and climatic year. Accordingly, annual maxima based on annual periods with different beginning months were considered to be equivalent for all stations used in the study.

\section{Combining Records from Nearby Sites}

Over the course of their operation, NWS stations occasionally are moved to new locations relatively close to the old locations. In addition, new stations may begin operation only a relatively short distance away from existing stations. If the distance and difference in elevation between nearby stations are small, their records can be considered to be equivalent and combined into one longer record. For this study, records from 7 pairs of stations were combined because these paired stations were less than 10 miles apart and less than 150 feet different in elevation. In addition, annual maxima from paired stations that were up to 20 miles apart and had elevation differences up to 320 feet were compared using the two-sided rank-sum test, and data from station pairs that did not have significantly different median values of precipitation maxima also were combined. Because the tested median values commonly were from different periods of record that might be expected to have different means simply because of the record difference, the significance level of the rank-sum test was set to 0.25 . This relatively large value of significance level helped to minimize the possibility that the null hypothesis (medians are equal and station records can be combined) would incorrectly be accepted. Seven stations had their records extended as a result of the rank-sum comparison with nearby stations. Table 2 shows stations for which records of annual maxima were extended by the addition of data from nearby stations.

At one station (247159) shown in table 2, one large recorded annual storm depth from a nearby shortterm station was added to the record even though the stations had substantially different elevations and mean values of precipitation maxima. The recorded value, known to be from a large general storm that caused significant flooding in a large area of west-central Montana, was from a station that did not have the required record length for inclusion in the study. The recorded value was added to the record at a station with a higher elevation that was not in operation during the large storm to ensure that the large storm would be considered. Because the higher-elevation station (247159) probably would have recorded a storm depth at least as large as the value recorded at the nearby lowerelevation station, the addition of the single large value was not considered to have unduly biased the record at station 247159.

Table 2. Precipitation stations for which records were extended by addition of data from nearby stations, Montana

\begin{tabular}{cccc}
\hline $\begin{array}{c}\text { Station } \\
\text { (plate 1) }\end{array}$ & $\begin{array}{c}\text { Original record } \\
\text { length } \\
\text { (years) }\end{array}$ & $\begin{array}{c}\text { Extended } \\
\text { record length } \\
\text { (years) }\end{array}$ & $\begin{array}{c}\text { t-test used to } \\
\text { determine if } \\
\text { records could } \\
\text { be combined? }\end{array}$ \\
\hline 240199 & 10 & 85 & Yes \\
241500 & 13 & 42 & Yes \\
243996 & 31 & 93 & Yes \\
244983 & 29 & 92 & No \\
245337 & 64 & 86 & Yes \\
245735 & 26 & 90 & Yes \\
246302 & 73 & 91 & Yes \\
246472 & 36 & 87 & No \\
246691 & 23 & 42 & No \\
247159 & 28 & 29 & No \\
247267 & 12 & 39 & No \\
247501 & 31 & 49 & Yes \\
248233 & 35 & 44 & No \\
248313 & 2 & 26 & No \\
248866 & 10 & 68 & No \\
\hline
\end{tabular}




\section{Tests for Serial Correlation and Stationarity of Annual Precipitation Maxima}

The methods of regionalization of annual precipitation maxima in this study are based on the assumption that the recorded values of annual maxima are independent and random events that have no significant serial correlation or trends over time (non-stationarity). To determine whether the annual data were serially correlated, the lag-one (serial) correlation coefficient was computed for the annual precipitation maxima for each duration at each station. For each duration, the mean value of serial correlation coefficient was computed and tested for significance against the null hypothesis that the mean value is zero. As shown in table 3 , the mean values of serial correlation coefficient for 2-, 6-, and 24-hour duration annual maxima were all close to zero. The p-values for attained level of significance were substantially greater than 0.05 for all durations, clearly indicating that the null hypothesis could not be rejected. On this basis, the annual precipitation maxima were considered to have no significant serial correlation.

Table 3. Mean value of serial correlation coefficient and attained significance level for annual precipitation maxima in Montana

\begin{tabular}{ccc}
\hline Duration, in hours & $\begin{array}{c}\text { Mean value of serial } \\
\text { correlation } \\
\text { coefficient }\end{array}$ & p-value \\
\hline 2 & 0.0003 & 0.99 \\
6 & -.0179 & .25 \\
24 & -.0051 & .56 \\
\hline
\end{tabular}

To determine whether recorded annual precipitation maxima were stationary over the general period of data collection (1900-92), stations having the longest periods of record for each duration were selected for testing. For 2-hour and 6-hour duration data respectively. 55 stations and 64 stations that had periods of record greater than 40 years were selected. For the substantially larger 24-hour-duration data base, 54 stations that had more than 75 years of record were selected. For each duration, each recorded annual precipitation maximum at each test station was divided by the mean value for the period of record, and the resultant dimensionless values of precipitation maxima at each station were regressed against the year of occurrence minus 1900. Thus, for the 2-, 6-, and 24-hour durations respectively, 55,64 , and 54 separate regressions were made. The slope of each regression line, if determined to be significantly different from zero, indicates the magnitude of trend in annual precipitation maxima over time at each station. Table 4 presents the results of the regressions for each duration and provides an overall indication of the stationarity of the annual precipitation maxima.

Table 4. Results of regression analyses for trend in annual precipitation maxima over time for selected stations in Montana

\begin{tabular}{rccc}
\hline Duration, & $\begin{array}{c}\text { Number of } \\
\text { in hours } \\
\text { (numbersions } \\
\text { stations) }\end{array}$ & $\begin{array}{c}\text { Average slope of } \\
\text { regression line, in } \\
\text { percent of mean } \\
\text { value of annual } \\
\text { maxima }\end{array}$ & $\begin{array}{c}\text { Number of } \\
\text { regressions } \\
\text { where p-level of } \\
\text { significance of } \\
\text { regression } \\
\text { slope was less } \\
\text { than } 0.05\end{array}$ \\
\hline 2 & 55 & 0.00075 & 2 \\
6 & 64 & .00253 & 3 \\
24 & 54 & .00277 & 8 \\
\hline
\end{tabular}

As shown in table 4, the average slope of the regression lines for each duration is close to zero, ranging from 0.00075 percent of the long-term mean value for 2-hour duration annual maxima to 0.00277 percent of the long-term mean value for 24-hour duration annual maxima. For both the 2-hour and 6-hour duration data, less than 5 percent of the regressions had slopes that were significantly different from zero, indicating that, overall, trends in annual maxima are not significant. For the 24-hour duration annual maxima, almost 15 percent of the regressions had slopes significantly different from zero, indicating that, overall, the trend might be different from zero. However, for the eight regressions for 24-hour annual maxima that had slopes significantly different from zero, four had positive slopes and four had negative slopes. Thus, while a trend may be more somewhat more likely for 24-hour duration data, no clear indication of the direction of trend is apparent. For purposes of this study, it was concluded that trends in annual precipitation maxima over the general period of data collection (1900-92) were not significant for any of the durations and that annual maxima thus could be considered to be stationary.

\section{Interstation Correlation}

To determine the degree of spatial independence of the database, the interstation correlation coefficient was calculated for the concurrent recorded annual maxima for every station pair for each duration. Based on the calculations, 6,409 values of interstation correlation coefficient, which have a mean of 0.037 , were calculated for the 2-hour duration. For the 6-hour 
duration, 6,625 values of interstation correlation coefficient, which have a mean of 0.057 , were calculated. For the 24-hour duration, 91,189 values, which have a mean of 0.074 , were calculated. For all durations, the mean values, although small, were significantly different from zero ( $p$-values all equal to 1.00). The distributions of the interstation correlation coefficients for each duration are displayed as box plots in figure 3 . The results in figure 3 indicate that the interstation correlation is least for 2-hour duration annual maxima and greatest for 24-hour duration annual maxima. Given that longer duration storms (24-hours) tend to be largescale, general storms that cover larger areas than the smaller-scale, convective storms with shorter durations (2- and 6-hours), the somewhat larger values of interstation correlation for longer durations appear to be reasonable.

To determine whether the interstation correlation coefficient is related to distance between sites, scatterplots of paired values of interstation correlation coeffi-

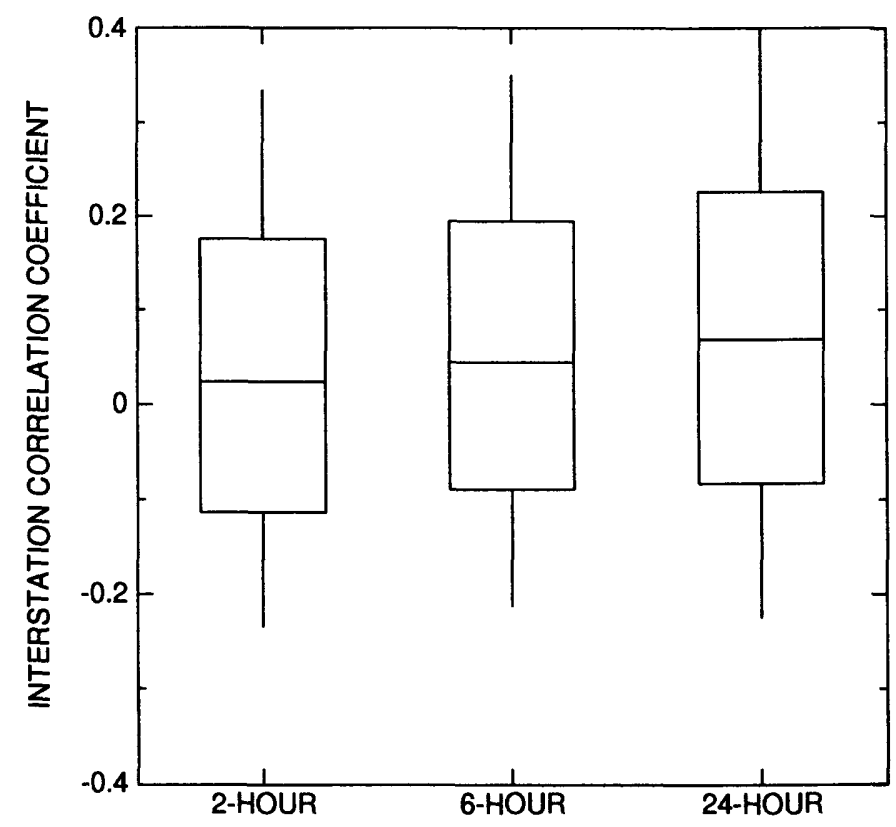

EXPLANATION

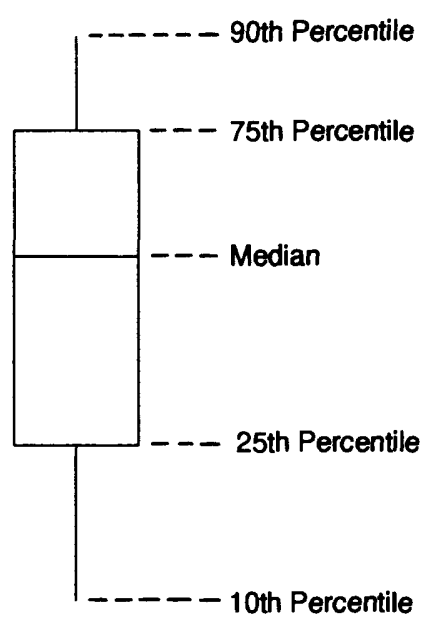

Figure 3. Distribution of interstation correlation coefficients by duration for annual precipitation maxima, Montana and northern Wyoming. 
cient and distance were made for each duration, and LOWESS smooth lines (Helsel and Hirsch, 1992, p. 288-291) fit to the paired data. A LOWESS line, like a regression line, indicates a relation between two variables. Unlike a regression line, however, a LOWESS line does not require a linear relation. A scatterplot of a small sample of the paired values for the 24-hour duration and the LOWESS line relating interstation correlation coefficient to interstation distance is shown on figure 4. The LOWESS lines for the 2-, 6-, and 24hour durations are compared on figure 5 . As shown on figure 4, the LOWESS line for 24-hour duration data does indicate a tendency for interstation correlation to increase with decreasing interstation distance, but, based on the large amount of scatter in the data, the relation is poor. Evidently, many other factors in addition to interstation distance affect the degree of interstation correlation and, hence, the spatial independence of annual precipitation maxima. The comparison of LOWESS lines for the three durations shown in figure 5 indicates that the relation between interstation correlation and distance is similar for each duration and that the spatial independence of annual precipitation maxima generally increases with decreasing duration. Overall, it is concluded that annual precipitation maxima are not completely spatially independent and that the degree of dependence is related to storm duration and distance between stations. Although the degree of spatial dependence is small and considered to have no significant effects on the methods of regionalization used in this study (Hosking and Wallis, 1988), it does indicate that the amount of regional information available may be less than that indicated by the total number of station-years of record. The effect of spatial dependence on equivalent record length within regions will be discussed later in the report.

\section{REGIONAL ANALYSIS APPROACH}

The regional analysis approach is based on the concept that at-site data can be pooled within regions that are "homogeneous." In this context, homogeneous is taken to mean that probability distributions and their

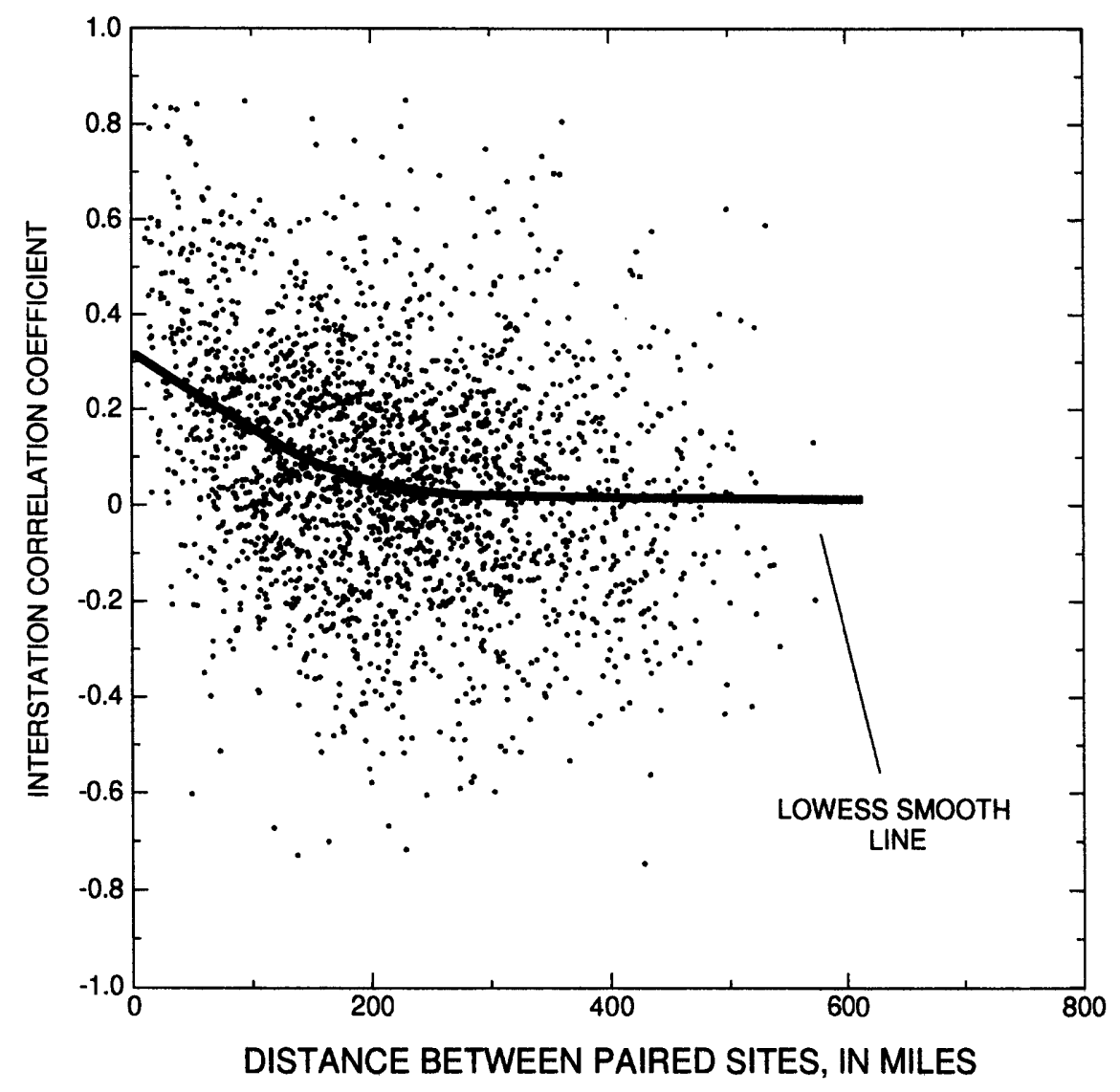

Figure 4. Relation between interstation correlation coefficient and distance between sites for 24-hour duration annual precipitation maxima, Montana and northern Wyoming. 


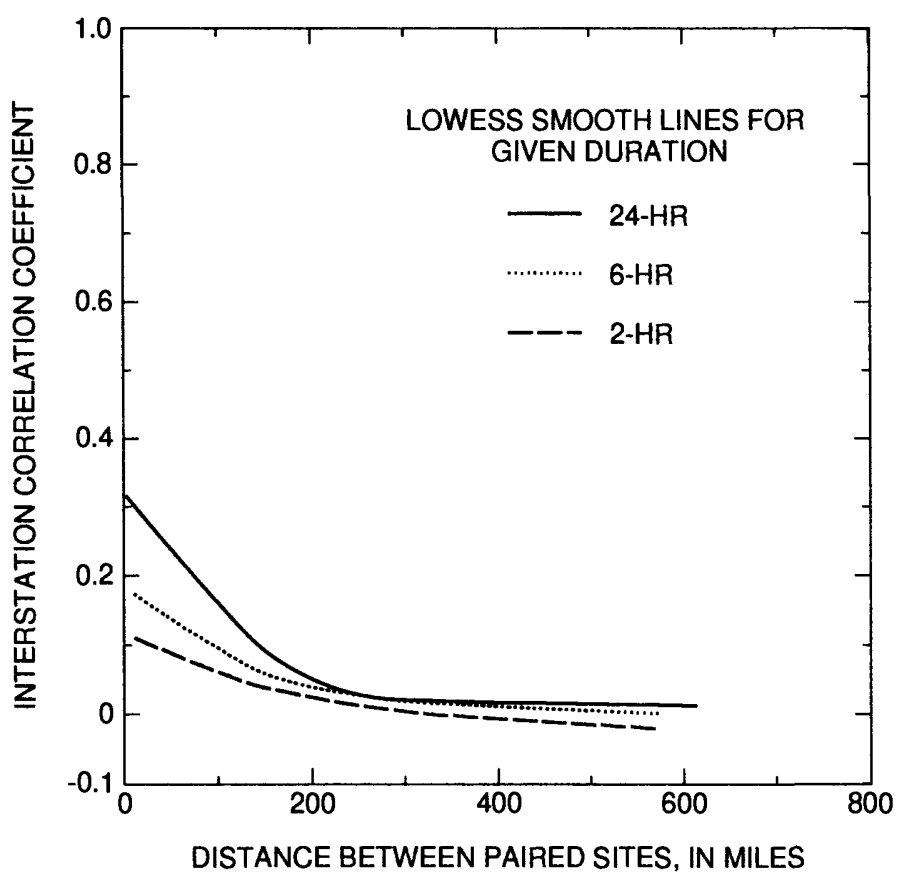

Figure 5. LOWESS trend lines for interstation correlation coefficient versus distance between sites for annual precipitation maxima, Montana and northern Wyoming.

resultant frequency curves for at-site data are identical, except for a site-specific scaling factor, at all sites in a region. The at-site mean value commonly is used as the scaling factor in regional analyses. Key elements in a regional analysis include: (1) determination of homogeneous regions, (2) determination of regional frequency curves, and (3) a method for estimation of the at-site mean (scaling factor) at any location in a region. The use of $L$-moment statistics aids in completion of the first two elements. The following sections include brief discussions of the theories of regional frequency curves and $L$-moments and the application of the key elements of a regional analysis to the current study in Montana.

\section{Theory of Regional Frequency Curves}

In flood-frequency analysis, the use of dimensionless frequency curves within homogeneous regions is well documented (Dalrymple, 1960; Wallis, 1989). In recent years, dimensionless frequency curves have increasingly been used in analyses of precipitation maxima (Alila and others, 1992; Hosking and Wallis, 1993; Schaefer, 1990; Vogel and Lin, 1992). The mean value of the at-site annual floods or storm depths was used as the scaling factor in each of these studies.

In general, for an analysis of storm depths, the quantiles $Q$ of non-exceedance probability $F$ at any site $i$ in a region (Hosking and Wallis, 1993) can be expressed as:

$$
Q_{i}(F)=\mu_{i} q(F)
$$

where

$Q_{i}(F)$ is the quantile of non-exceedance probability $F$ at site $i$,

$\mu_{i} \quad$ is the mean value of storm depth at site $i$, and

$q(F)$ is the regional quantile of non-exceedance probability $F$.

The regional quantiles $q(F), 0<F<1$, form a "regional growth curve" that is common to all sites in the region.

Determination of the regional quantiles, $q(F)$, in equation (1) is dependent upon the type of probability distribution that fits the regional data. For example, the relation between the quantile function and the 3parameter Generalized Extreme Value (GEV) probability distribution (Hosking, 1990) is as follows:

$$
q(F)=\xi+\alpha\left(\left\{1-(-\log F)^{k}\right\} / k\right),
$$

where

$\xi, \alpha$, and $k$ are the parameters of the GEV distribution, and

$\log F$ is the natural logarithm of non-exceedance probability. 
Hosking (1990) provides equations for estimating the parameters of various probability distributions from the $L$-moments and $L$-moment ratios of the data. For regional data, $L$-moments and $L$-moment ratios for each site are weighted by record length and averaged in order to calculate parameters of the regional probability distribution. Herein, the term average as applied to $L$-moments or $L$-moment ratios means a recordlength weighted average.

Regional growth curves are analogous to dimensionless regional frequency curves, except that frequency curves typically are expressed in terms of recurrence intervals rather than non-exceedance probabilities. For annual maxima, recurrence interval, in years, can be simply determined as the reciprocal of 1 minus the non-exceedance probability. In addition, frequency curves typically are plotted on special forms of probability plotting paper that tend to linearize the curves.

To plot the regional growth curves as regional dimensionless frequency curves, the non-exceedance probabilities are first converted to Gumbel reduced variates by using the following equation (Hosking and Wallis, 1993):

$$
G R V=-\log (-\log F),
$$

where

$G R V$ is the Gumbel reduced variate corresponding to non-exceedance probability $F$.

Plotting regional quantiles on the ordinate $(\mathrm{Y}$ axis) and uniformly spaced values of $G R V$ on the abscissa ( $\mathrm{X}$ axis) has the same linearizing effect as plotting the regional growth curve on extreme-value plotting paper. The plots of regional quantiles versus $G R V$ take the form of regional frequency curves when, after plotting, $G R V$ are converted to recurrence intervals, commonly expressed as $T$-year, using the following equation:

$$
T \text {-vear }=\frac{1}{\left[1-e^{(-e)^{G R t}}\right]} \text {. }
$$

Estimation of the dimensionless storm depth having a $T$-year recurrence interval at any site within a homogeneous region can then be obtained from the regional frequency curve. Multiplication of the dimensionless storm depth by the at-site mean yields the $T$ year at-site storm depth.

\section{Theory of Regional L-moments}

$L$-moments, like conventional moments, are used to summarize theoretical probability distributions and observed samples. $L$-moments, however, are computed as linear combinations of the ranked observations and do not require that the observations be squared and cubed as do conventional moments (Stedinger and others, 1992). As a result, $L$-moments are more robust and unbiased than conventional moments and provide more reliable estimates of the parameters of probability distributions than do conventional moments. This is particularly important for precipitation data which are characterized by large values of skewness and kurtosis.

The first $L$-moment estimator, $l_{l}$, is the mean, which can be expressed in terms of expected value as (Stedinger and others, 1993):

$$
l_{l}=E(X),
$$

where $E(X)$ is the expected value of some variable $X$.

If $X\left({ }_{i \mid n}\right)$ is the $i$ th-largest observation in a sample of size $n$ ( $i=1$ corresponds to largest), then the second $L$-moment is based on the expected difference between two randomly selected observations (Stedinger and others, 1993):

$$
l_{2}=\frac{1}{2} E\left[X_{(1 \mid 2)}-X_{(2 \mid 2)}\right] \text {. }
$$

Similarly, the third and fourth $L$-moments are defined as follows (Stedinger and others, 1993):

$$
\begin{gathered}
l_{3}=\frac{1}{3} E\left[X_{(1 \mid 3)}-2 X_{(2 \mid 3)}+X_{(3 \mid 3)}\right] \text { and, } \\
l_{4}=\frac{1}{4} E\left[X_{(1 \mid 4)}-3 X_{(2 \mid 4)}+3 X_{(3 \mid 4)}-X_{(4 \mid 4)}\right] .
\end{gathered}
$$

Three $L$-moment ratios that are needed to describe probability distributions and apply various statistical tests are defined in terms of the first four $L$-moments as follows:

$$
\begin{aligned}
& t_{2}=l_{2} / l_{1}=L \text {-coefficient of variation }(L-\mathrm{CV}), \\
& t_{3}=l_{3} / l_{2}=L \text {-skewness }(L \text {-Skew }), \text { and } \\
& t_{4}=l_{4} / l_{2}=L \text {-kurtosis }(L \text {-Kurtosis }) .
\end{aligned}
$$

These $L$-moments and $L$-moment ratios are analagous to their counterparts defined for conventional moments. Hosking and Wallis (1993) describe three statistical tests based on $L$-moments that are used to help identify homogeneous regions and the appropriate probability distributions for use in those regions. These tests are briefly described in the following sections. 


\section{Discordancy Test}

The discordancy test is used to identify sites that are grossly discordant from the group as a whole. The discordancy measure is based on the $L$-moments of the sample data and is defined as

$$
D_{i}=\frac{N}{3(N-1)}\left(\mathbf{u}_{i}-\overline{\mathbf{u}}\right)^{T} \mathbf{s}^{-1}\left(\mathbf{u}_{i}-\overline{\mathbf{u}}\right),
$$

where

$D_{i}$ is the discordancy measure for site $i$,

$N$ is the number of sites in the group,

$\overline{\mathbf{u}}_{i}$ is the vector of $L-\mathrm{CV}, L$-Skew, and $L$-Kurtosis for site $i$,

$\mathbf{u}$ is the mean of vector $\mathbf{u}_{i}$,

$\mathbf{S}$ is the sample covariance matrix of $\mathbf{u}_{i}$.

A site is considered to be discordant if $D_{i}$ is greater than 3. Hosking and Wallis (1993) provide the background and theory for the test, which is used to identify sites that may not be consistent with other sites in a group and may need to be moved to another group.

\section{Heterogeneity Test}

The heterogeneity test described by Hosking and Wallis (1993) is used to estimate the degree of heterogeneity in a group of sites and to assess whether they might reasonably be considered to compose a homogeneous region. Specifically, the heterogeneity measure, $H$, compares the between-site variations in sample $L$ moments for the group with the variations that would be expected for a homogeneous region. The heterogeneity measure is defined as

$$
H=\frac{\left(V-m_{v}\right)}{s_{v}},
$$

where

$V \quad$ is the standard deviation, weighted by record length, of $L-C V$ for sites in the group,

$m_{v}, s_{v}$ are the mean and standard deviation of a large number of Monte Carlo simulations of $V$.

A group of sites generally is considered to be homogeneous if $H<2$. The Monte Carlo simulations, usually 500 in number, are performed using a 4parameter Kappa distribution applied to a hypothetical homogeneous region where the sites have record lengths and average $L$-moments the same as those of the group being tested (Hosking and Wallis, 1993).

\section{Goodness-of-fit Test}

The goodness-of-fit test is used to determine whether a particular probability distribution fits the regional data acceptably close. Five 3-parameter distributions generally are evaluated: Generalized Extreme Value (GEV), Generalized Logistic (GLO), Generalized Normal (GN), Pearson Type III (PEAR), and Generalized Pareto (GP). The Wakeby distribution, a 5-parameter distribution, is also evaluated for use if no 3-parameter distribution is considered to be acceptable. The goodness-of-fit test is defined as

$$
Z^{D I S T}=\frac{\left(\overline{t_{4}}-t_{4}^{D I S T}\right)}{s_{4}},
$$

where

$Z^{D I S T}$ is the goodness-of-fit measure for some dis-

- $\quad$ tribution, DIST,

$\bar{t}_{4} \quad$ is the mean $L$-Kurtosis, corrected for bias, (Hosking and Wallis, 1993) for a group of sites,

$t_{4}{ }^{D I S T}$ is the mean $L$-Kurtosis of the fitted distribution, DIST,

$s_{4} \quad$ is the standard deviation of $L$-Kurtosis based on 500 simulations previously described.

In general, a distribution is considered to have a good fit if $\left|Z^{D i S T}\right|<1.64$. As noted by Hosking and Wallis (1993), this criterion is somewhat arbitrary and may be unreliable if relatively high serial or interstation correlation is present in the data.

\section{Determination of Homogeneous Regions}

Determination of acceptable homogeneous regions commonly requires several attempts. The first attempts for the current study were based on a unique, "super-region" approach used in Washington. The final delineation of homogeneous regions for Montana generally was based on physiography and climate.

\section{Super-Region Approach}

In Washington State, Schaefer (1990) found that sites could be grouped into homogeneous regions for the analysis of annual precipitation maxima if they had similar values of mean annual precipitation. Thirteen regions within which the at-station mean annual precipitation varied over a narrow range were thus determined to be homogeneous in Washington (M.G. Schaefer, written commun., 1994). Further, Schaefer 
found that the statistical parameters used to define the regional probability distributions varied systematically across the State in the same manner as mean annual precipitation varied across the State. Functional relations between mean annual precipitation and parameters of the Kappa probability distribution were developed so that the entire State could be treated as a homogeneous "super-region" within which a single probability distribution was applicable. On this basis, Schaefer was able to avoid the problem of abrupt geographical boundaries between homogeneous regions and the difficulties in estimation that often result near such boundaries.

As a result of Schaefer's work in Washington, the first attempt at definition of homogeneous regions for the analysis of annual precipitation maxima in Montana was based on the grouping of sites having similar values of mean annual precipitation. The 24-hour duration data were used in all attempts to determine homogeneous regions in Montana because of the much greater number of sites and better spatial coverage, particularly in mountain areas, of the 24-hour data. Thus, 6 groups having the following ranges in value of mean annual precipitation were tested for heterogeneity: (1) less than 12 inches, (2) between 12 and 15 inches, (3) between 15 and 20 inches, (4) between 20 and 25 inches, (5) between 25 and 30 inches, and (6) greater than 30 inches. The results of the heterogeneity tests indicated that none of the 6 groups could be considered homogeneous $(H<2)$. Moreover, the average $L$-moment ratios ( $L$-CV, $L$-Skew, and $L$-Kurtosis) for the six groups did not systematically vary with mean annual precipitation as they did in Washington. Determination of a homogeneous super-region based on mean annual precipitation thus was considered not to be feasible for Montana.

Site elevation was also tried as a super-region grouping variable in the same fashion as was mean annual precipitation. Thus, five groups whose sites had elevations within ranges of 1,000 feet were tested for heterogeneity. Only one of the five groups was found to be homogeneous $(H<2)$. Heterogeneity test values for the other four groups ranged from 2.56 to 7.35 . In addition, the $L$-moment ratios did not vary systematically with site elevation. Determination of a homogeneous super-region on the basis of site elevation also was considered not to be feasible for Montana.

\section{Physiographic and Climatic Approach}

In previous flood-frequency studies in Montana (Omang, 1992; Omang and others, 1986), physiography and climate were used in a general way to delineate eight regions within which flood-frequency characteristics were considered to be similar. For the current study, the same eight regions were tested for heterogeneity of 24-hour annual precipitation maxima. Three regions were found to be homogeneous $(H<2)$. Heterogeneity test values for the other five regions ranged from 2.63 to 4.54 . Various combinations and modifications of the eight regions, including the removal of sites having large discordancy values, were also tested for heterogeneity. In some instances, the test result for heterogeneity improved as a result of the modifications; in other instances, the heterogeneity-test result worsened. Overall, the use of the same or modified regions for the analysis of annual precipitation maxima as for the analysis of flood frequency was considered not to be feasible.

In an unpublished report on flood frequency (P.E. Farnes, formerly with Natural Resources Conservation Service, written commun., 1994), Farnes used physiography and climate to delineate three regions for which large storm characteristics appeared to be generally distinct. These three regions, with minor modifications (pl. 1, at the back of the report), were tested and found to be acceptably homogeneous for purposes of this study. Region 1 is a largely mountainous area in western Montana where large, general storms commonly receive their moisture from the Pacific Ocean and generally move in an easterly direction. Most large storms in this region occur in the spring (April-June), but occasionally occur during fall and winter. Region 2 generally consists of a relatively narrow band of mountains running largely north-south along the eastern edge of the Rocky Mountains and includes two isolated small mountainous areas east of the contiguous band. Moist airmasses that cause large, general storms in this region often arise in the Gulf of Mexico during May and June and produce large amounts of precipitation from orographic effects when they collide with cold air masses over the mountains. Fall and winter storms that originate from Pacific moisture occur less frequently in Region 2 than in Region 1. Region 3 is composed of the plains areas of eastern Montana. Large storms in this region may receive moisture from either Pacific or Gulf sources. Large winter storms rarely occur in Region 3. Orographic effects are not a factor in storm generation in this region, but summer convective storms may be more intense than in the other two regions because of generally higher daytime temperatures.

Results of the initial heterogeneity tests for these three regions are shown in table 5 and indicate that for the 24-hour duration none of the regions was homogeneous. Although these results are seemingly no better 
Table 5. Results of heterogeneity tests and regional average $L$-moment ratios for 24-hour duration annual precipitation maxima in Montana

\begin{tabular}{cccccc}
\hline Region & Number of sites & $\boldsymbol{H}$ value & L-CV & L-Skew & L-Kurtosis \\
\hline 1 & 149 & 3.58 & 0.187 & 0.200 & .154 \\
2 & 89 & 3.14 & .220 & .250 & .189 \\
3 & 221 & 2.46 & .228 & .220 & .159 \\
\hline
\end{tabular}

Table 6. Results of heterogeneity tests and regional average $L$-moment ratios for 2 -hour duration annual precipitation maxima in Montana

\begin{tabular}{cccccc}
\hline Region & Number of sites & $\boldsymbol{H}$ value & L-CV & L-Skew & L-Kurtosis \\
\hline 1 & 44 & 0.13 & 0.212 & 0.276 & 0.224 \\
2 & 24 & 1.72 & .232 & .288 & .226 \\
3 & 51 & .56 & .260 & .272 & .189 \\
\hline
\end{tabular}

Table 7. Results of heterogeneity tests and regional average $L$-moment ratios for 6 -hour duration annual precipitation maxima in Montana

\begin{tabular}{cccccc}
\hline Region & Number of sites & $\boldsymbol{H}$ value & L-CV & L-Skew & L-Kurtosis \\
\hline 1 & 46 & -1.23 & 0.189 & 0.246 & 0.208 \\
2 & 24 & 2.15 & .207 & .225 & .184 \\
3 & 52 & .90 & .232 & .242 & .187 \\
\hline
\end{tabular}

than results previously described for other trial regional groupings, the maximum heterogeneity test value $(H=$ 3.58) was smaller than that for the other groupings. In addition, Regions 1, 2, and 3 each contained more than 75 sites. Previous trial regions that had 75 or more sites also were all determined to be heterogeneous. As noted by Hosking and Wallis (1993, p. 276), the test value for heterogeneity tends to be correct for large sample size, but may falsely indicate homogeneity for small sample size. On that basis, findings of homogeneity for previous trial regions, all of which had sample sizes smaller than 75 , may not be correct.

An additional reason for the relatively large heterogeneity test values for 24-hour duration data is that many of the relatively short-record SNOTEL sites were found to be discordant. When the discordant sites were removed from the database and the heterogeneity tests re-run, $H$ values for Regions 1 and 2 were reduced to 2.84 and 1.80, respectively. Nevertheless, because it could not be determined whether the discordancy of the SNOTEL sites was due to their unique, high-elevation, mountainous locations or their relatively short record lengths, it was considered more important to retain those sites in the database for their uniqueness than to improve regional homogeneity by excluding them. Most importantly, whether the sites were retained or excluded, the regional average $L-\mathrm{CV}, L$-Skew, and $L$ Kurtosis were not significantly different, so the overall effect of the discordant SNOTEL sites on the regional frequency curves was considered to be slight.
In general, Regions 1,2 , and 3 were considered to be more nearly homogeneous for the 24-hour duration than previous trial regions because the heterogeneity test values for Regions 1, 2, and 3 did not have such wide variation from region to region as those for the other trial regions. Regions 1, 2, and 3 also were considered to have a stronger physical basis for homogeneity based on such factors as precipitation source and storm direction, seasonality of storms, and orographic effects on storms than did other trial regions. Regions 1,2 , and 3 were divided into smaller regions based on elevation and tested for homogeneity in an attempt to more fully account for orographic effects, but test results did not improve. Overall, given the more consistent regional variation in $H$ values, the effects of the unique SNOTEL sites, and the better physical basis for homogeneity, Regions 1, 2, and 3 were considered to be acceptably close to homogeneous regions for the 24hour duration for purposes of this study and were further tested for homogeneity for the 2-hour and 6-hour durations.

Tables 6 and 7 summarize the heterogeneity test results for the selected three regions for 2- and 6-hour duration data and indicate that $H$ values for the 2- and 6 -hour data for all regions were substantially smaller than for the 24-hour duration. For the 2- and 6-hour duration data, all regions were found to be homogeneous on the basis of $H$ values, except for Region 2 for the 6-hour duration. 


\section{BEHAVIOR OF REGIONAL L-MOMENT STATISTICS}

To determine whether the regional average $L$ moment ratios varied consistently with duration for each of the three regions, plots of $L-\mathrm{CV}, L-\mathrm{Skew}$, and $L$ Kurtosis versus duration were made for each region (fig. 6-8). As shown on figures 6-8, $L$-moment ratios decreased with increasing duration except for Region 2 , where $L$-moment ratios for the 6-hour duration data were smaller than for the 2-hour and 24-hour data. Preliminary analyses of regional frequency curves developed from the unadjusted $L$-moment ratios indicated that the shape of the 6-hour curve for Region 2 was inconsistent with the shape of all other regional curves. Much of this inconsistency could be traced to the magnitude of $L-C V$ and $L$-Skew for 6-hour duration data in Region 2. Because the trend for decreasing $L$-moment ratios with increasing duration was clear for both Regions 1 and 3 and because the heterogeneity tests indicated that Region 2 was the most heterogeneous of the three regions for 6 -hour duration data, the small $L$-moment ratios for 6 -hour duration data in Region 2 were considered to be anomalous. To determine whether adjustments to the $L$-moment ratios for 6-hour duration data in Region 2 might reasonably be made, the upper limit of the 90-percent confidence interval for the regional average value of each $L$-moment ratio was calculated based on the standard deviation and number of at-site values (Helsel and
Hirsch, 1992). As shown on figures 6-8, the regional average values for $L-C V, L-S k e w$, and $L$-Kurtosis for 6hour data in Region 2 could each be adjusted upward far enough to result in a smoothly decreasing curve without exceeding the value for the upper limit of the 90 -percent confidence interval. On that basis, the adjustments to the $L$-moment ratios for Region 2 were considered to be reasonable and necessary in order to provide consistent relations between regional average $L$-moment ratios and storm durations and to provide consistency among regional frequency curves. The adjusted regional average values of $L-C V, L-S k e w$, and $L$-Kurtosis for 6-hour data in Region 2 are shown in table 8 . A review of table 8 shows the magnitudes of the adjustment to be relatively small.

\section{Determination of Regional Frequency Curves}

The regional average $L$-moment ratios were used to calculate parameters of five probability distributions (Hosking and Wallis, 1993), and the goodness-of-fit test was used as previously described to determine whether the distributions fit the regional data acceptably close. Goodness-of-fit tests were used for all durations and regions except for 6 -hour duration data in Region 2 where $L$-moment ratios had been adjusted as previously described. For most regions and durations, more than one distribution met the goodness-of-fit

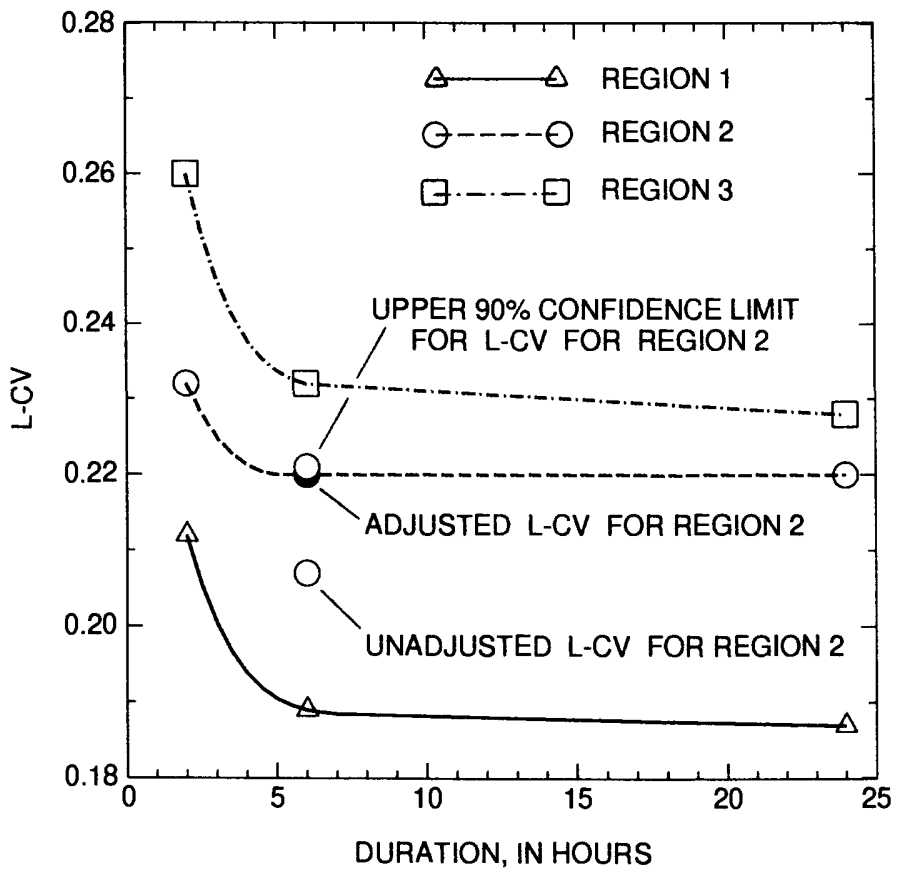

Figure 6. Relation between $L-C V$ and duration of precipitation in each region and adjustment to regional average value of $L-C V$ for 6-hour duration annual precipitation maxima in Region 2, Montana. 


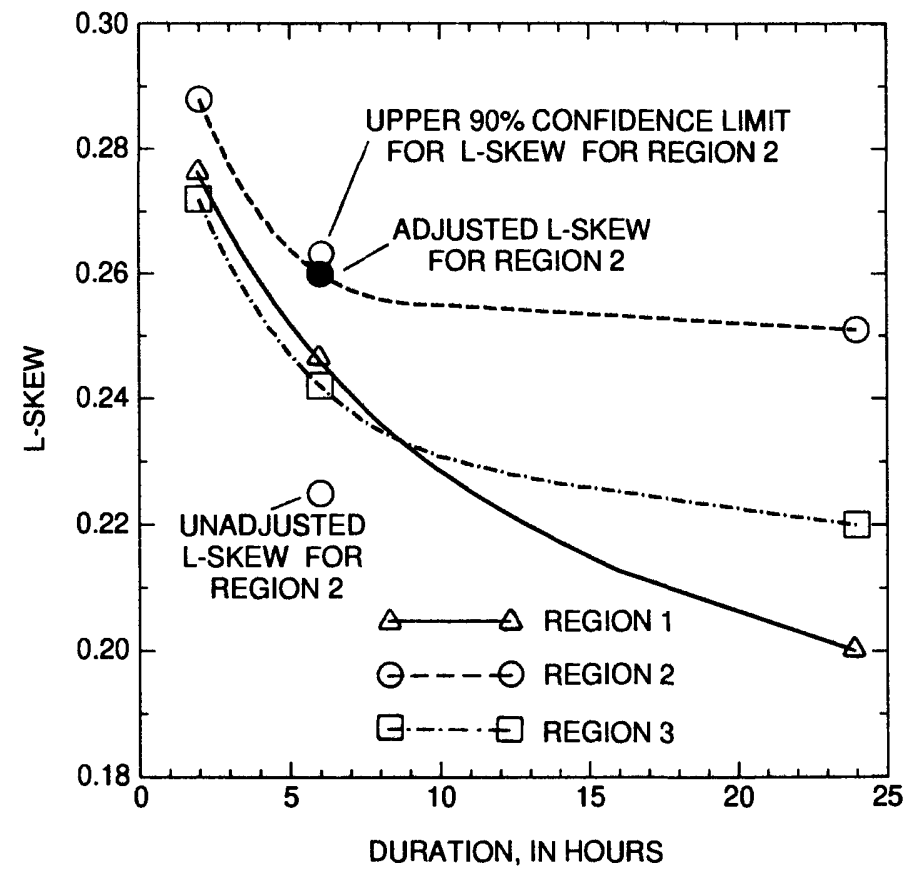

Figure 7. Relation between L-Skew and duration of precipitation in each region and adjustment to regional average value of L-Skew for 6-hour duration annual precipitation maxima in Region 2, Montana.

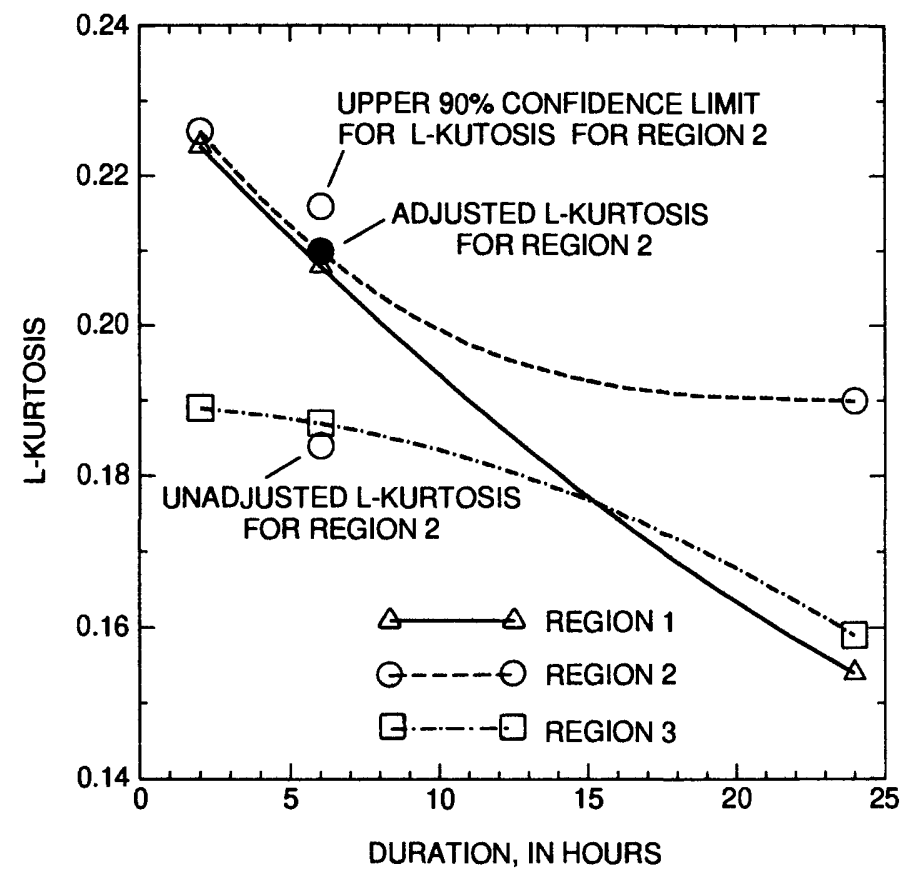

Figure 8. Relation between $L$-Kurtosis and duration of precipitation in each region and adjustment to regional average value of L-Kurtosis for 6-hour duration annual precipitation maxima in Region 2, Montana. 
Table 8. Regional average $L$-moment ratios for 6 -hour data in Region 2, Montana

\begin{tabular}{lccc}
\hline & L-CV & L-Skew & L-Kurtosis \\
\hline Unadjusted & 0.207 & 0.225 & 0.184 \\
Adjusted & 0.221 & 0.260 & 0.210 \\
Percent & +6.8 & +15.6 & +7.1 \\
$\quad$ change & & & \\
\hline
\end{tabular}

criterion. The probability distribution that most often satisfied the goodness-of-fit test was the GEV. To ensure consistency among durations and regions, the GEV was selected as the appropriate distribution for use in all regions for all durations. For the 6-hour duration data in Region 2, the adjusted values of $L-C V$ and $L$-Skew were used to calculate parameters of the GEV distribution. Table 9 shows the parameters of the GEV distribution for each region and duration.

$L$-moment ratio diagrams were prepared for each duration and region to provide a visual indication of how well the GEV distribution fit the regional data (figs. 9-11). In each figure, paired values of at-site $L$-Skew and $L$-Kurtosis were plotted together with the regional average paired value and lines representing the theoretical relation between $L$-Skew and $L$ Kurtosis for three probability distributions. A distribution is considered to have an acceptable fit to the regional data if the theoretical relation between $L$-Skew and $L$-Kurtosis is acceptably close to the regional average value. The three selected probability distributions, GEV, GLO, and GNO, were those most frequently found to satisfy the goodness-of-fit test. As indicated by figures $9-11$, the regional average paired value of $L$ Skew and $L$-Kurtosis was relatively close to the line for the GEV distribution for all durations and regions.

While there is substantial scatter of L-moment data pairs in figures 9-11, this degree of scatter is entirely consistent with the variability expected from sample statistics. This same type of scatter was observed when computer simulations were used to generate data sets from known distributions with known population parameters (Hosking, 1990). The important feature in figures $9-11$ is the relation between the regional mean and the GEV distribution line.

The values of the GEV parameters shown in table 9 were used in equation 2 to calculate regional quantiles for various non-exceedance probabilities up to 0.9998 . Regional frequency curves were developed by plotting the calculated quantiles ( $\mathrm{Y}$ axis) against selected results from equations 3 and 4 (X axis) and are shown on figures 12-14 grouped by region and on figures 15-17 grouped by duration. For example, using the GEV parameters in table 9 for 2-hour duration in Region 1 and solving equation 2 for a non-exceedance probability of 0.99 yields the following:

$$
\begin{aligned}
q(F) & =\xi+\alpha\left(\left\{1-(-\log F)^{\mathrm{k}}\right\} / \mathrm{k}\right) \\
q(0.99) & =0.803+0.258\left(\left\{1-(-\log 0.99)^{-0.159}\right\} /-0.159\right) \\
& \left.=0.803+0.258\left(1-(0.010)^{-0.159}\right) /-0.159\right) \\
& =0.803+0.258(1-2.080) /-0.159 \\
& =0.803+0.258(-1.080) /(-0.159) \\
& =0.803+0.258(6.792) \\
q(0.99) & =2.55
\end{aligned}
$$

The recurrence interval for a non-exceedance probability of 0.99 is $1 /(1-0.99)$, or 100 years.

To make the frequency curve more linear, nonexceedance probability is converted to GRV using equation 3 as follows:

$$
\begin{aligned}
\text { GRV } & =-\log (-\log F) \\
& =-\log (-\log 0.99) \\
& =-\log (0.010) \\
& =4.60
\end{aligned}
$$

\begin{tabular}{|c|c|c|c|c|c|c|c|c|c|}
\hline \multirow{3}{*}{ REGION } & \multicolumn{9}{|c|}{ Duration, in hours } \\
\hline & \multicolumn{3}{|c|}{2} & \multicolumn{3}{|c|}{6} & \multicolumn{3}{|c|}{24} \\
\hline & $\xi$ & $\alpha$ & $\mathbf{k}$ & $\xi$ & $\alpha$ & $\mathbf{k}$ & $\xi$ & $\alpha$ & k \\
\hline 2 & .783 & .276 & -.176 & .79 & .275 & -.135 & .801 & .280 & -.120 \\
\hline 3 & .765 & .314 & -.150 & .791 & .300 & -.109 & .799 & .304 & -.076 \\
\hline
\end{tabular}

Thus, the quantile value, which corresponds to a dimensionless storm depth, is plotted 2.55 units from the origin on the Y-axis and 4.60 units, corresponding to a recurrence interval of 100 years, from the origin on the X-axis (figs. 12 and 15). After plotting the complete frequency curve, the X-axis labels are expressed in terms of recurrence intervals rather than GRV.

Table 9. Parameters for Generalized Extreme Value (GEV) distribution applied to 2-6-, and 24-hour duration storm depths in Montana

$[\xi, \alpha$, and $\mathbf{k}$ are parameters for the GEV distribution] 


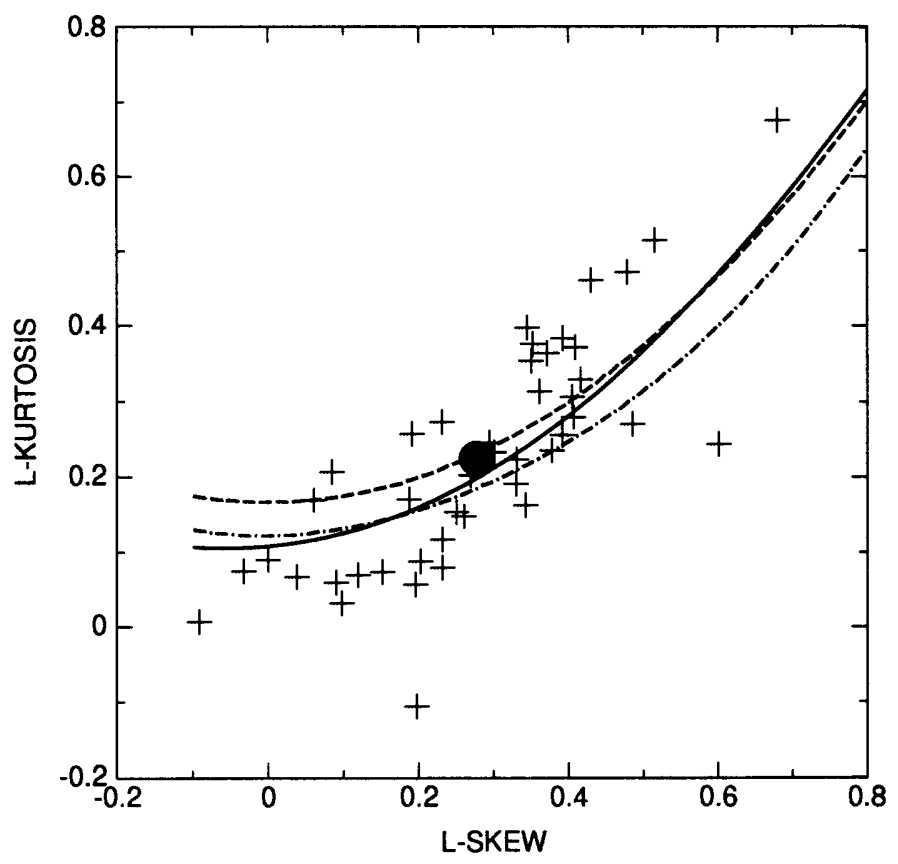

A. 2-HR DURATION

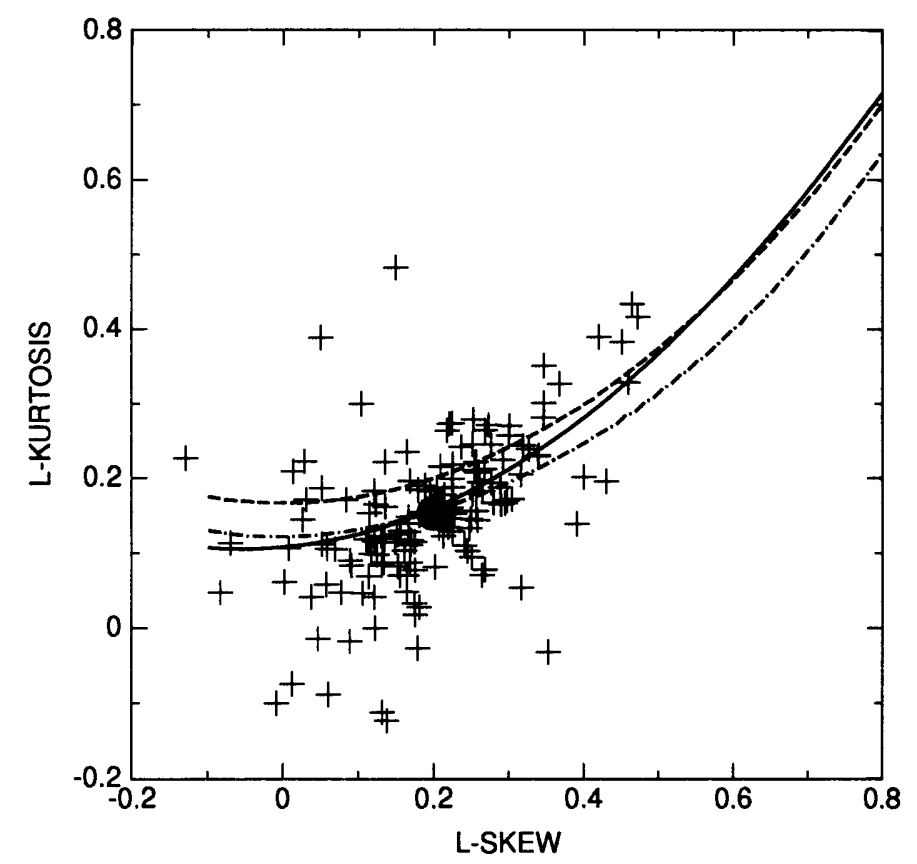

C. 24-HR DURATION

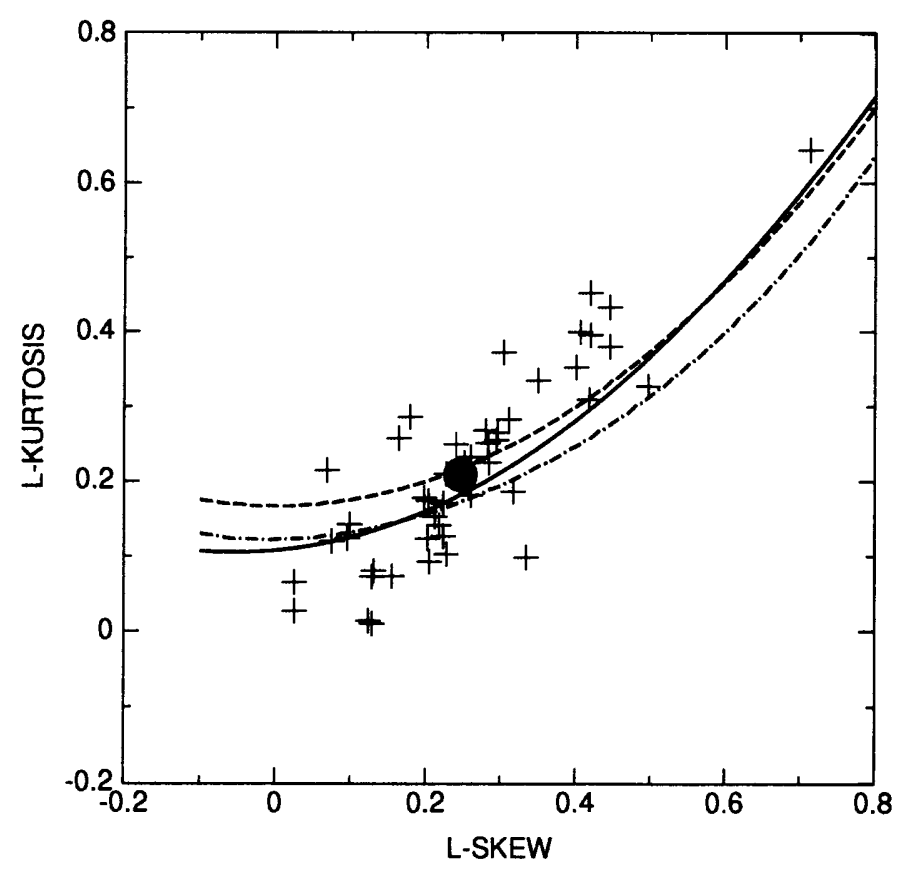

B. 6-HR DURATION

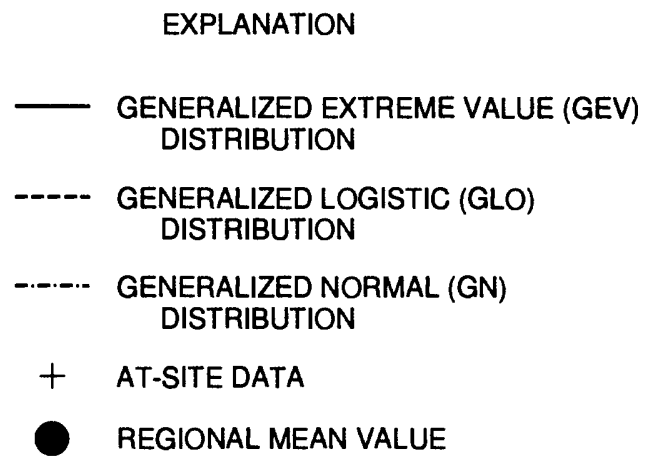

Figure 9. L-moment ratios for annual precipitation maxima in Region 1, Montana. 


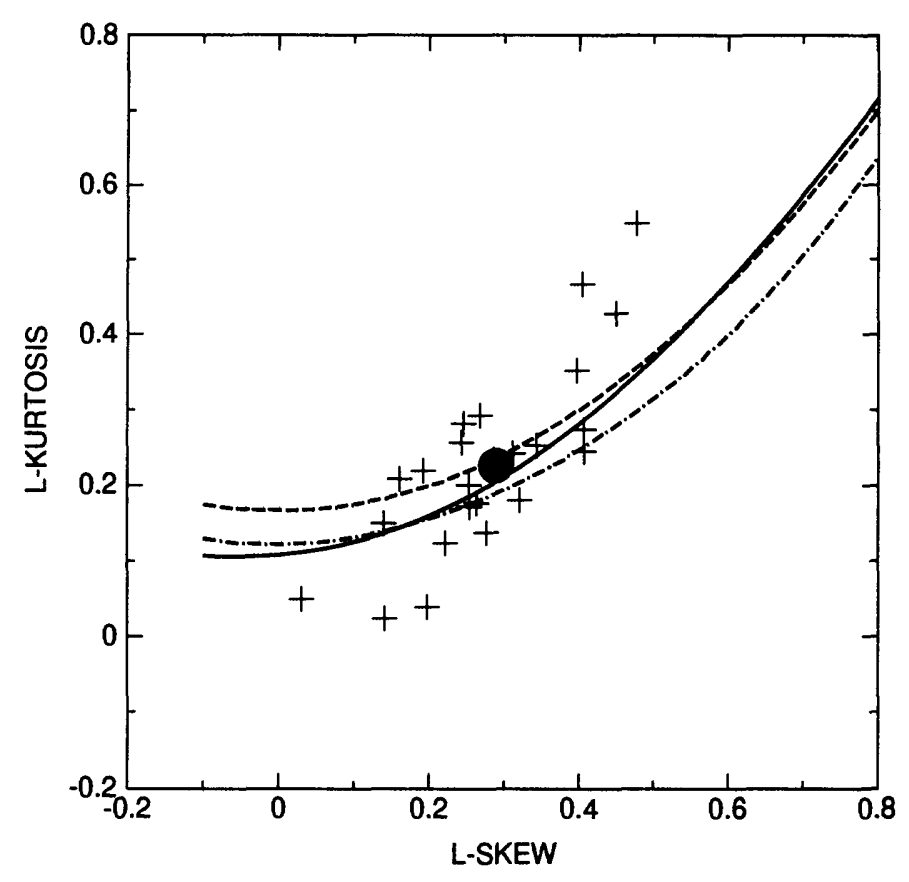

A. 2-HR DURATION

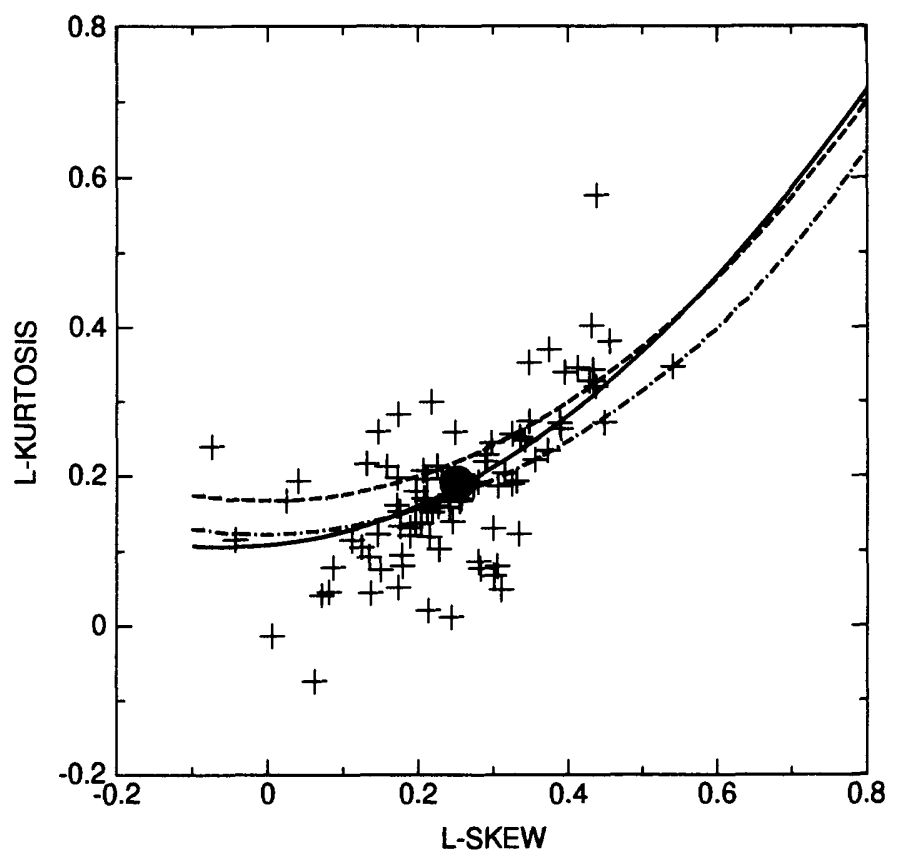

C. 24-HR DURATION

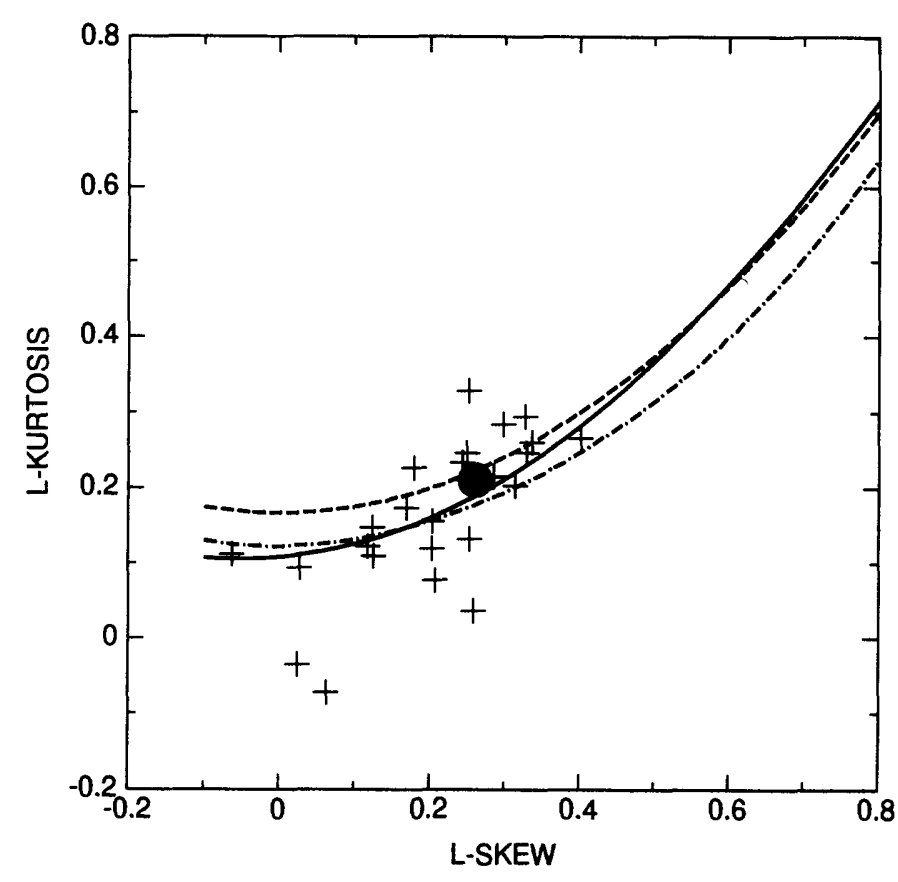

B. 6-HR DURATION

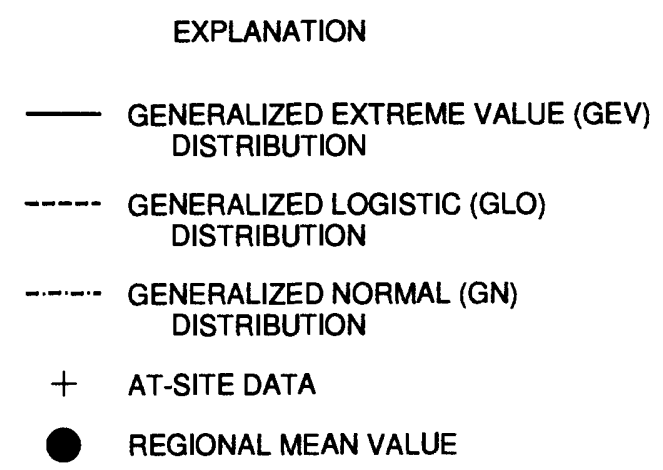

Figure 10. L-moment ratios for annual precipitation maxima in Region 2, Montana. 


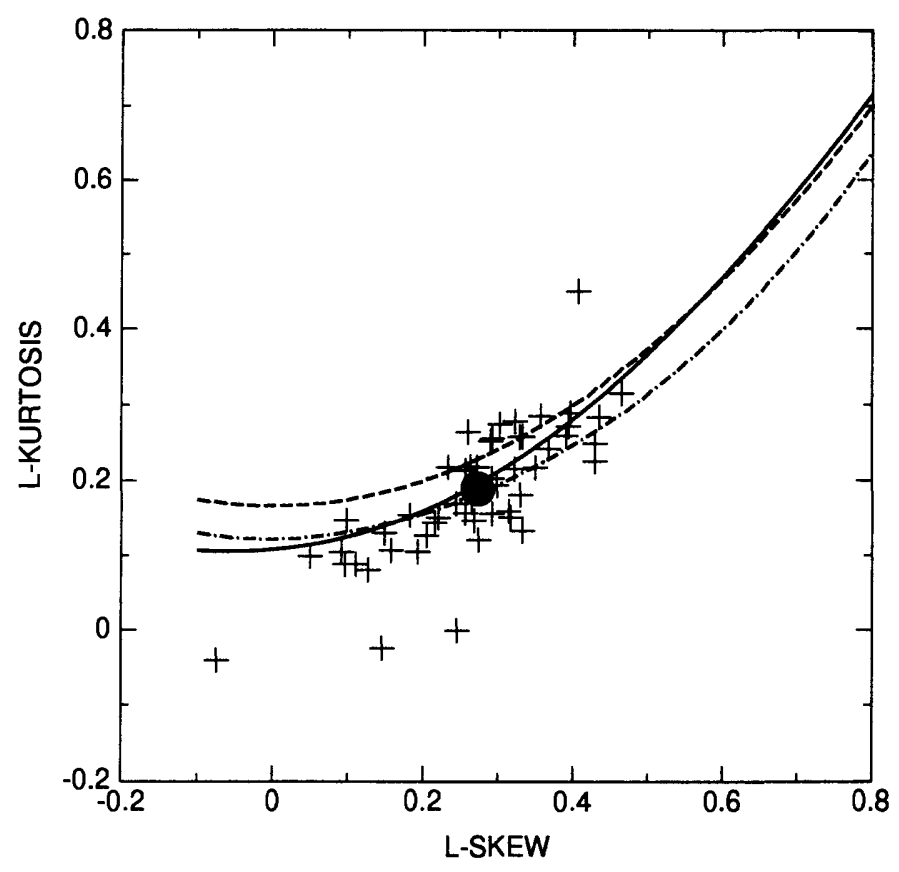

A. 2-HR DURATION

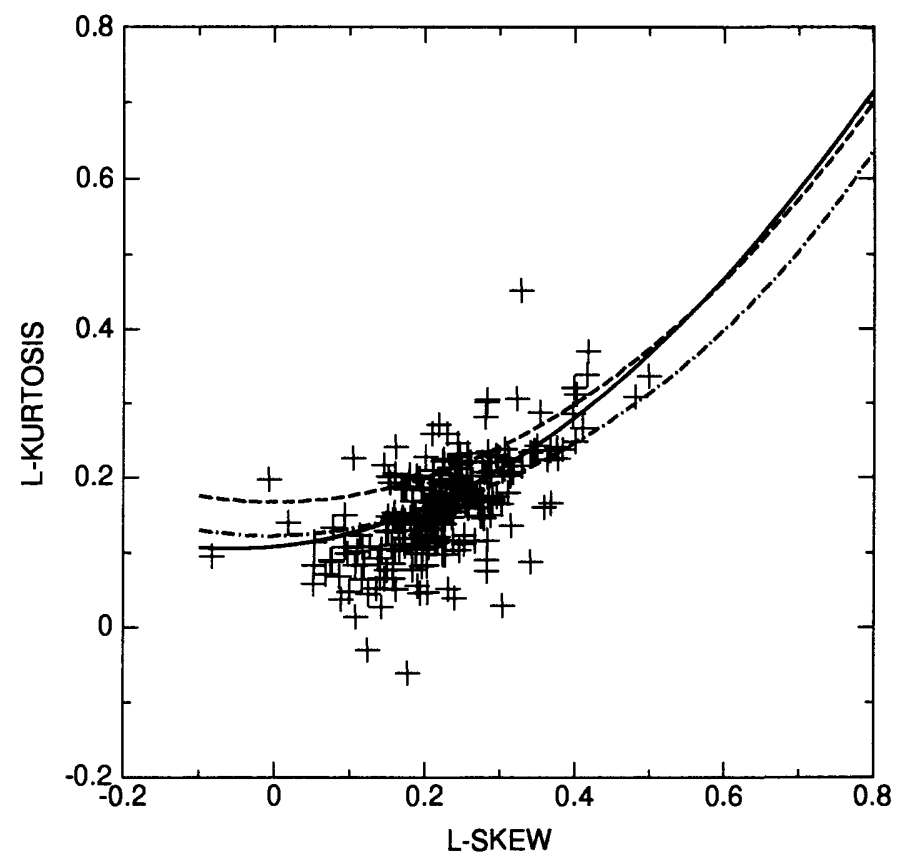

C. 24-HR DURATION

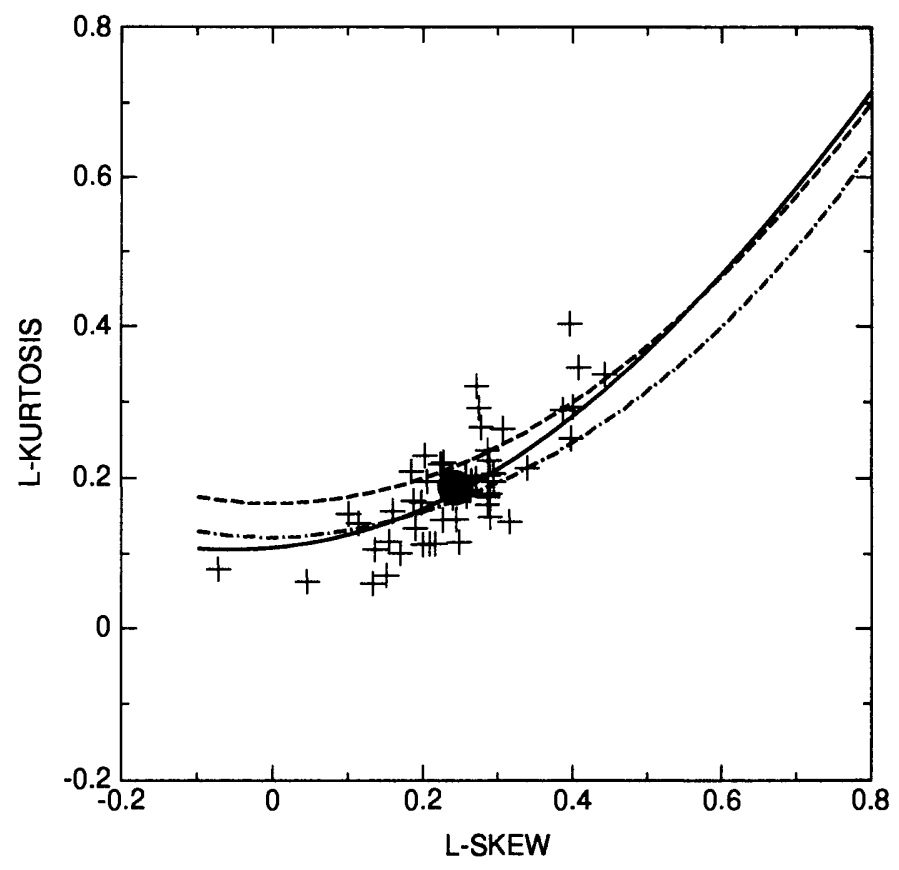

B. 6-HR DURATION

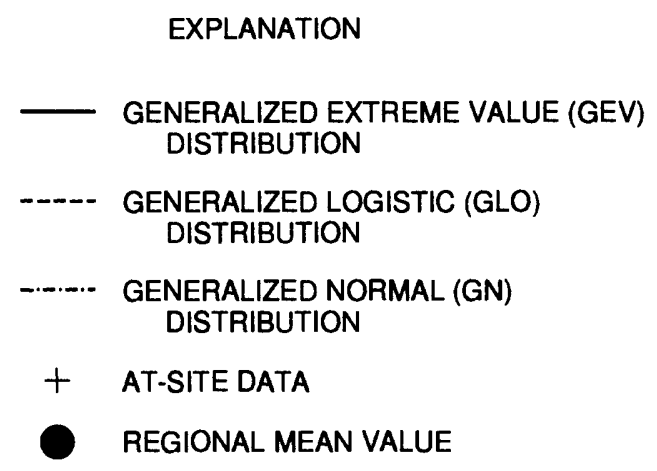

Figure 11. L-moment ratios for annual precipitation maxima in Region 3, Montana. 


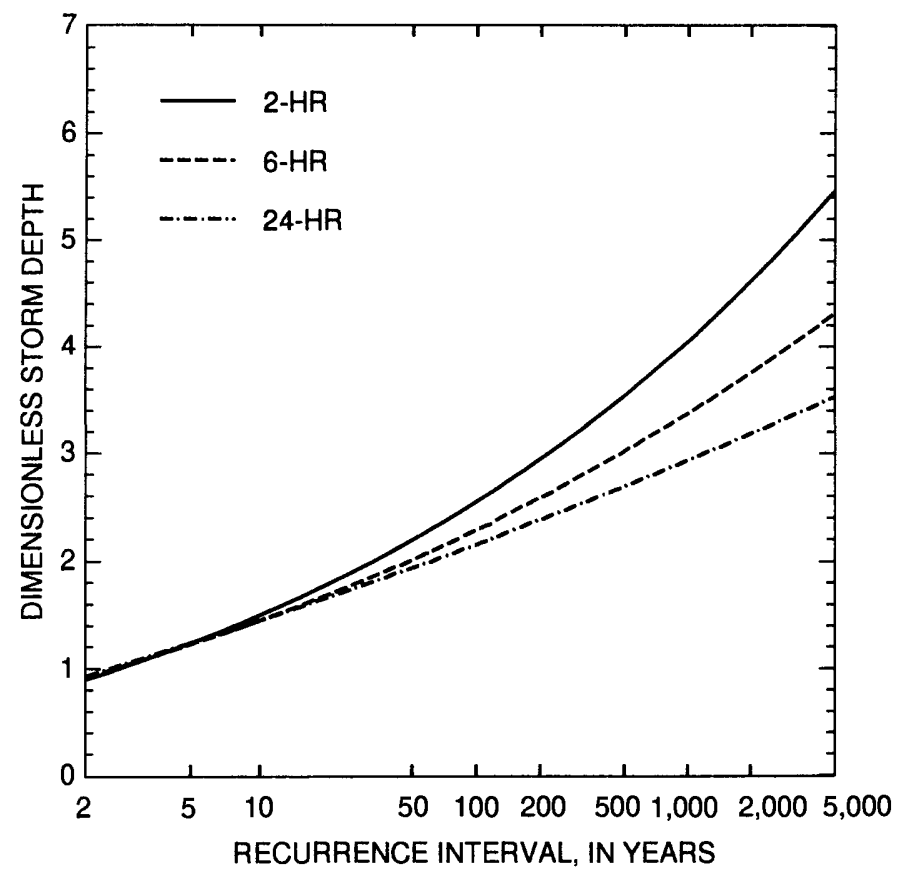

Figure 12. Regional frequency curves for dimensionless annual storm depths in Region 1, Montana.

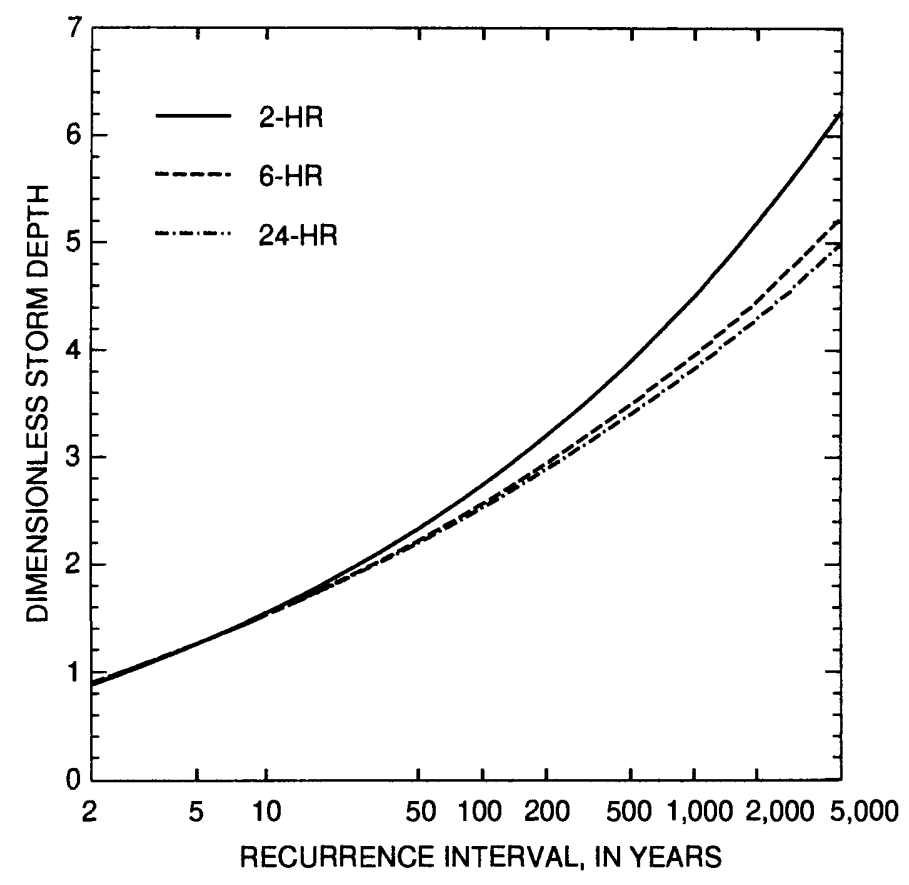

Figure 13. Regional frequency curves for dimensionless annual storm depths for Region 2, Montana. 


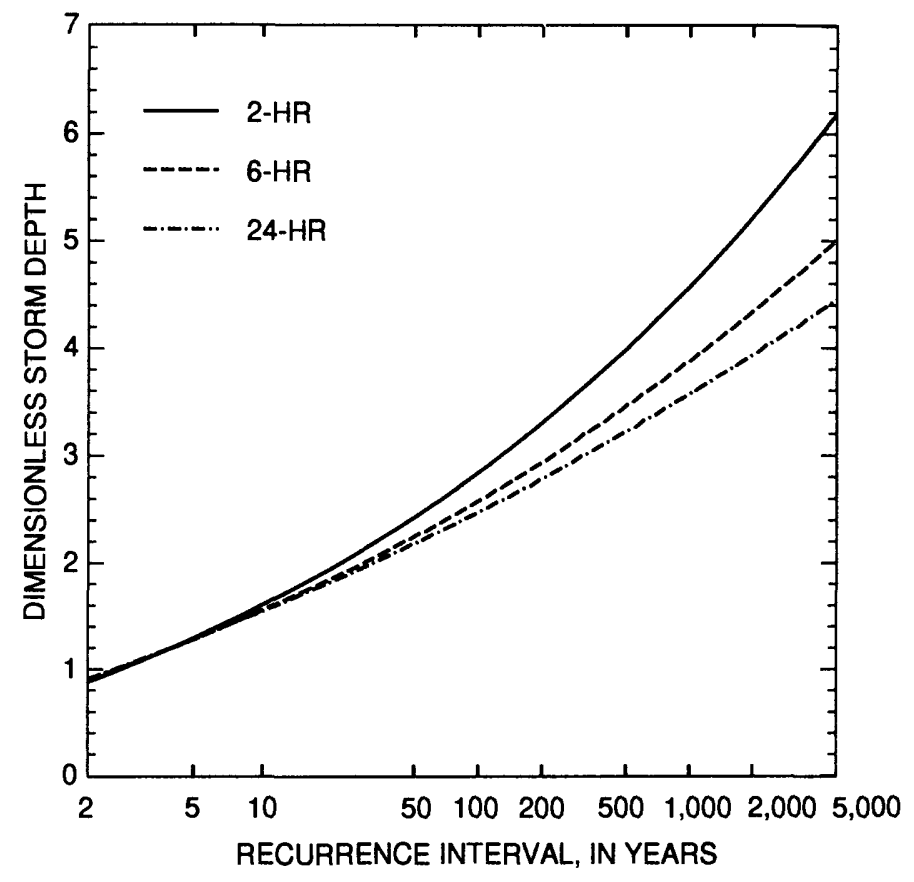

Figure 14. Regional frequency curves for dimensionless annual storm depths for Region 3, Montana.

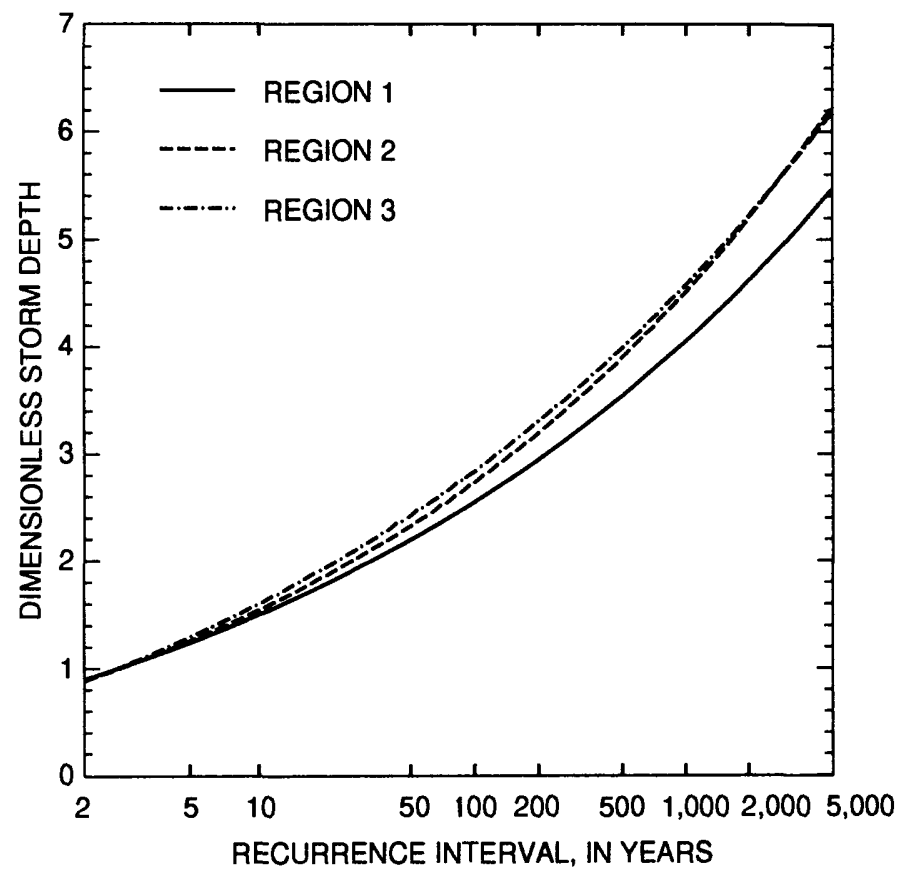

Figure 15. Regional frequency curves for dimensionless 2-hour duration annual precipitation depth, Montana. 


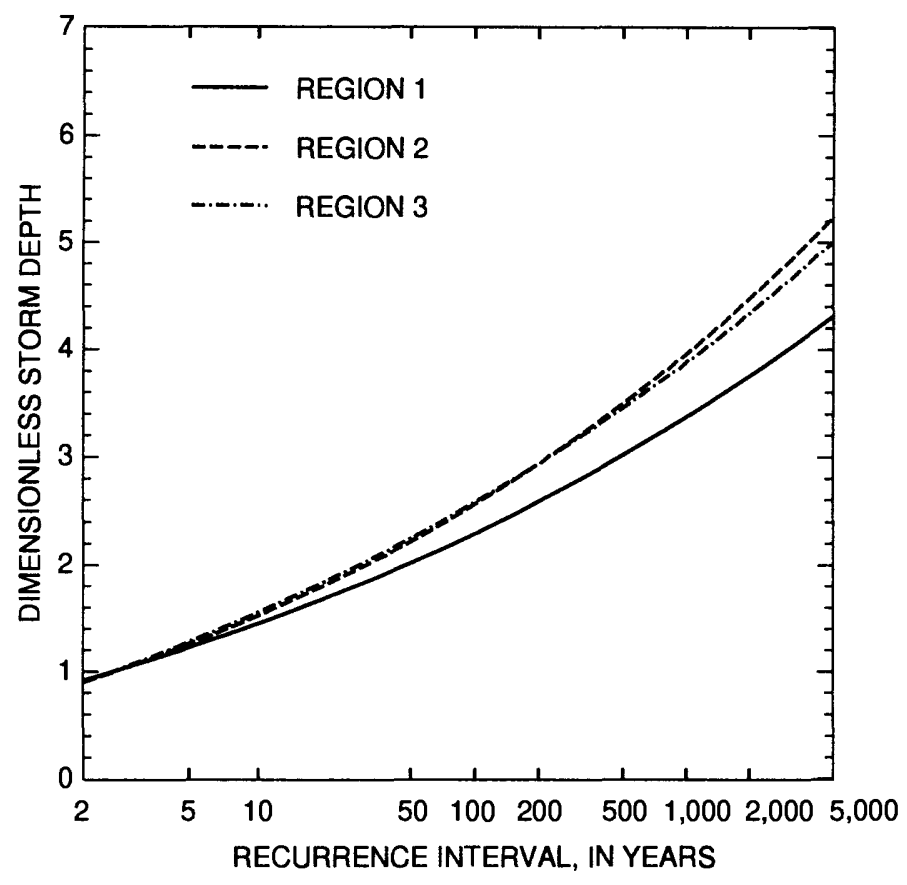

Figure 16. Regional frequency curves for dimensionless 6-hour duration annual precipitation depth, Montana.

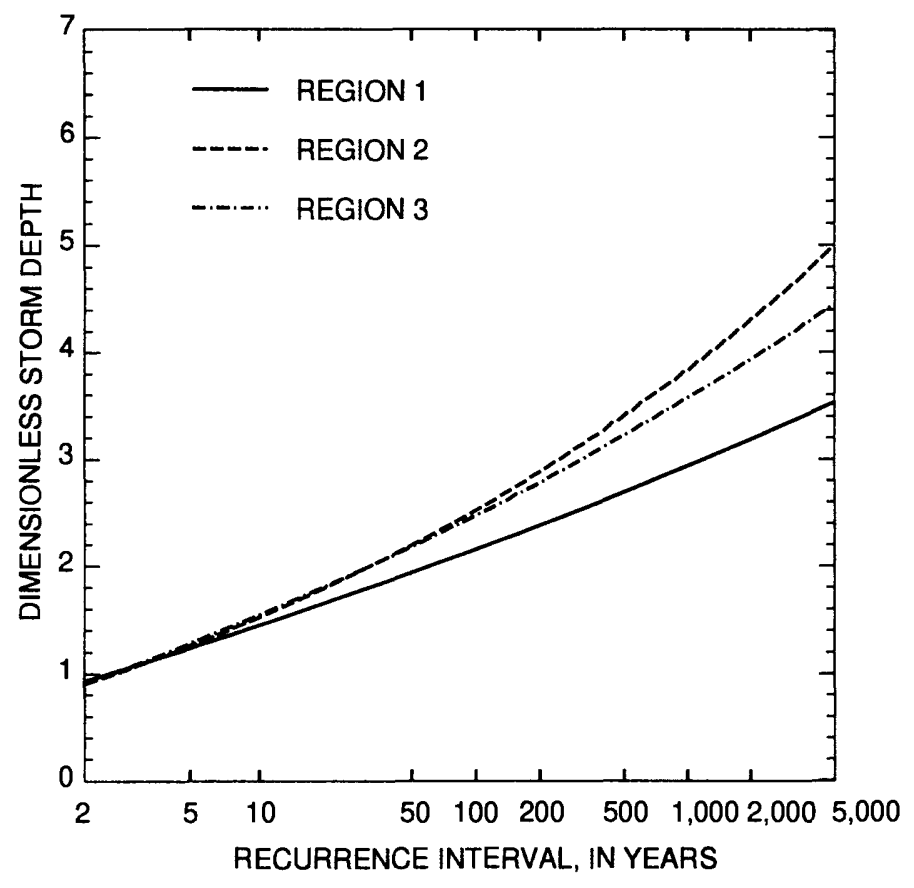

Figure 17. Regional frequency curves for dimensionless 24-hour duration annual precipitation depth, Montana. 
For recurrence intervals greater than about 10 years, figures 12-14 indicate that the regional dimensionless frequency curves for 2-hour durations are steeper than those for either 6-hour or 24-hour durations in all regions. Similarly, for recurrence intervals greater than about 50 years, the regional dimensionless frequency curves for 6-hour durations are steeper than those for 24-hour durations. Steeper curves for shorter durations is a natural consequence of the behavior of the regional $L$-moments, which tend to decrease with increasing duration. In particular, the relatively larger $L$-moments and the steeper regional curves for 2-hour durations are likely due to the greater effect of thunderstorms, which tend to be more severe and localized than long-duration general storms.

The reader needs to keep in mind that steeper dimensionless frequency curves for shorter durations do not mean that calculated at-site storm depths are greater for the shorter durations. A value of dimensionless depth obtained from a dimensionless frequency curve needs to be multiplied by an at-site mean value of storm depth to obtain an at-site storm depth for some specified return period. At-site mean depth increases with increasing duration, so a calculated storm depth for any recurrence interval will also increase, although at a lesser rate than the mean, with increasing duration.

Figures 15 and 16 indicate that the dimensionless frequency curves for 2- and 6-hour durations are similar for Regions 2 and 3 and are steeper than those for Region 1. Figure 17 shows that the dimensionless frequency curves for the 24-hour duration are distinctly different for all regions with Region 2 having the largest dimensionless regional quantiles and Region 1 having the smallest. Although Regions 1 and 2 generally are both mountainous, their dimensionless frequency curves are substantially different for all durations. The substantial differences between dimensionless 24-hour duration curves in Regions 1 and 2 are presumed to be largely the result of large, general storms from the Gulf of Mexico that commonly affect the eastern portions of the Rocky Mountains in Montana but only rarely the western portions. Although the plains area of eastern Montana (Region 3) is also affected by storms arising in the Gulf, the lack of mountains and their orographic effect apparently results in generally less severe 24 hour duration storms than in the more mountainous Region 2 . The similarity between frequency curves for 2- and 6-hour duration data in Regions 2 and 3 indicates that orographic differences between Regions 2 and 3 do not affect short-duration storms as much as they do long-duration, general storms.

\section{Determination of Effective Regional Record Length}

Frequency curves developed from at-site data commonly are used to estimate the magnitude of rare events for which the recurrence intervals are greater than the periods of at-site record. The greater the extrapolation beyond the period of record, the less reliable is the frequency-curve estimate. As reported by Schaefer (1990), a common rule of thumb in conventional at-site frequency analysis is to not exceed about twice the record length when making an estimate of a $T$-year event. For example, if a frequency curve is based on 50 years of at-site record, the rule of thumb indicates that the curve not be used to estimate events having greater than a 100-year recurrence interval.

For a regional analysis wherein all at-site data are combined, an analagous rule of thumb might be to not exceed twice the total station-years of record for all stations used in the analysis. Because of interstation correlation among sites, however, the equivalent regional record length is less than the total station-years of record. In order to estimate a reasonable equivalent regional record length for purposes of evaluating the reliability of regional frequency curves, a graphical method developed by Schaefer (1990) was used. Within each region, annual maxima for each duration were divided by the at-site mean and ranked from largest to smallest. The resultant dimensionless maxima that had common dates of occurrence were compared, and only the largest value was retained in the ranked data set. Counting each storm only one time for each duration within a region was an attempt to eliminate the small degree of interstation correlation and thus ensure that the ranked data would be independent.

After elimination of all storms but one having common dates of occurrence, the recurrence intervals of the 40 largest remaining dimensionless maxima for each duration in each region were determined from the appropriate regional frequency curve. Each calculated recurrence interval was plotted against the rank of each maxima. Thus, the largest recurrence interval was plotted against a rank of 1 ; the second largest recurrence interval was plotted against a rank of 2 ; and the smallest recurrence interval was plotted against a rank of 40 . The resultant plots of rank versus recurrence interval for the recorded data were compared to smooth curves that relate rank to recurrence interval for theoretical, independent data sampled from a probability distribution that can be described by the following plotting position formula: 


$$
T^{\prime} \text {-year }=\frac{1}{\left(\frac{i-0.4}{N+0.2}\right)}
$$

where $T^{\prime}$-year is the recurrence interval for each ranked data value, $i$ is the rank of the data from largest, 1 , to smallest, $N$, and $N$ is the number of years in the data set.

This plotting position formula has been shown to be generally unbiased and applicable for plotting data from 3-parameter probability distributions such as the GEV (Cunnane, 1978). Comparisons between the plots of recurrence interval versus rank for the 40 largest recorded maxima for each duration and curves from equation 12 for $500 ; 1,000 ; 2,000$; and 5,000 years are shown by region in figure 18 .

As indicated by figure 18 the plots of recurrence interval computed from the GEV distribution versus rank generally lie parallel to and between the curves for the theoretical data sets of various sizes. The approximate sample size (effective regional record length) for each plot can be visually interpolated from its location relative to the smooth curves. On that basis, the effective regional record lengths were determined for each duration within each region and are compared to the total station-years of record in table 10 . Although the visual interpolations are somewhat arbitrary and approximate, the results shown in table 10 indicate that the method for estimating effective regional record length is reasonable. For example, table 10 shows that the effective regional record lengths for all durations and regions are less than the total station-years of record. Also, table 10 indicates that the differences between effective regional record lengths and total station-years of record are greatest for 24-hour duration data in all regions and least for 2-hour duration data in all regions. Given that interstation correlation was shown to be greatest for 24-hour duration storm depths and least for 2-hour duration storm depths, the results in table 10 indicate the effects of the interstation correlation. Because the at-site values of precipitation maxima are not completely independent and because the three selected regions had some degree of heterogeneity, a suggested rule of thumb for extrapolation of regional frequency curves for Montana is to not exceed the effective regional record lengths. While this is a heuristic argument and not a statistical one, the rule of thumb appears to be reasonable and supportable by the data given the inherent complexities in the meteorology of extreme storms and the complexity of any rigorous statistical approach. On that basis, the effective regional record lengths shown in table 10 are considered to be reasonable maximum values of recurrence interval for making estimates of at-site annual storm depths in Montana.

\section{Determination of At-Site Mean Storm Depths}

As previously discussed, the at-site mean value of storm depth is required to estimate at-site storm depth from the dimensionless regional frequency curves. Regression equations for estimating at-site mean values of storm depth for each duration were developed for each region based on data at all sites used in the regionalization. Explanatory variables considered for use in the regressions were at-site latitude, longitude, mean annual precipitation, and elevation. These variables were selected because they (1) were available at all gaged sites used in the regionalization, and (2) can be fairly easily determined at ungaged sites from topographic maps and maps of mean annual precipitation recently prepared for Montana from digital data compiled by the Oregon State University Climate Center (George Taylor, unpub. data, 1995) (pl. 2).

A regression routine that used all possible combinations of explanatory variables was used, and the "best" model for each duration was considered to be the one that resulted in the minimum value of Mallows' Cp (Helsel and Hirsch, 1992, p. 312-313). Residual plots were also examined to ensure that residuals generally (1) were normally distributed, (2) had constant variance throughout the range of mean precipitation maxima, and (3) were linear. The "best" equation for each duration and two statistics indicating relative regression reliability, standard error of estimate and coefficient of determination $\left(R^{2}\right)$, are shown in table 11 . At-site elevation was not a significant explanatory variable for any duration within any region, presumably because it was highly correlated with mean annual precipitation.

As indicated in table 11, the regression equations for 2- and 6-hour duration mean storm depths had smaller standard errors than did the equation for 24hour duration mean storm depth. The difference may be partly due to the inclusion of SNOTEL sites in the 24-hour duration database, but not in the 2- or 6-hour duration database.

As a test of the overall reliability of the regression equations, 20 precipitation stations were randomly selected from each of the 3 regions of the State and considered to be ungaged sites for which the regression equations were used to calculate mean values of storm depth for 2-, 6-, and 24-hour durations. Methods for estimating mean values of storm depth described in the National Oceanic and Atmospheric Administration (NOAA) Precipitation-frequency Atlas 2 (Miller and 
Table 10. Total station-years of storm-depth record and effective record length by duration and region, Montana

\begin{tabular}{ccccc}
\hline Duration, in hours & Region & $\begin{array}{c}\text { Total station-years of } \\
\text { record }\end{array}$ & $\begin{array}{c}\text { Effective record } \\
\text { length, in years }\end{array}$ & $\begin{array}{c}\text { Effective record } \\
\text { length, in percent of } \\
\text { total station-years }\end{array}$ \\
\hline 2 & 1 & 1,375 & 1,300 & 95 \\
& 2 & 685 & 600 & 88 \\
3 & 1,874 & 1,800 & 96 \\
\hline & 1 & 1,574 & 1,500 & 95 \\
& 2 & 762 & 500 & 66 \\
& 3 & 2,185 & 1,900 & 87 \\
\hline
\end{tabular}

Table 11. Regression equations for estimation of mean storm depth for indicated duration in Montana

[Regression equation: Pmaxt, storm depth in inches, with t indicating duration in hours; $L A T$, site latitude, in decimal degrees minus 40; $L O N G$, site longitude, in decimal degrees minus 100; and $M A P$, mean annual precipitation, in inches, as determined from State maps prepared from digital data from Oregon State University Climate Center (pl. 2)]

\begin{tabular}{|c|c|c|c|c|}
\hline Region & & Equation & $\begin{array}{l}\text { Standard } \\
\text { error, } \\
\text { inches }\end{array}$ & $\begin{array}{c}\text { Coefficient of } \\
\text { determi- } \\
\text { nation, } R^{2}\end{array}$ \\
\hline \multirow[t]{3}{*}{1} & $P \max 2$ & $0.44+(0.0027 \times M A P)$ & 0.05 & 0.10 \\
\hline & Pmax6 = & $0.60+(0.0067 \times M A P)$ & 0.07 & 0.31 \\
\hline & $\operatorname{Pmax} 24=$ & $1.0+(0.078 \times L A T)-(0.059 \times L O N G)+(0.025 \times M A P)$ & 0.16 & 0.80 \\
\hline \multirow[t]{3}{*}{2} & Pmax 2 & $0.69+(0.034 \times L A T)-(0.029 \times L O N G)$ & 0.09 & 0.16 \\
\hline & Pmax6 = & $0.75+(0.087 \times L A T)-(0.041 \times L O N G)$ & 0.12 & 0.30 \\
\hline & $\operatorname{Pmax} 24=$ & $1.4+(0.18 \times L A T)-(0.13 \times L O N G)+(0.019 \times M A P)$ & 0.27 & 0.52 \\
\hline \multirow[t]{3}{*}{3} & $\operatorname{Pmax} 2$ & $0.70+(0.031 \times L A T)-(0.040 \times L O N G)+(0.0087 \times M A P)$ & 0.08 & 0.62 \\
\hline & Pmax6 & $0.85+(0.031 \times L A T)-(0.038 \times L O N G)+(0.015 \times M A P)$ & 0.08 & 0.59 \\
\hline & Pmax24 = & $0.62+(0.039 \times L A T)-(0.016 \times L O N G)+(0.058 \times M A P)$ & 0.16 & 0.49 \\
\hline
\end{tabular}


others, 1973) were also used to calculate mean values of storm depth for the same durations at the same 20 test sites. Results from the regression equations and from the methods described in NOAA Atlas 2 were compared to actual values of mean storm depth determined from the gaged record, and the standard deviation of the differences (residuals) between calculated and actual values are shown in table 12. As shown in table 12 , the results from the regression equations generally had lower standard deviations of residuals than did the results from the methods described in NOAA Atlas 2. Accordingly, the regression equations are considered to be generally more reliable within Montana than the methods described in NOAA Atlas 2.

Table 12. Results of comparison test between regression equations and methods in NOAA Atlas 2, volume 1 , Montana ${ }^{1}$

\begin{tabular}{ccc}
\hline $\begin{array}{c}\text { Duration, } \\
\text { hours }\end{array}$ & $\begin{array}{c}\text { Standard deviation of } \\
\text { residuals for } \\
\text { estimates of mean } \\
\text { storm depth from } \\
\text { regression equations, } \\
\text { inches }\end{array}$ & $\begin{array}{c}\text { Standard deviation of } \\
\text { residuals for estimates } \\
\text { of mean storm depth } \\
\text { made using NOAA } \\
\text { Atlas 2, inches }\end{array}$ \\
\hline 2 & 0.05 & 0.09 \\
6 & .08 & .11 \\
24 & .15 & .20 \\
\hline
\end{tabular}

Tiller and others, 1973.

An alternative method for the estimation of an atsite mean value of storm depth is to use the mean storm depth obtained from recorded data at a nearby station. If the station is relatively close to the ungaged site and has a similar elevation, the mean storm depth at the station is likely to be similar to that at the ungaged site and, perhaps, a better estimate of mean storm depth at the ungaged site than that from a regression equation.

To test whether estimates from nearby stations could be considered to be as reliable as estimates from regression equations, the nearest station having data for the same storm duration to each of the 20 test stations was used to estimate mean storm depth for 2-, 6-, and 24-hour durations at each test station. The standard deviation of differences (residuals) in mean storm depth was calculated for the 20 pairs of stations. The standard deviation of differences for each duration is shown in table 13, together with the mean values of interstation distance and elevation difference for the 20 pairs of stations. The standard deviations shown in table 13 generally are the same or smaller than the standard deviations of differences for the regression equations and for the methods of NOAA Atlas 2 (table 12). On that basis, the use of a nearby station to estimate mean storm depth at an ungaged site is considered to be at least as reliable as the use of regression equations so long as the interstation distance and elevation difference between the nearby station and the site of interest are not substantially greater than the mean values in table 13.

Table 13. Standard deviation of residuals and mean values of interstation distance and elevation difference for use of nearby station to estimate mean storm depth. Montana

\begin{tabular}{cccc}
\hline $\begin{array}{c}\text { Standard deviation } \\
\text { of residuals for } \\
\text { hours } \\
\text { estimates of mean } \\
\text { storm depth using } \\
\text { nearby stations, } \\
\text { inches }\end{array}$ & $\begin{array}{c}\text { Mean } \\
\text { interstation } \\
\text { distance, } \\
\text { miles }\end{array}$ & $\begin{array}{c}\text { Mean } \\
\text { elevation } \\
\text { difference, } \\
\text { feet }\end{array}$ \\
\hline 2 & 0.05 & 24.3 & 707 \\
6 & .06 & 23.3 & 712 \\
24 & .11 & 10.4 & 358 \\
\hline
\end{tabular}

\section{Depth-Area Adjustment Curves}

For most rainfall-runoff applications, a basinaverage value of storm depth is required rather than an at-site or point value. For any given storm, precipitation depth varies spatially from the storm center, or point of maximum depth, to the storm edges where precipitation depth is zero. Thus, for storms centered on a basin, the basin-average value of storm depth will always be less than the value at the basin or storm center. The degree to which point estimates of precipitation depth need to be adjusted downward to yield basin-average values depends upon basin size and storm duration. Storms that are large in areal extent will completely cover small basins so that little or no downward adjustment of point values of precipitation depth is required for small basins. Storms that are large in areal extent also generally have longer durations, so the degree of downward adjustment of point values to basin-average values generally decreases with increasing storm duration.

Adjustments to point values of precipitation depth to produce basin-average values commonly are made through the use of depth-area adjustment curves. Although the determination of depth-area adjustment curves for Montana was beyond the scope of the current study, various depth-area adjustment curves have been developed for other studies (Hansen and others, 1988; Miller and others, 1973; U.S. Weather Bureau, 1981; U.S. Department of Agriculture, 1972). The variation among these published depth-area adjustment curves is fairly large, especially for short-duration 
(2-hour) storms and large basins (drainage areas greater than about 100 square miles). Of these published depth-area adjustment curves, those developed by Miller and others (1973) result in the smallest reduction of point precipitation depths and thus are considered to be the most conservative. For most dam-safety and design applications, the depth-area adjustment curves by Miller and others (1973) thus are considered to be most applicable and are included here for easy reference (fig. 19).

Estimation of a basin-average storm depth for a specified recurrence interval generally requires that several estimates of at-site storm depth be averaged. The number of at-site estimates required to provide a reasonable basin-average value depends upon the areal variation in mean at-site storm depth as determined by equations in table 11 . In relatively small basins in eastern Montana where mean annual precipitation does not have much variation, calculated mean at-site storm depth also will not have much variation. For these basins, a single at-site estimate of storm depth at the basin centroid can be used with the appropriate curve in figure 19 to estimate basin-average storm depth. For larger basins in eastern Montana and for most basins in the mountains of Region 1 and 2 where mean annual precipitation varies substantially, several at-site estimates of storm depth are required. A grid-sampling method can be used for these basins to uniformly select points for at-site calculation of mean storm depth. To apply the grid-sampling method, a transparent grid is overlaid on a map of the basin, and a calculation of atsite mean storm depth is made for each grid intersection within the basin boundary. For each calculated mean storm depth, the appropriate dimensionless precipitation-frequency curve is used to calculate atsite storm depth for the specified recurrence interval, and all estimates of at-site storm depth are averaged. The areally averaged value of at-site storm depth is then used with the appropriate depth-area curve in figure 19 to estimate basin-average storm depth.

\section{Application of Regional Analysis Approach and Limitations}

Determination of an at-site storm depth for a selected recurrence interval and storm duration requires an estimate of at-site mean storm depth for the selected duration and application of one of the three dimensionless precipitation frequency curves (figures 12-14 or figures 15-17). Selection of an appropriate storm duration and recurrence interval depends upon the problem under consideration and is beyond the

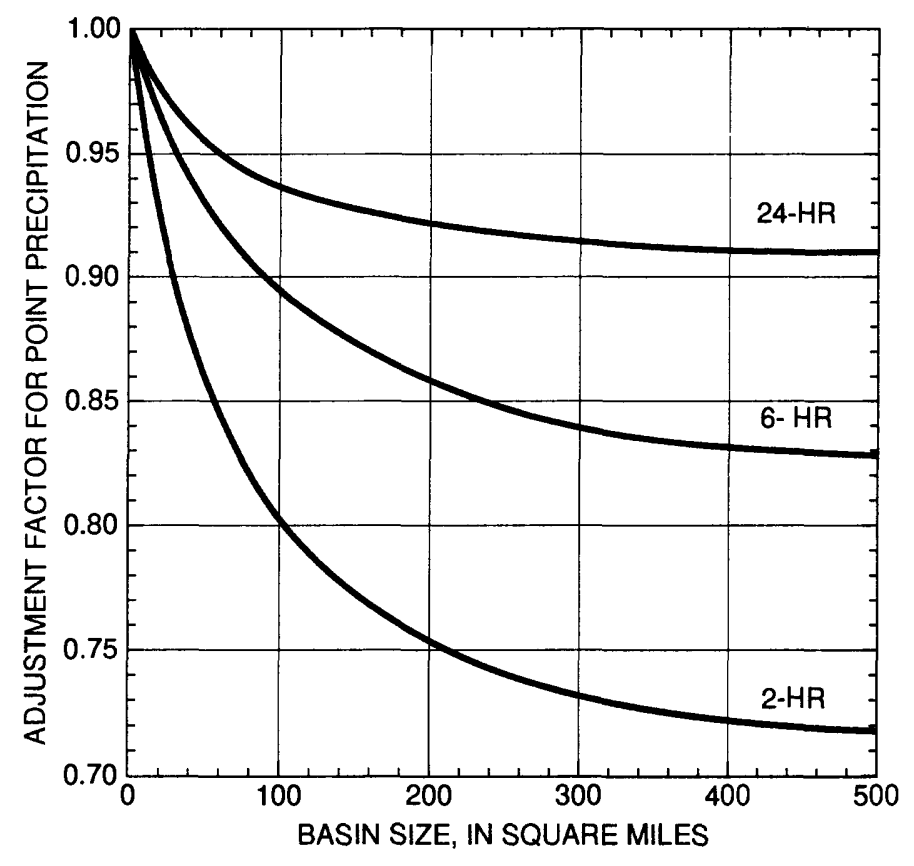

MODIFIED FROM MILLER

AND OTHERS (1973)

Figure 19. Depth-area adjustment curves for Montana. 
scope of this report. For rainfall-runoff determinations, storm duration generally is a function of the size of watershed under consideration and needs to be sufficiently long to ensure that the maximum rate of runoff results from the total depth of precipitation. In addition, depending upon the storage capacity of a reservoir relative to the runoff-generating capability of the watershed, total runoff volume from a storm may, in some instances, be more important than the maximum rate of runoff. If so, the appropriate storm duration will likely be longer than that required to produce the maximum rate of runoff. Given these considerations, an appropriate minimum storm duration is related to the time of travel of runoff from the farthest point in the basin to the point of interest and can be calculated from the physical characteristics of the basin (Holnbeck and Parrett, 1996). Selection of an appropriate recurrence interval for a rainfall-runoff problem relates to the risk of failure, and what constitutes an acceptable level of risk needs to be determined administratively. In general terms, the greater the risk to life or property, the greater the recurrence level needs to be.

The following examples are intended to illustrate the methods for estimation of annual precipitation maxima for typical dam-safety applications in Montana where storm duration and recurrence interval previously have been determined. The examples require some hydrologic judgment about: (1) the relation between recurrence interval of a storm and recurrence interval of the resultant runoff, (2) the use of precipitation-frequency curves for sites near regional boundaries, (3) application of the gridsampling method for estimation of at-site storm depths, or (4) the use of alternative methods for estimation of mean values of storm depth. Discussion about the degree of judgment required and its effect on the reliability of the estimates is provided for each example. The choices made in the examples are intended to be reasonable and are not necessarily the same choices that would be made for actual design applications where larger, more conservative, or smaller, less conservative, estimates might be required.

\section{Example 1:}

An estimate of an at-site precipitation depth for a 6-hour duration storm is required for a location at the centroid of a small, 5 -square mile basin in southwestern Montana. The site latitude is $45^{\circ}$, and the site longitude is $112^{\circ} 30^{\prime}$. The estimate will be used in a rainfall-runoff model where the required recurrence interval of the runoff is 100 years. Average conditions of basin infiltration are assumed, so the recurrence interval of the precipitation maximum is assumed to be the same as that for the runoff ( 100 years).

\section{Solution:}

Based on the latitude and longitude, the site is determined to be in Region 1. The dimensionless storm depth for a 6 -hour duration storm having a 100year recurrence interval is determined from figure 12 to be 2.3. From the map of mean annual precipitation ( $\mathrm{pl}$. 2 ), the mean annual precipitation for the site is determined to be 18 inches. The at-site mean 6 -hour storm depth is calculated from the equation for $P \max 6$ in table 11 as follows:

$$
\begin{aligned}
P \max 6 & =0.60+(0.0067 \times \text { MAP }) \\
& =0.60+(0.0067 \times 18) \\
& =0.60+0.12 \\
& =0.72 \text { inches }
\end{aligned}
$$

Multiplying the dimensionless storm depth times the at-site mean storm depth yields the following estimate of precipitation depth for a 6 -hour duration storm having a 100 -year recurrence interval:

$$
\begin{aligned}
\text { Depth } & =2.3 \times 0.72 \\
& =1.7 \text { inches. }
\end{aligned}
$$

\section{Discussion:}

The assumption that recurrence interval of the storm is equivalent to recurrence interval of the runoff is commonly made. Readers need to be aware, however, that the rainfall-runoff process is very complex, and that a storm depth having a given recurrence interval can produce runoff having a wide range in recurrence intervals depending upon the location, uniformity, and temporal characteristics of the storm and hydrologic conditions in the basin. For example, a storm having a small recurrence interval can produce runoff having a large recurrence interval if basin infiltration is abnormally small. In a very general sense, if storm characteristics and hydrologic conditions in a basin are typical for the season (average values), it seems reasonable to assume that recurrence intervals for storm depth and runoff are similar.

Because the site is not located close to a regional boundary and because the recurrence interval is much less than the equivalent record length of 1,500 years, no adjustments to the estimated storm depth or conditions on its use are considered necessary.

\section{Example 2:}

A basin-average estimate of precipitation depth for a 24-hour duration storm is required for spillway modification on a reservoir having a 150 -square mile drainage basin in Central Montana. Because the basin is relatively large and varies in elevation, the gridsampling method is used to select five grid intersections for the calculation of at-site storm depths. The 
latitudes of the five grid intersections range from $46^{\circ} 45^{\prime}$ to $46^{\circ} 55^{\prime}$ and the longitudes of the five grid intersections range from $109^{\circ} 45^{\prime}$ to $109^{\circ} 55^{\prime}$. The site is considered to be a relatively high-risk site, and the required recurrence interval for the 24-hour duration storm-depth estimate is selected to be 2,000 years.

\section{Solution:}

From the given latitudes and longitudes, the basin is determined from plate 1 to be partly in Region 2 and partly in Region 3. Three of the grid intersections where at-site storm depth is to be calculated are determined to be in Region 2, and two are determined to be in Region 3. From figure 17, values of dimensionless precipitation depth for a 24-hour storm having a 2,000 year recurrence interval are found to be 4.3 in Region 2 and 3.9 in Region 3.

From plate 2 , the mean annual precipitation at the 5 grid intersections ranges from 14 to 30 inches. The at-site mean precipitation depth for a 24 -hour storm is calculated for each grid intersection using the equations for Pmax24 in table 11. The results of the calculations are shown below:

\begin{tabular}{|c|c|}
\hline$\underline{\text { Region }}$ & $\begin{array}{l}P \max 24, \\
\text { in inches }\end{array}$ \\
\hline 2 & 1.9 \\
\hline 2 & 1.8 \\
\hline 2 & 1.7 \\
\hline 3 & 1.7 \\
\hline 3 & 1.5 \\
\hline
\end{tabular}

Storm depths for the three grid intersections in Region 2 are calculated by multiplying each value of Pmax 24 by the dimensionless precipitation depth, 4.3, as follows:

$$
\begin{aligned}
& \text { Depth }(1)=4.3 \times 1.9=8.2 \text { inches } \\
& \text { Depth }(2)=4.3 \times 1.8=7.7 \text { inches } \\
& \text { Depth (3) }=4.3 \times 1.7=7.3 \text { inches }
\end{aligned}
$$

Likewise, storm depths for the two grid intersections in Region 3 are calculated by multiplying each value of $P \max 24$ by the dimensionless precipitation depth, 3.9, as follows:

$$
\begin{aligned}
& \text { Depth (4) }=3.9 \times 1.5=5.9 \text { inches } \\
& \text { Depth (5) }=3.9 \times 1.7=6.6 \text { inches }
\end{aligned}
$$

The five calculated at-site storm depths are averaged to obtain a value of 7.1 inches. From the depth-area curve for 24-hour duration storms in figure 19, the depth-area adjustment factor for a 150-square mile basin is found to be 0.93 . Finally, multiplication of the depth-area adjustment factor by the average at-site storm depth yields the basin-average precipitation depth for a 2,000-year, 24-hour duration storm as:

$$
\begin{aligned}
\text { Basin-average depth } & =0.93 \times 7.1 \text { inches } \\
& =6.6 \text { inches }
\end{aligned}
$$

Discussion:

Although the recurrence interval of 2,000 years is large, it is less than the equivalent record length for 24hour duration data in Region 3 (5,100 years) and only slightly greater than the equivalent record length for 24-hour duration data in Region 2 (1,900 years). The basin-average estimate based on the at-site estimates for Regions 2 and 3 is thus considered to meet the suggested rule of thumb for extrapolation of regional precipitation-frequency curves for Montana and to be a reasonable estimate.

Because the location of regional boundaries is somewhat arbitrary, an alternative approach for this problem would be to use only the dimensionless precipitation-frequency curve for Region 2 rather than curves for both Regions 2 and 3. The calculated at-site precipitation depths at the two grid intersections in Region 3 would then be as follows:

$$
\begin{aligned}
& \text { Depth (4) }=4.3 \quad \text { x } 1.7=7.3 \text { inches } \\
& \text { Depth }(5)=4.3 \quad \text { x } 1.5=6.5 \text { inches }
\end{aligned}
$$

The average value of at-site precipitation depth would be 7.4 inches, and the basin-average storm depth would be:

$$
\begin{aligned}
\text { Basin-average depth } & =0.93 \times 7.4 \\
& =6.9 \text { inches }
\end{aligned}
$$

Given the large recurrence interval required, the alternative approach, which provides a conservatively larger storm depth, might be more appropriate for this example.

\section{Example 3:}

Estimates of storm depths for 2-,6-, and 24-hour durations are required for design of a flood-control structure on a small, 3.5 square mile basin in the mountains of western Montana (Region 1). The latitude and longitude of the basin outlet are $47^{\circ} 11^{\prime}$ and $113^{\circ} 18^{\prime}$, respectively. The mean annual precipitation at this site is determined from plate 2 to be 40 inches. An appropriate recurrence interval for design has not been determined, so a precipitation frequency curve will be determined for each duration. A long-term precipitation station is located about 3 miles south of the basin at an elevation about 100 feet lower than the basin outlet. The mean storm depths for durations of 2-, 6-, and 24-hours at the station are 0.70, 1.0, and 1.9 inches, respectively. 


\section{Solution:}

Because of the small size of the basin, a single atsite estimate of precipitation depth at the basin outlet is considered to be representative of average precipitation over the basin.

Using the equations for $P \max 2, P \max 6$, and Pmax 24 for Region 1 in Table 11 to calculate at-site mean storm depth gives the following:

$$
\begin{array}{rl}
P_{\max 2} & =0.44+(0.0027 \times 40) \\
& =0.44+0.11 \\
& =0.55 \mathrm{inch} \\
P_{\max 6} & 0.60+(0.0067 \times 40) \\
& =0.60+0.27 \\
& =0.87 \mathrm{inch} \\
P_{\max 24} & 1.0+(0.078 \times 7.2)-(0.059 \times 13)+(0.025 \times 40) \\
& =1.0+0.56-0.77+1.0 \\
& =1.8 \text { inch }
\end{array}
$$

Because the nearby precipitation station is considered to be meteorologically similar to the basin outlet, the slightly larger mean storm depths at the nearby station are used to calculate storm depths from the dimensionless precipitation frequency curves rather than the mean depths obtained from the regression equations.

From figure 12, ordinates for various recurrence intervals for each duration were selected to produce table 14.

The columns of dimensionless storm depths in table 14 were each multiplied by the mean storm depth for the appropriate duration to produce table 15 for plotting storm depth frequency curves. Equations 3 and 4 were used to convert the $T$-year recurrence interval in table 15 to GRV for plotting purposes as previously described, and the final storm-depth frequency curves for the example site are shown in figure 20 . Data in tables 14 and 15 are all shown to two decimal places to ensure that the final storm-depth frequency curves would be relatively smooth.

\section{Discussion:}

Figure 20 indicates that, as expected, at-site storm depths increase with increasing duration for any given recurrence interval. As was previously discussed, this result may not have been evident from the dimensionless precipitation frequency curves in figures 12-14.

Table 14. Dimensionless storm depths for indicated durations and recurrence intervals for hypothetical site in Region 1, Montana

\begin{tabular}{cccc}
\hline $\begin{array}{c}\text { Recurrence interval } \\
\text { (years) }\end{array}$ & \multicolumn{3}{c}{ Dimensionless storm depth for indicated duration } \\
\cline { 2 - 4 } & 2-hour & 6-hour & 24-hour \\
\hline 2 & 0.90 & 0.90 & 0.90 \\
5 & 1.25 & 1.25 & 1.25 \\
10 & 1.50 & 1.45 & 1.45 \\
50 & 2.20 & 2.05 & 1.95 \\
100 & 2.55 & 2.30 & 2.15 \\
200 & 2.95 & 2.60 & 2.40 \\
500 & 3.55 & 3.00 & 2.70 \\
1,000 & 4.05 & 3.40 & 2.95 \\
2,000 & 4.65 & 3.80 & 3.20 \\
5,000 & 5.45 & 4.30 & 3.52 \\
\hline
\end{tabular}

Table 15. Storm depths for indicated durations and recurrence intervals for hypothetical site in Region 1, Montana

\begin{tabular}{clcc}
\hline \multirow{2}{*}{$\begin{array}{c}\text { Recurrence interval } \\
\text { (years) }\end{array}$} & \multicolumn{3}{c}{ Storm depth (in inches) for indicated duration } \\
\cline { 2 - 4 } & 2-hour & 6-hour & 24-hour \\
\hline 2 & 0.63 & 0.90 & 1.71 \\
5 & 0.88 & 1.25 & 2.38 \\
10 & 1.05 & 1.45 & 2.76 \\
50 & 1.54 & 2.05 & 3.70 \\
100 & 1.78 & 2.30 & 4.08 \\
200 & 2.06 & 2.60 & 4.56 \\
500 & 2.48 & 3.00 & 5.13 \\
1,000 & 2.84 & 3.40 & 5.60 \\
2,000 & 3.26 & 3.80 & 6.08 \\
5,000 & 3.82 & 4.30 & 6.69 \\
\hline
\end{tabular}




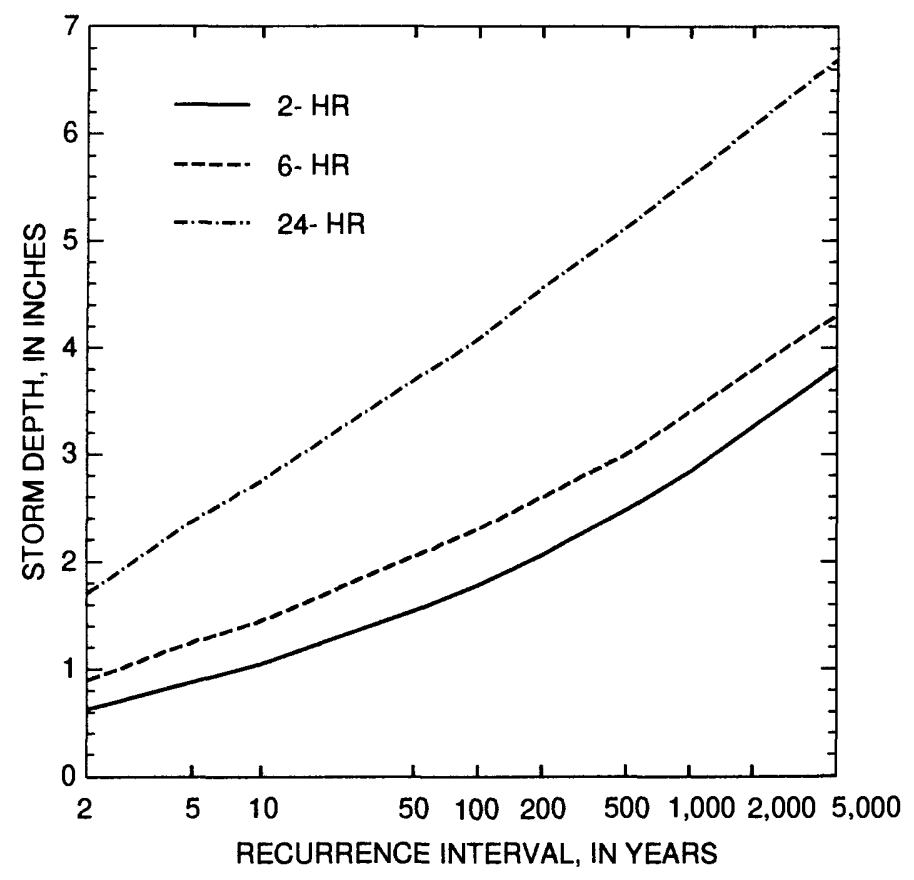

Figure 20. Storm-depth frequency curves for hypothetical site in Region 1, Montana.

The dimensionless curves generally increase in steepness and have larger ordinates as the durations decrease. On that basis, the dimensionless curves seem to imply that calculated at-site storm depths for a given recurrence interval might be larger for short durations than for long durations. As the results in example 3 indicate, scaling the dimensionless ordinates by the mean storm depth removes the anomalous appearance of the dimensionless frequency curves and results in atsite storm-depth frequency curves that are reasonable.

\section{SUMMARY}

Methods for estimating precipitation depths based on probability of exceedance are required to better evaluate risk of dam failure and establish a more consistent basis for spillway design. A regional analysis of annual precipitation maxima for Montana resulted in dimensionless precipitation-frequency curves for 2-, 6-, and 24-hour storm durations for three acceptably homogeneous regions in Montana. Within each homogeneous region, at-site annual precipitation maxima were made dimensionless by dividing by the at-site mean and pooled for analysis to yield a single dimensionless frequency curve applicable for each duration. $L$-moment statistics were used to help define the homogeneous regions and to develop the dimensionless precipitation-frequency curves.
Data from 122 hourly and 283 daily precipitation stations operated by the National Weather Service and 54 daily precipitation stations operated by the Natural Resources Conservation Service were used to develop the database of annual precipitation maxima. Four hourly and 22 daily sites were located in northern Wyoming. All stations had at least 10 years of data. Because of periods of missing data, precipitation data were carefully scrutinized to ensure that reported annual maxima were true maxima. Data were tested to ensure that 24-hour duration maxima from the daily stations were, after application of an adjustment factor, equivalent to 24-hour duration maxima determined from hourly stations. Data were also tested to ensure that annual maxima based on different annual periods were equivalent. Statistical tests were applied to the annual precipitation maxima to ensure that the data were not serially correlated and were stationary over the general period of data collection (1900-92). The data also were tested for spatial independence using the interstation correlation coefficient and found to have a small, but significant, degree of interstation correlation.

Several attempts were made to delineate homogeneous regions. The first attempt, based on a previous study in Washington State, delineated regions such that each had a small range in values of mean annual precipitation. Results of a statistical test for regional heterogeneity based on $L$-moments indicated that regions delineated on the basis of a small range in values of 
mean annual precipitation generally were not homogeneous in Montana. A second attempt delineated regions such that each had a small range in values of site elevation. This attempt also generally resulted in non-homogeneous regions based on results of the heterogeneity test. Three regions previously delineated on the basis of physiography and climate also were tested and found to be acceptably homogeneous for purposes of this study. One region (Region 1) consisted of generally mountainous western Montana where large storms generally receive their moisture from the Pacific Ocean. A second region (Region 2) included the mountains forming the eastern edge of the Rocky Mountain range where large storms are often the result of the orographic uplifting of moisture systems originating in the Gulf of Mexico. The third region (Region 3 ) consisted of the plains areas of eastern Montana where large storms may originate from moisture sources in the Pacific Ocean or the Gulf of Mexico. Although the three regions did not meet the statistical test for homogeneity based on $L$-moments for all storm durations, the same regional boundaries were used for all storm durations to define acceptably "homogeneous" regions.

Within each homogeneous region, regional values of $L$-moments and $L$-moment ratios were used to calculate parameters of several candidate probability distributions. A goodness-of-fit test was used to help select an acceptable distribution for each duration within each region. The distribution that most often satisfied the goodness-of-fit test and was thus selected as the best distribution for all durations and regions was the 3parameter Generalized Extreme Value (GEV) distribution. The GEV distribution was used to construct dimensionless frequency curves of annual storm depth for each duration within each region. Each dimensionless frequency curve was considered to be reliable for recurrence intervals up to the effective record length. Because of significant, though small, interstation correlation in all regions for all durations, and because the selected regions exhibited some heterogeneity, the effective record length was considered to be less than the total number of station-years of data. The effective record length for each duration in each region was estimated using a graphical method and found to range from 500 years for 6-hour duration data in Region 2 to 5,100 years for 24-hour duration data in Region 3.

Because the dimensionless frequency curves are scaled by the mean values of annual storm depth, using the curves to estimate precipitation depths for specified durations and exceedance probabilities at ungaged sites requires the estimation of mean storm depths for the specified durations. Regression equations for the estimation of mean storm depths for durations of 2,6 , and
24 hours were developed. Explanatory variables for the regression equations included site location (latitude and longitude) and mean annual precipitation. The regression equations were tested against methods for estimating mean values previously developed by the National Weather Service and were determined to be generally more reliable within Montana than the previously developed methods. Use of a nearby precipitation station to estimate mean storm depths at an ungaged site also was tested and found to be at least as reliable as use of a regression equation.

\section{SELECTED REFERENCES}

Alila, Y., Pilon, P.J., and Adamowski, K.,1992, An evaluation of rainfall frequency data for Canada using $L$ moments, in Conference on Probability and Statistics in the Atmospheric Sciences, 12th, Toronto, Ont., Canada, 1992: American Meteorological Society, p. 237-241.

Cunnane, C., 1978, Unbiased plotting positions---a review: Journal of Hydrology, v. 37, p. 205-222.

Dalrymple, Tate, 1960, Flood-frequency analyses: U.S. Geological Survey Water-Supply Paper 1543-A, 80 p.

Hansen, E.M., Fenn, D.D., Schreiner, L.C., Stodt, R.W., and Miller, J.F., 1988, Probable maximum precipitation estimates--United States between the Continental Divide and the 103rd Meridian: U.S. Department of Commerce, U.S. Department of the Army, and U.S. Department of the Interior, Hydrometeorological Report No. 55-A, 242 p.

Helsel, D.R., and Hirsch, R.M.. 1992, Statistical methods in water resources: New York, Elsevier, Studies in Environmental Science 49, $522 \mathrm{p}$.

Holnbeck, S.R., and Parrett, Charles, 1996. Procedures for estimating unit hydrographs for large floods at ungaged sites in Montana: U.S. Geological Survey WaterSupply Paper 2420, $60 \mathrm{p}$.

Hosking, J.R.M, 1990, L-moments--Analysis and estimation of distributions using linear combinations of order statistics: Journal of Royal Statistical Society, v. B52, no. 1, p. 105-124.

Hosking, J.R.M., and Wallis, J.R., 1988, The effect of intersite dependence on regional flood frequency analysis: Water Resources Research, v. 24, no. 4, p. 588-600.

1993, Some statistics useful in regional frequency analysis: Water Resources Research, v. 29, no. 2, p. 271-281.

1995, Correction to "Some statistics useful in regional frequency analysis": Water Resources Research, v. 31, no. 1, p. 251.

Miller, J.F., Frederick, R.H., and Tracey, R.J., 1973, NOAA Atlas 2, Precipitation-frequency atlas of the western 
United States, volume 1, Montana: Silver Spring, MD., National Weather Service, 41 p.

Omang, R.J., 1992, Analysis of the magnitude and frequency of floods and the peak-flow gaging network in Montana: U.S. Geological Survey Water-Resources Investigations Report 92-4048, 70 p.

Omang, R.J., Parrett, Charles, and Hull, J.A., 1986, Methods for estimating magnitude and frequency of floods in Montana based on data through 1983: U.S. Geological Survey Water-Resources Investigations Report 864027, $85 \mathrm{p}$.

Schaefer, M.G., 1989, Characteristics of extreme precipitation events in Washington State: Washington State Department of Ecology 89-51, 108 p.

1990, Regional analyses of precipitation annual maxima in Washington State: Water Resources Research, v. 26, no. 1, p. 119-131.

Stedinger, J.R., Vogel, R.M., and Foufoula-Georgiou, Efi, 1993, Frequency analysis of extreme events, chap. 18 of Maidment, D.R., ed., Handbook of hydrology: McGraw-Hill, p. 18.1-18.5.
U.S. Department of Agriculture, 1972, Soil Conservation Service national engineering handbook, section 4 , hydrology: U.S. Department of Agriculture, p. 21-121-115.

U.S. Weather Bureau, 1981, Probable maximum precipitation, northwest States, reprinted with revision of April, 1981: U.S. Department of Commerce and U.S. Department of the Army, Hydrometerological Report No. 43, $228 \mathrm{p}$.

Vogel, J. L., and Lin, Bingzhang, 1992, Precipitation return frequencies and $L$-moment statistics, in Conference on Probability and Statistics in the Atmospheric Sciences, 12th, Toronto, Ont., Canada, 1992: American Meteorological Society, p. 251-254.

Wallis, J.R., 1989, Regional frequency studies using $L$ moments: New York, Yorktown Heights, IBM Research Report IBM RC14597. Thomas J. Watson Research Center, $17 \mathrm{p}$.

Weiss, L.L., 1964, Ratio of true to fixed-interval maximum rainfall: Journal of the Hydraulics Division, American Society of Civil Engineers, v. 90, HY-1, January, p. 7782. 


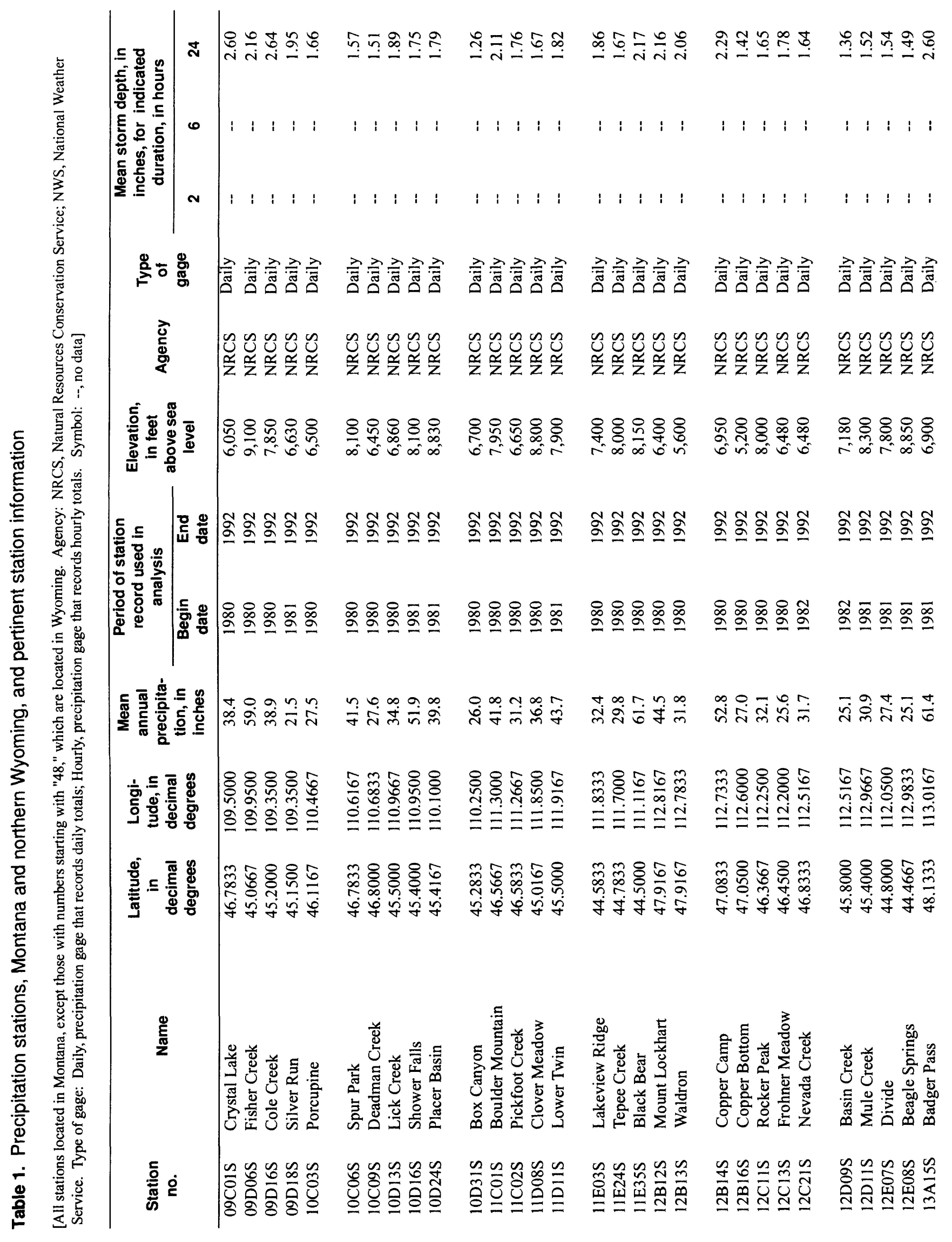




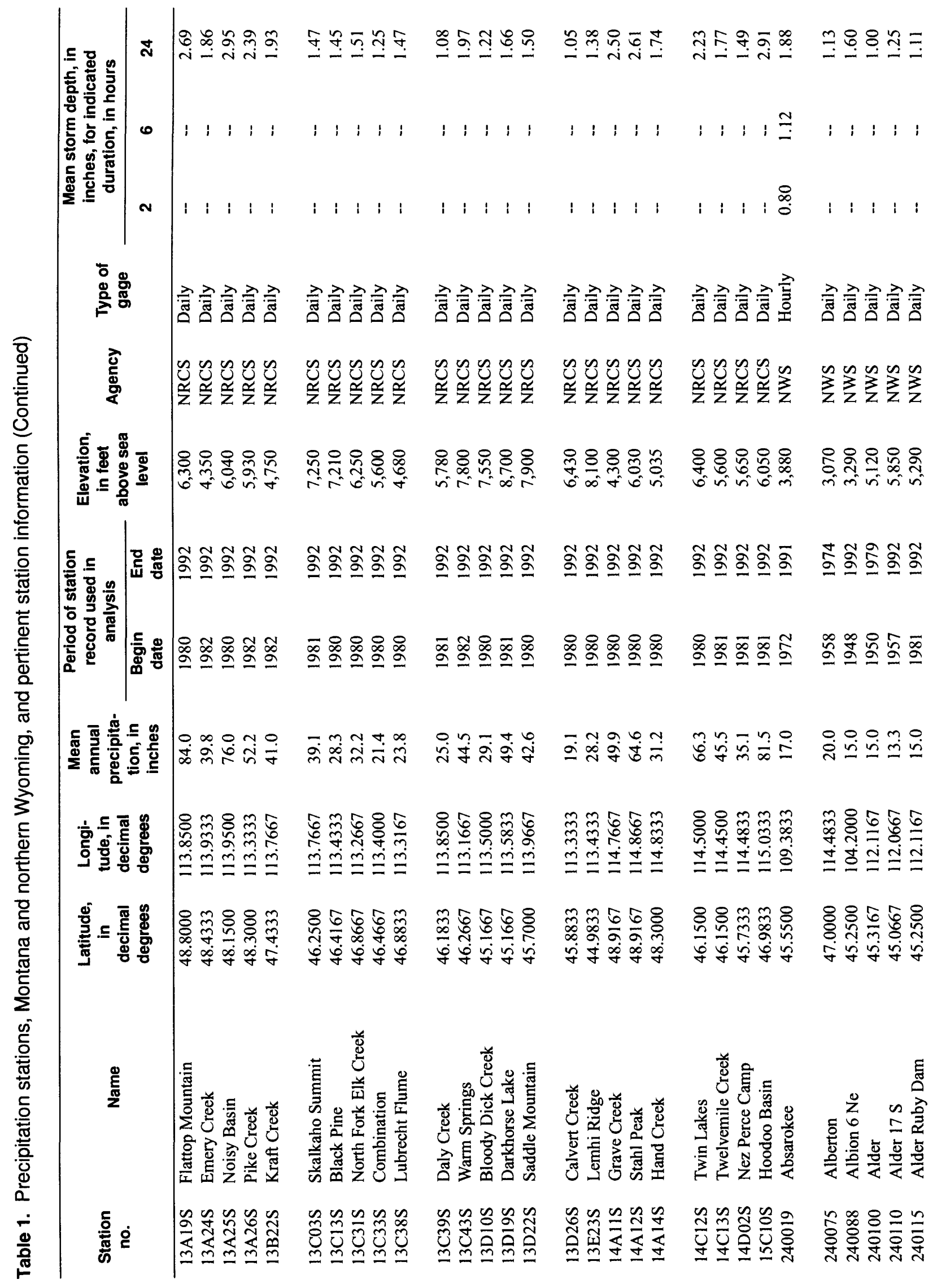




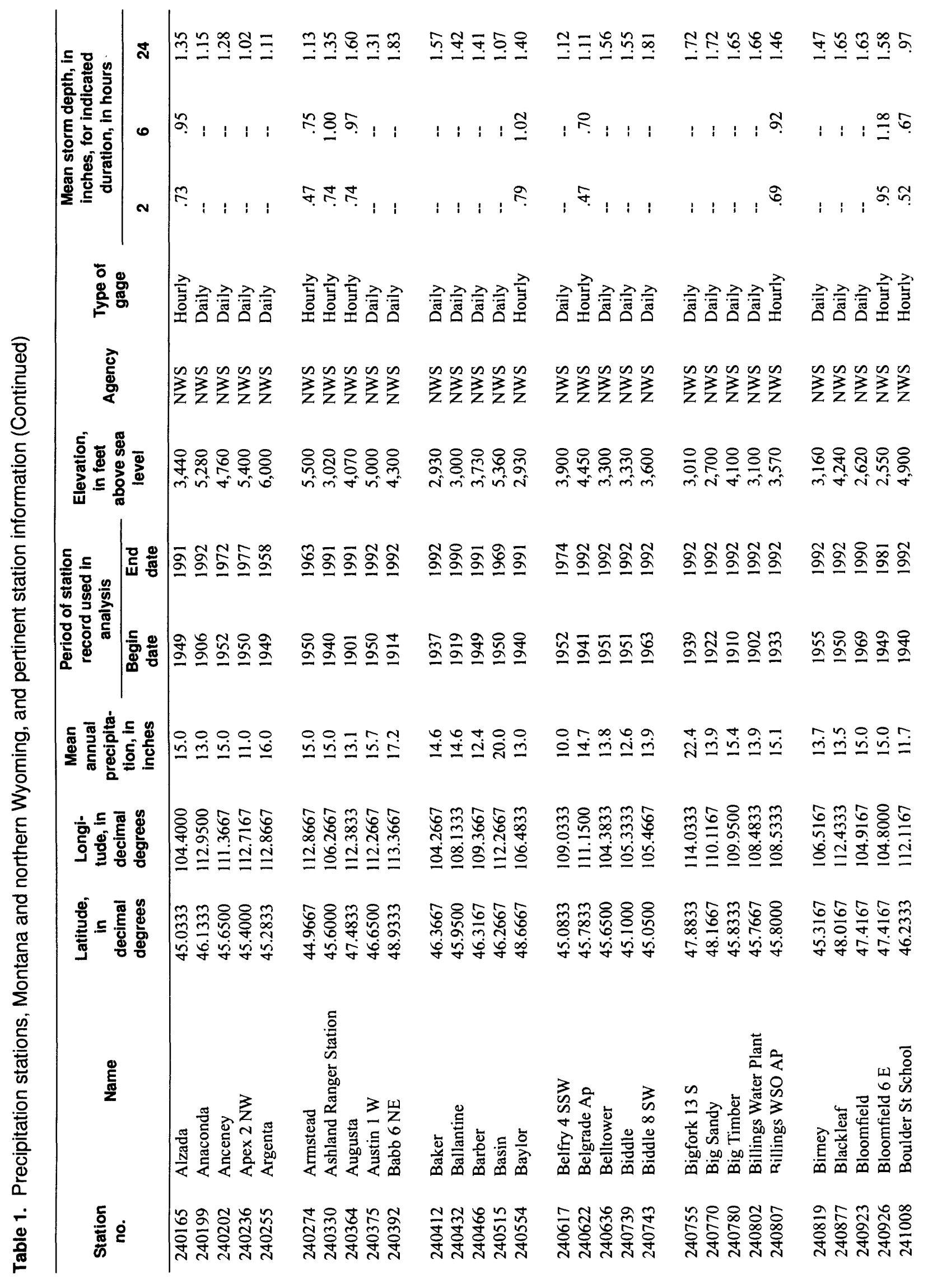




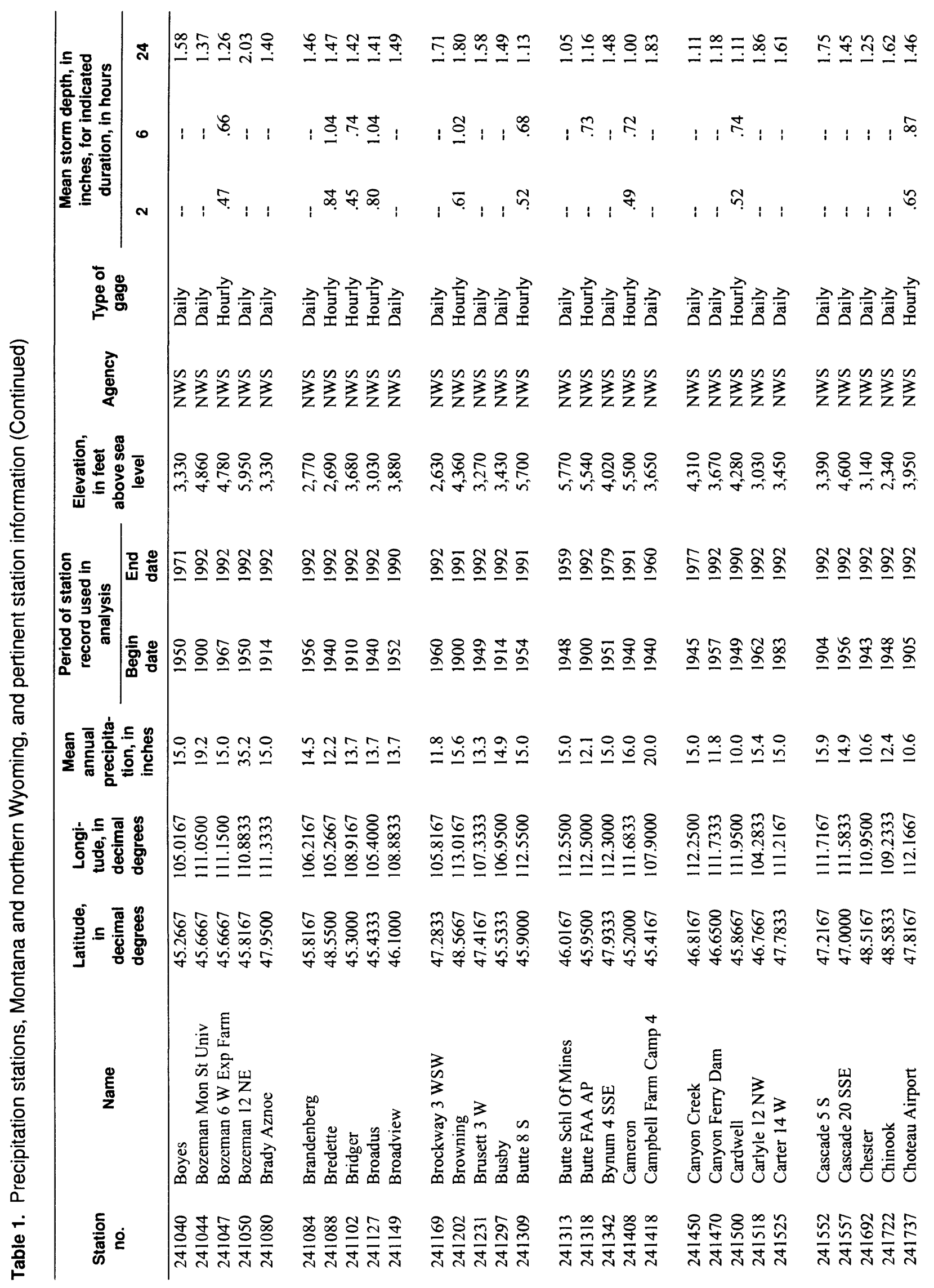




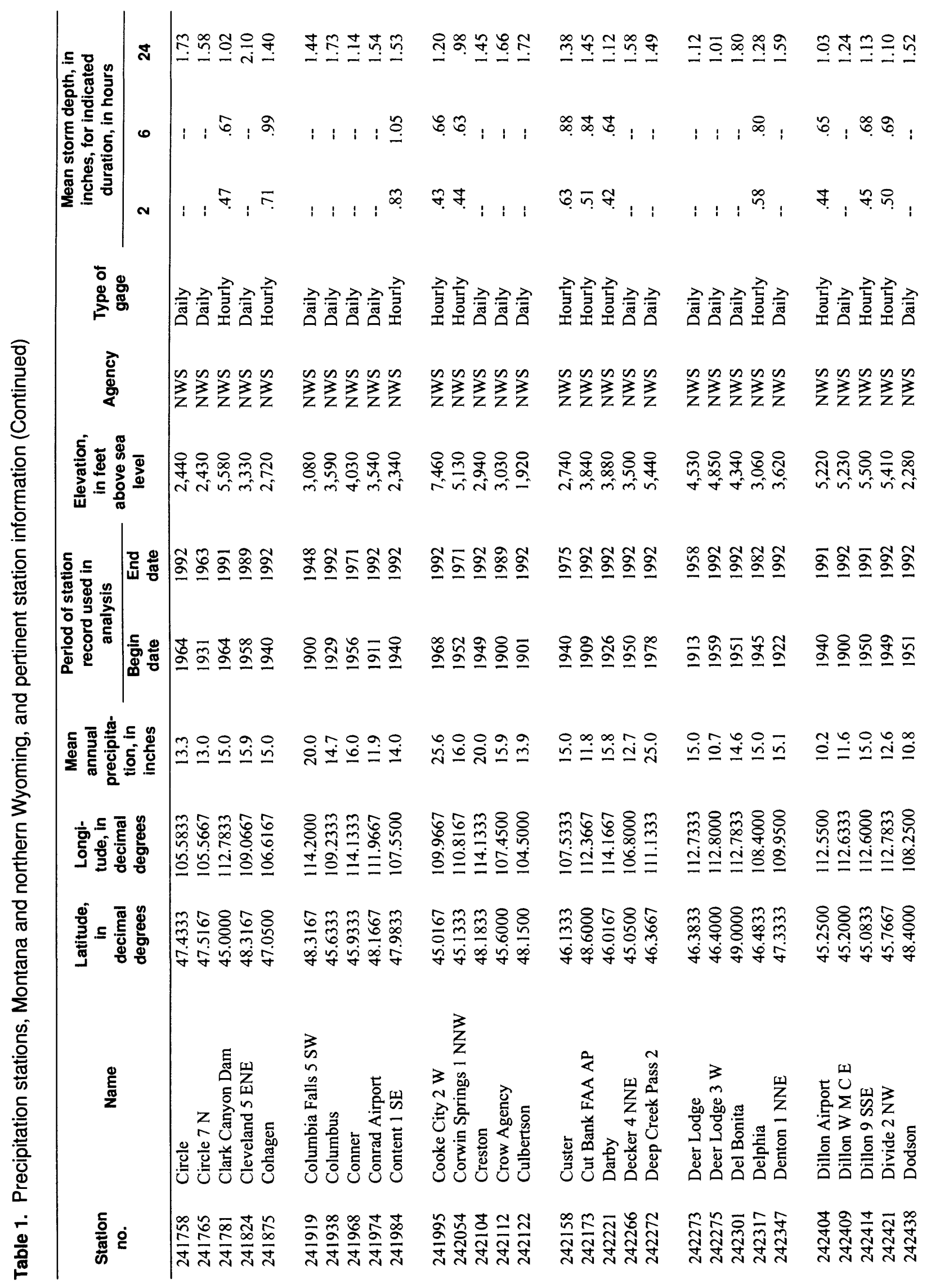




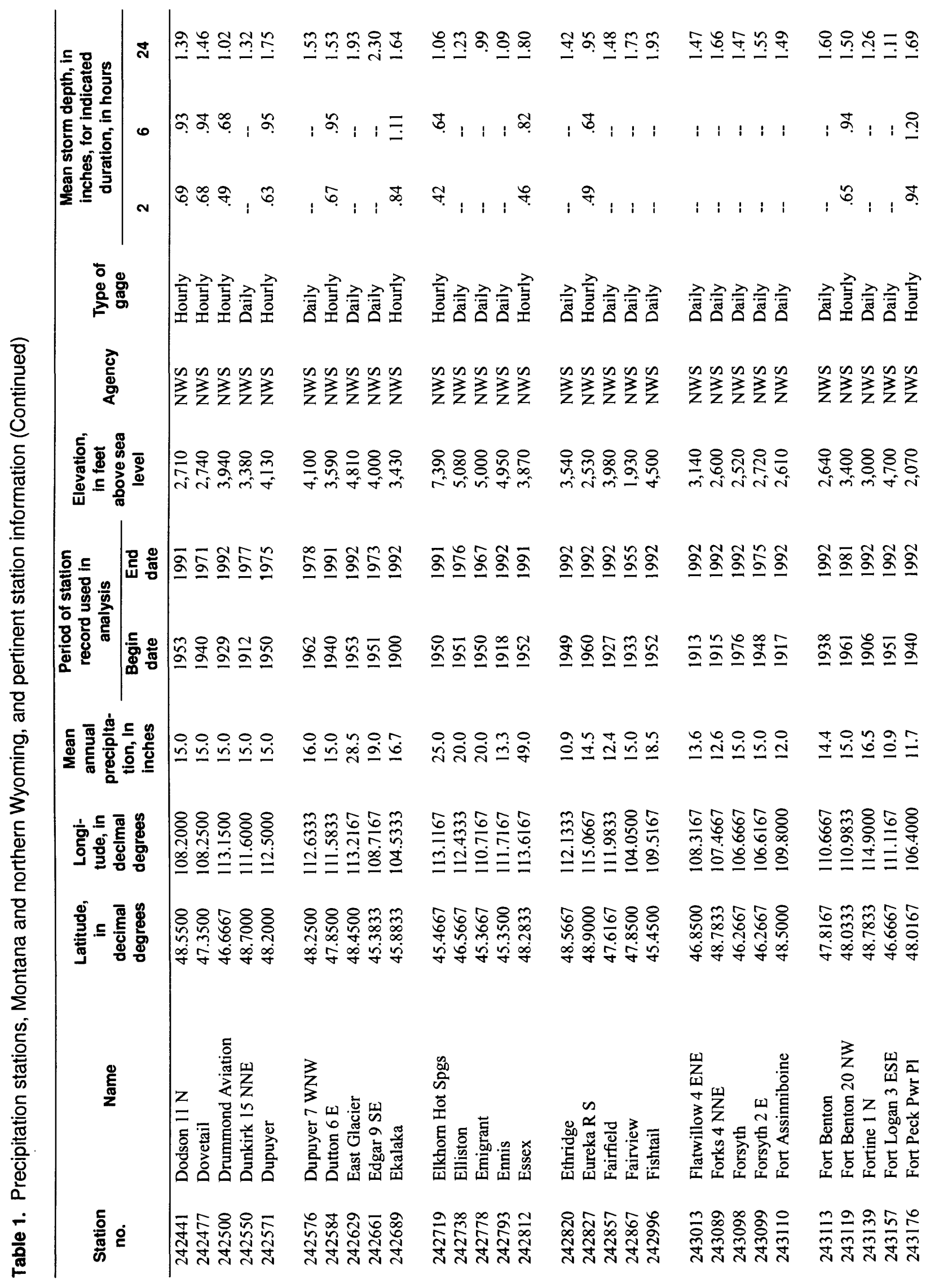




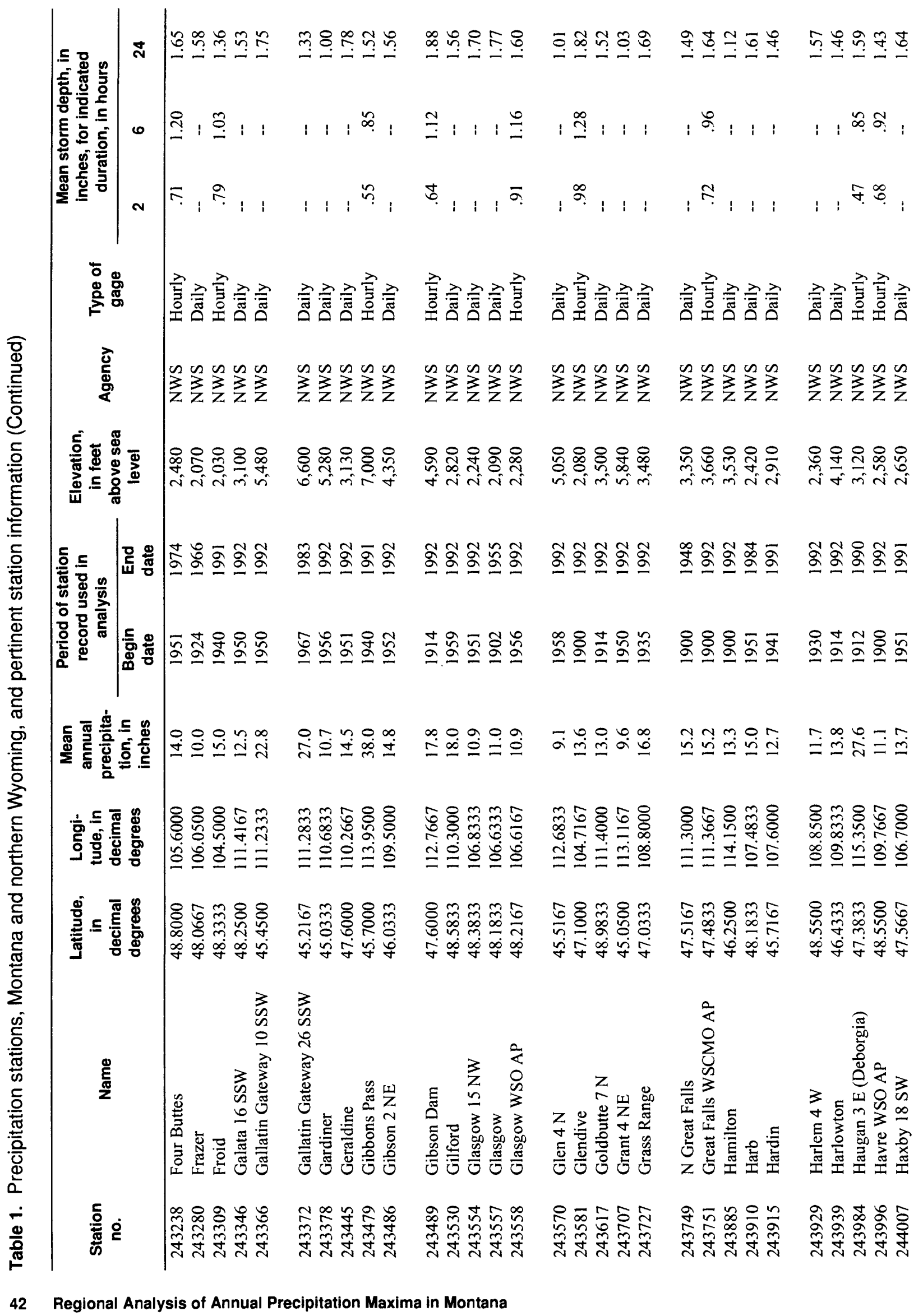




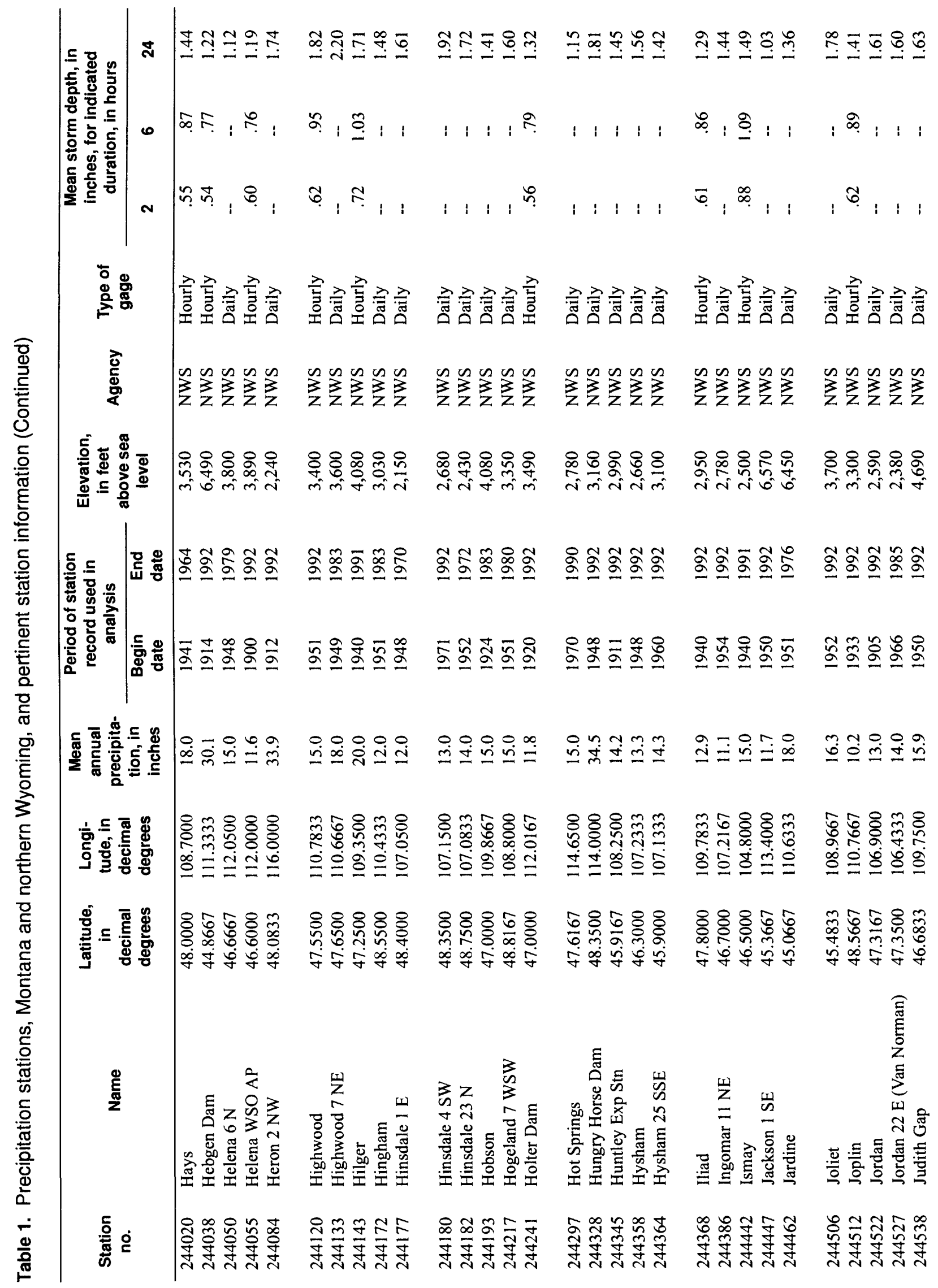




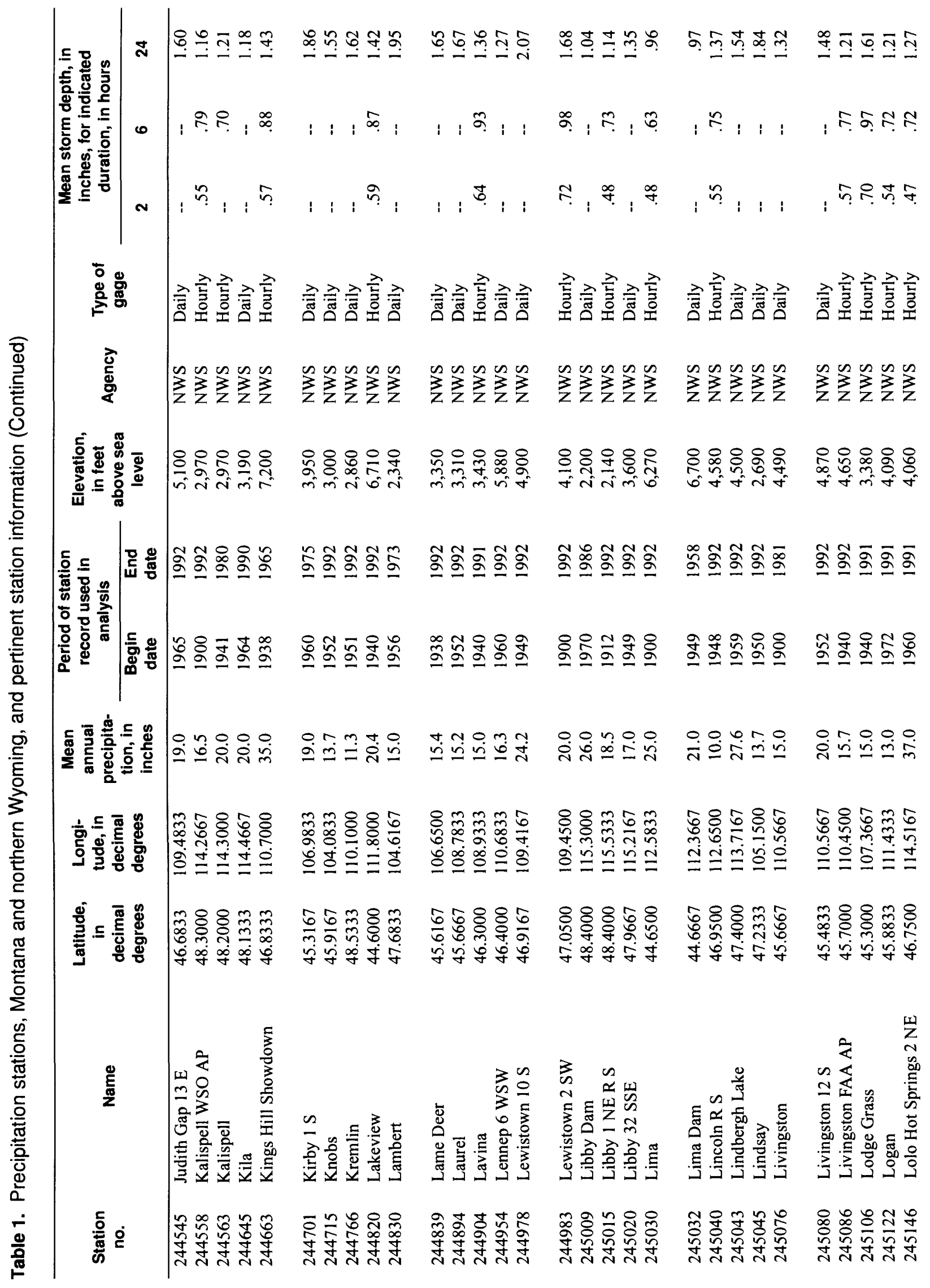




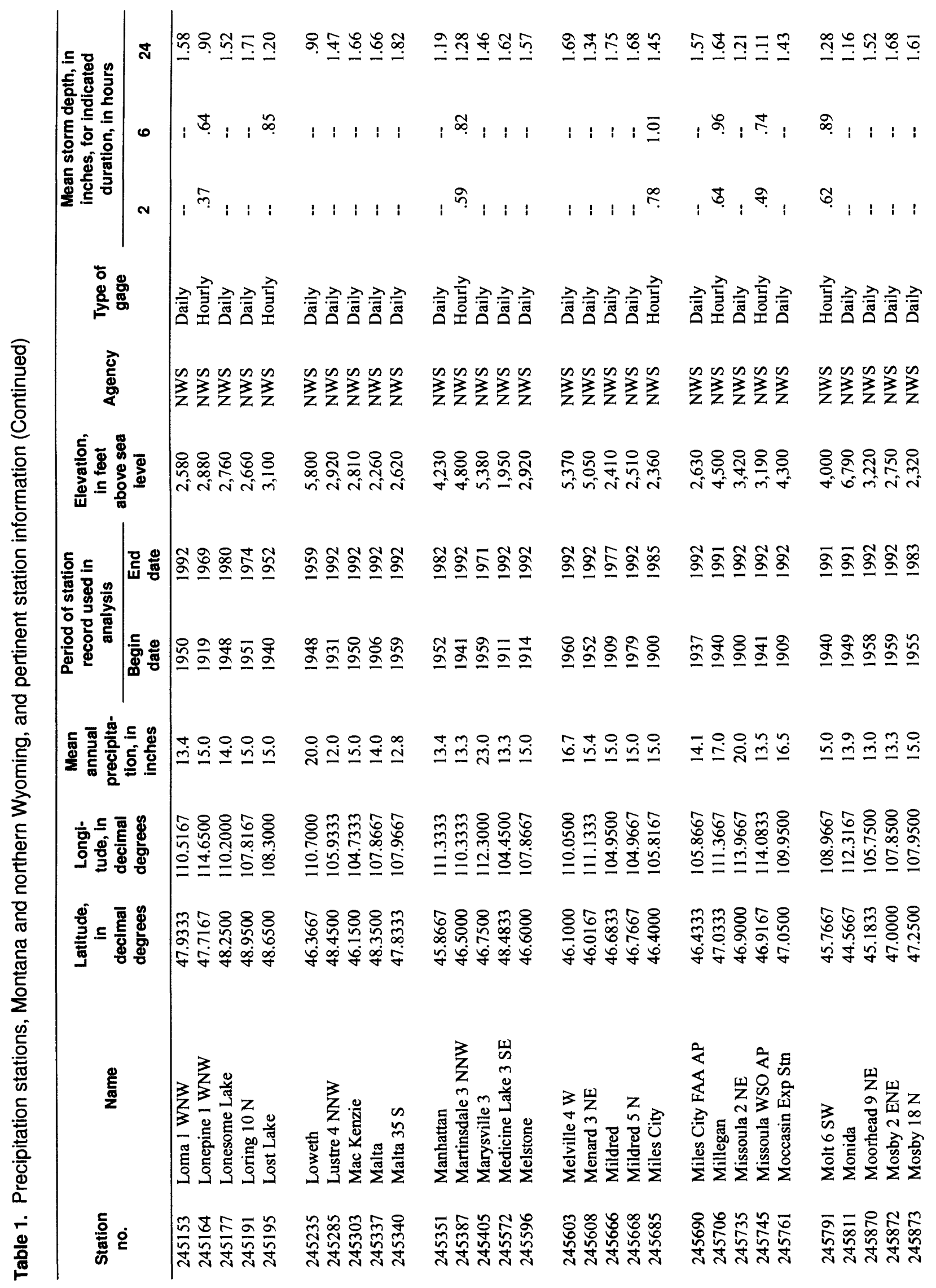




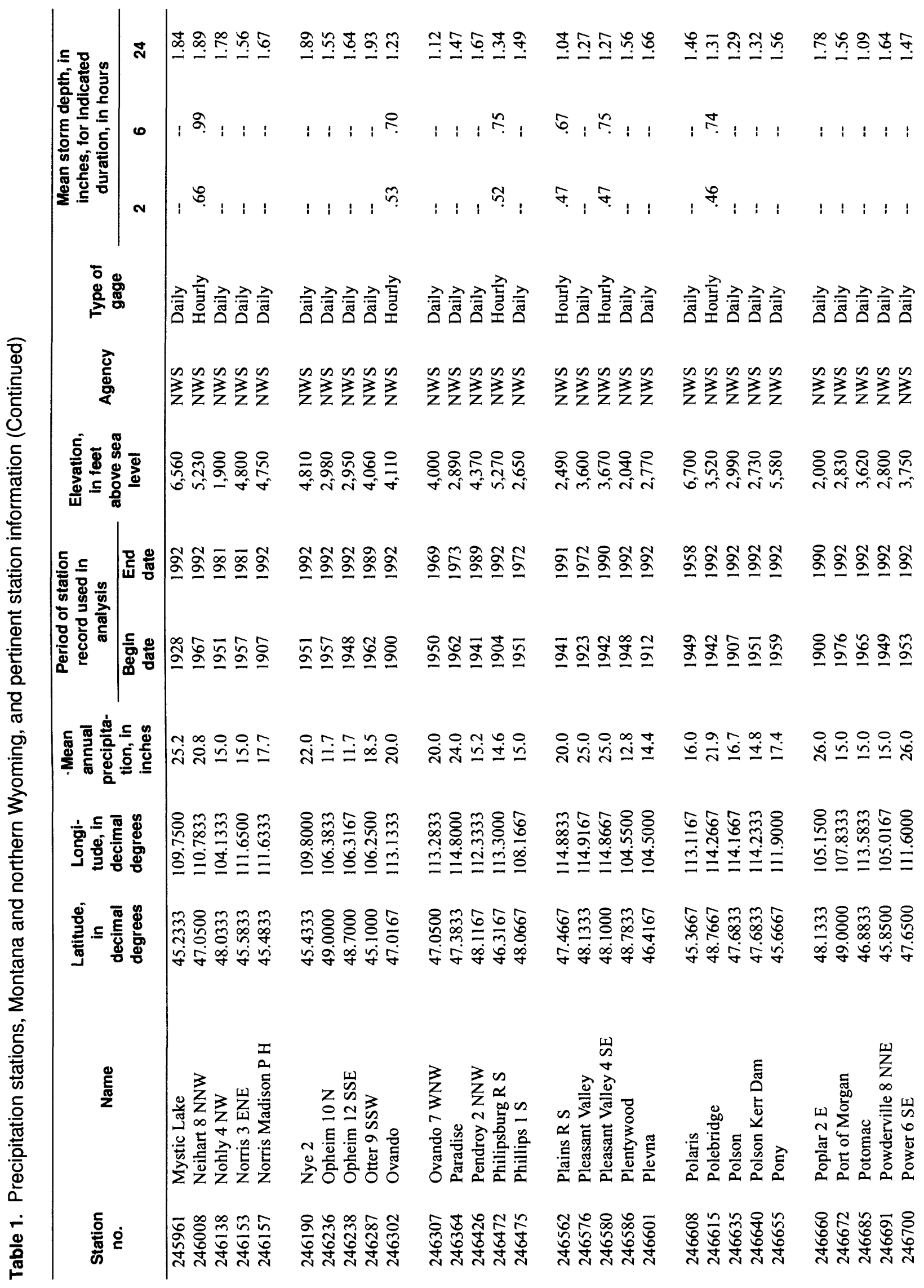




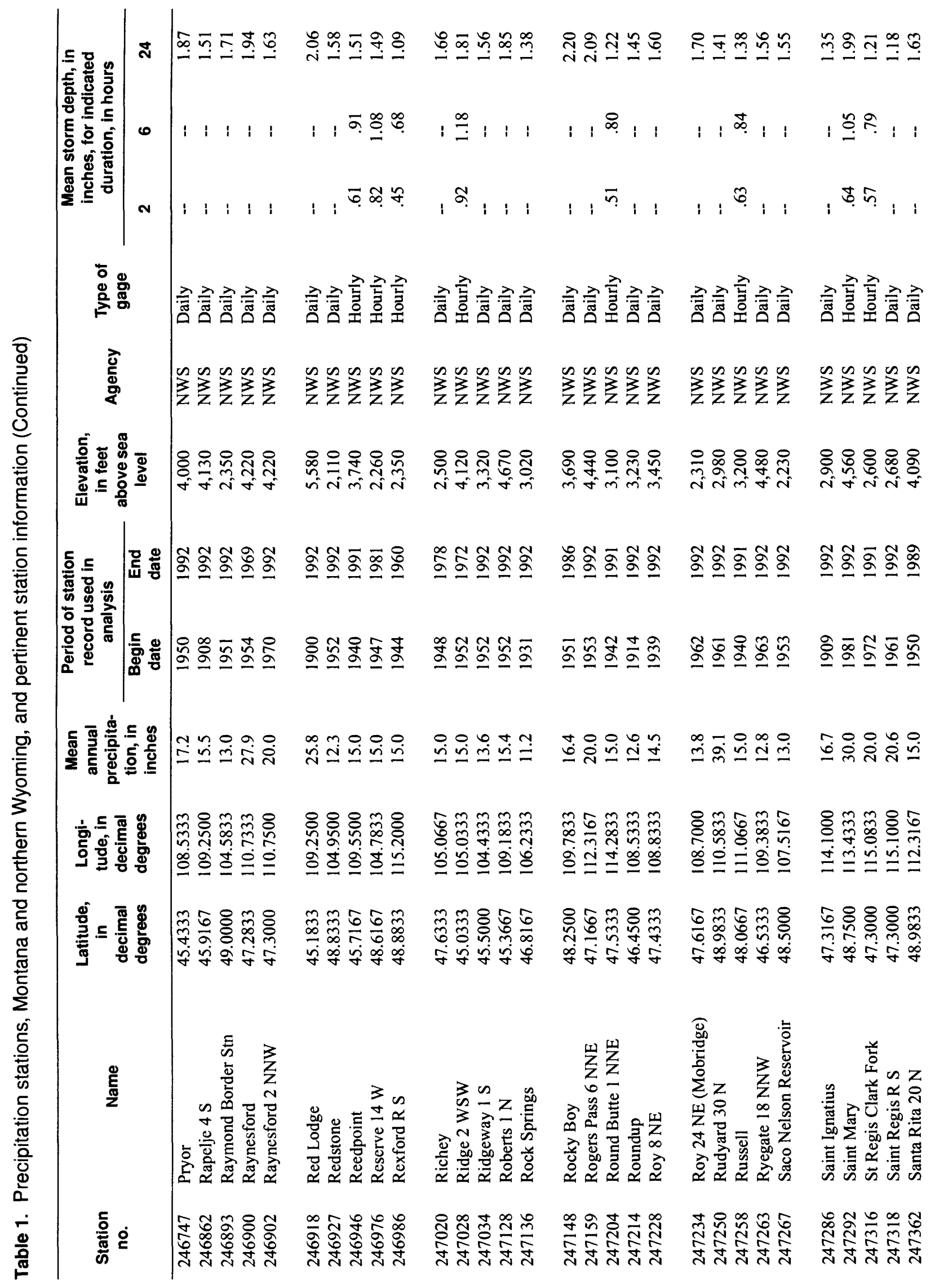




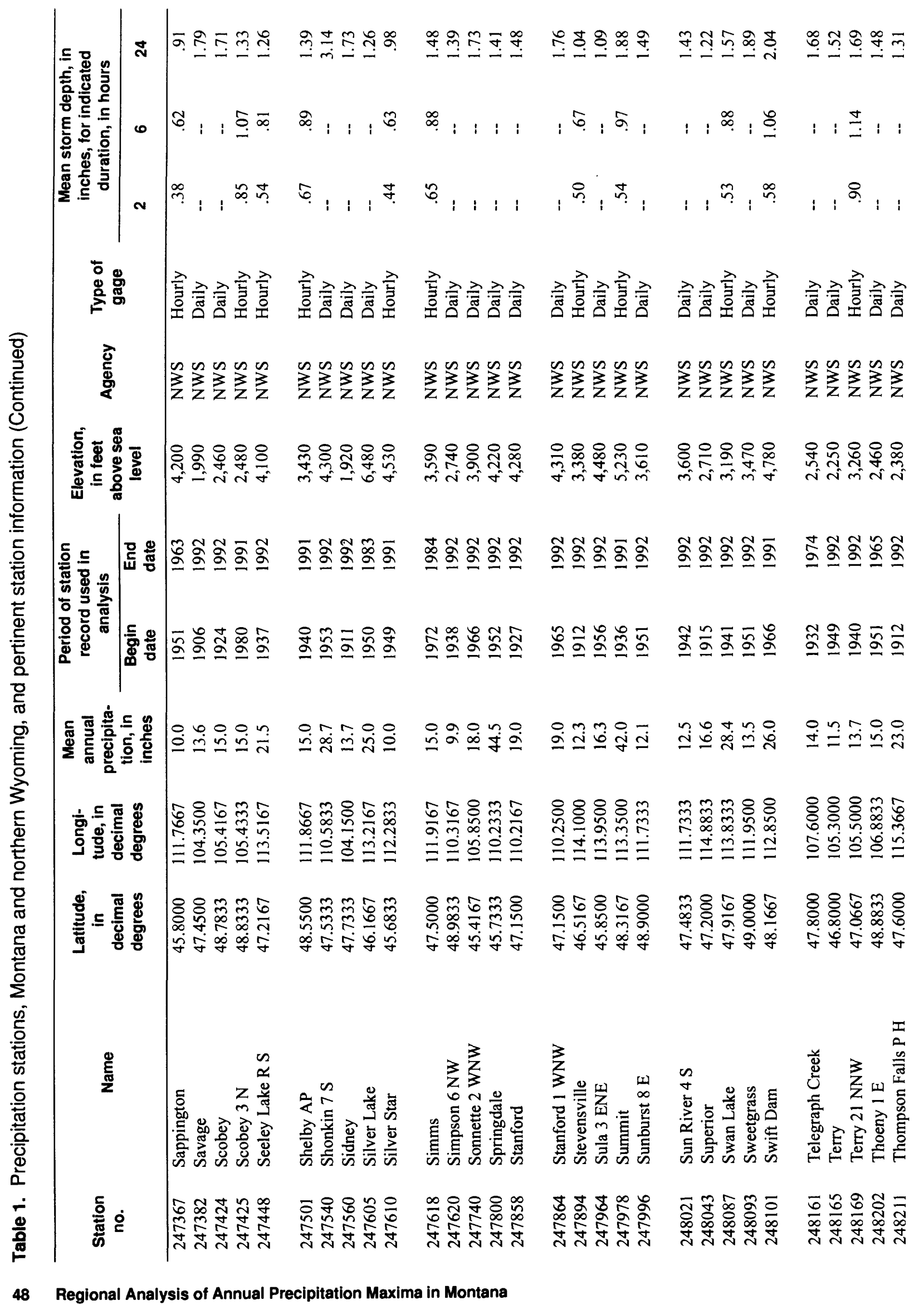




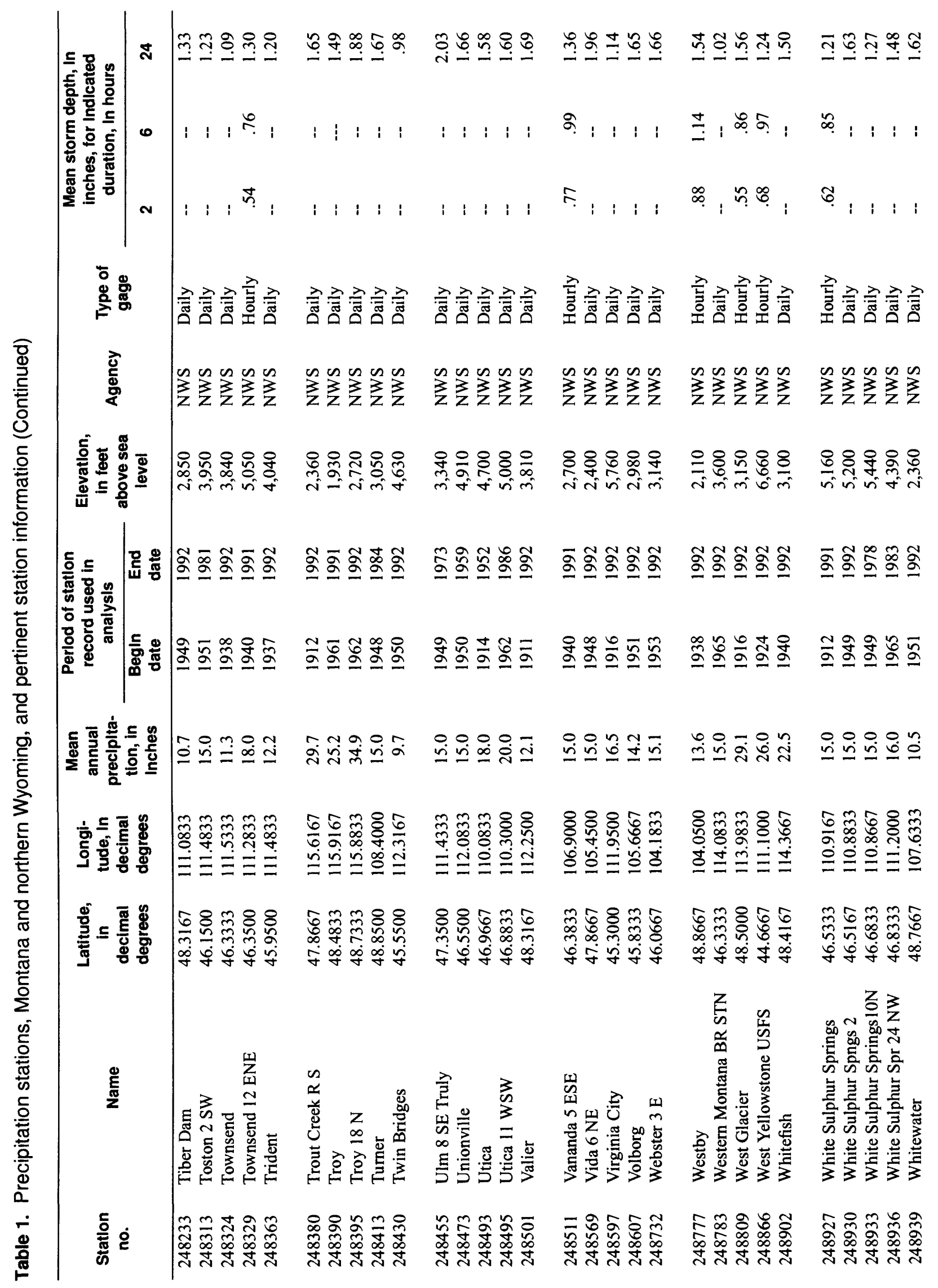




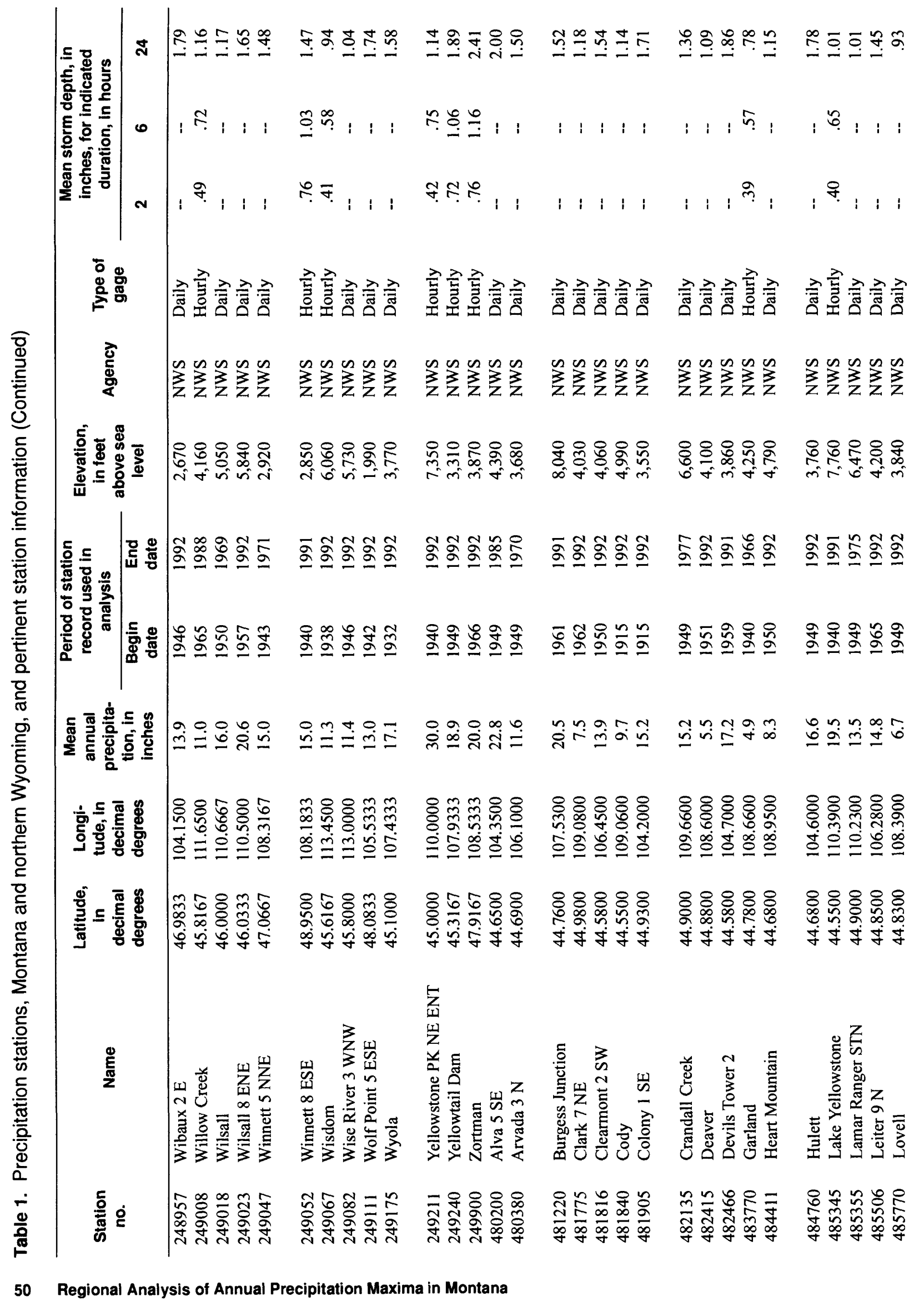




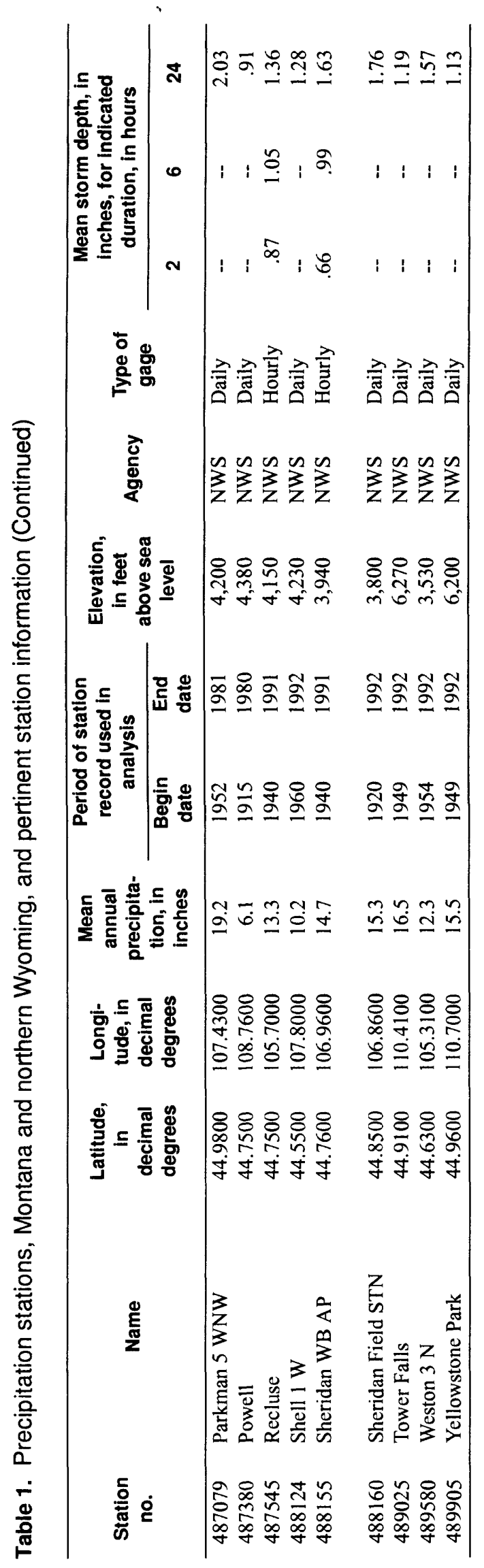

TABLE 1 